\title{
STEADY-STATE AND TRANSIENT-STATE ANALYSES OF RENEWABLE ENERGY INVERTER
}

\author{
A Dissertation by \\ Perlekar Tamtam \\ M.S., Wichita State University, 2006 \\ B.Tech., Acharya Nagaruna University, AP, India 2004
}

Submitted to the Department of Electrical Engineering and Computer Science and the faculty of the Graduate School of

Wichita State University

in partial fulfillment of

the requirement for the degree of

Doctor of Philosophy

May 2012 
C Copyright 2012 by Perlekar Tamtam

All Rights Reserved 


\section{STEADY-STATE AND TRANSIENT-STATE ANALYSES OF RENEWABLE ENERGY INVERTER}

The following faculty members have examined the final copy of this dissertation for form and content, and recommend that it be accepted in partial fulfillment of the requirement for the degree of Doctor of Philosophy with a major in Electrical Engineering.

Ward T. Jewell, Committee Chair

M. Edwin Sawan, Committee Member

Asrat Teshome, Committee Member

Vinod Namboodiri, Committee Member

Lawrence E. Whitman, Committee Member

Accepted for the College of Engineering

Zulma Toro-Ramos, Dean

Accepted for the Graduate School

J. David McDonald, Dean 


\section{DEDICATION}

To my uncle, Dr. Sankarao; my aunt, Dr. Sailaja; and my family 


\section{ACKNOWLEDGMENTS}

My deepest gratitude goes to my guidance counselor, Professor Ward T. Jewell, for his support and encouragement throughout my studies. He introduced me to new technologies in power systems and helped me to understand them better. Throughout my graduate studies, he sat patiently with me to discuss problems and ideas. I am so blessed to have him as my adviser.

I also thank my dissertation committee members: Dr. M. Edwin Sawan, Dr. Asrat Teshome, Dr. Vinod Namboodiri, and Dr. Lawrence Whitman for their precious time and constructive suggestions on my dissertation. They are also great teachers who taught me during my five years of graduate study.

I am pleased to thank my uncle, Dr. Sankara Rao Tamtam, and my aunt, Dr. Sailaja Tamtam, who inspired me to come to the United States and supported me during my education. I also thank Ravi Denavahi, Ram Serin Yatam, Sachin Argade, Atila Akhil, Visvakumar Aravinthan, Santosh Rudrabatla Madhu Narla, Vijay Sankar, and Srinivas Malagiri, who have been my good friends for years. They have always wholeheartedly offered their sincere advice. I thank my colleagues in the power group at Wichita State University. I also thank Kristie Bixby for her help editing this dissertation work.

Finally, special thanks go to my parents and my wife, for their love and support. 


\begin{abstract}
Distributed resources (DR), such as residential small wind turbines and solar cells, generate electrical energy in the form of a direct current (DC). An inverter is needed to convert this DC power into an alternating current (AC) for regular usage. The main purpose of this dissertation was to determine the performance of the inverter under steady-state and transientstate conditions, and then develop a power flow model that would be useful for power system operators and planners to determine how much high penetration of distributed photovoltaic energy would affect their power systems.

These test results are useful for analyzing the inverter behavior in order for power system operators and planners to regulate the active power and reactive power flow if $5 \%$ to $10 \%$ of renewable energy penetrates into their neighborhoods in the near future.
\end{abstract}




\section{TABLE OF CONTENTS}

Chapter

Page

1. CHAPTER 1

1.1 INTRODUCTION

1

1.2 Organization of Dissertation 2

2. CHAPTER $2 \quad 3$

2.1 Literature Review 3

2.2 Methodology 5

2.2.1 Steady-State Analysis 5

2.2.2 Determining Inverter Efficiency $\quad 6$

2.2.3 Determining Battery Efficiency $\quad 8$

2.2.4 Transient-State Analysis 9

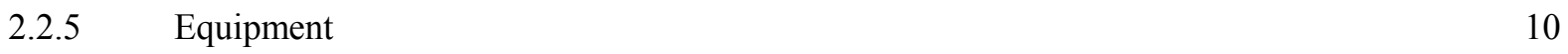

2.2.6 Steady-State Test Connections 17

3. CHAPTER 3 19

3.1 IEEE 13-Bus System 19

3.2 Commercial Distribution Power Flow Software 20

3.3 IEEE 1547 Standards 22

4. CHAPTER $4 \quad 28$

4.1 Steady-State Analysis with Programmable DC Supply 30

4.2 Steady-State Analysis of Inverter When Acting as Pass-Through 48

5. CHAPTER $5 \quad 51$

5.1 Transient-State Analysis with Load Connected to Grid 51

5.2 Transient-State Analysis with Load Connected to Inverter 61

5.3 Transient-State Analysis When Load Connected to Inverter and Grid 64

5.4 Transient-State Analysis with Voltage Spike $\quad 66$

6. CHAPTER $6 \quad 71$

6.1 Active Power Relation $\quad 71$

6.2 Regression Analysis $\quad 73$

7. CHAPTER $7 \quad 76$

7.1 Simulation Results $\quad 76$

8. CHAPTER $8 \quad 85$

$\begin{array}{ll}8.1 \text { Conclusions } & 85\end{array}$

8.2 Future Work 86

$\begin{array}{lr}\text { REFERENCES } & 88\end{array}$

$\begin{array}{ll}\text { APPENDIX } & 92\end{array}$ 


\section{LIST OF FIGURES}

Figure

Page

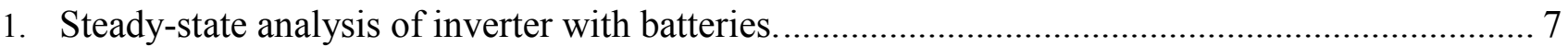

2. Test equipment connections for steady-state analysis. ................................................ 8

3. Equipment connections for transient-state analysis....................................................... 10

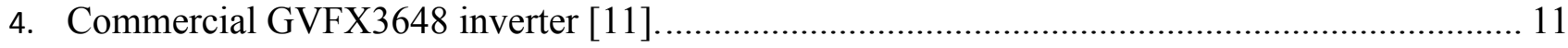

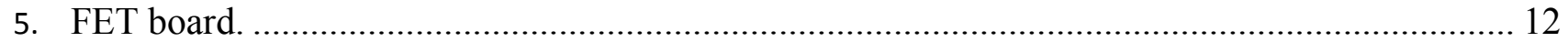

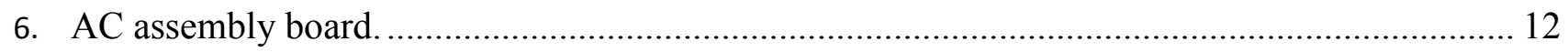

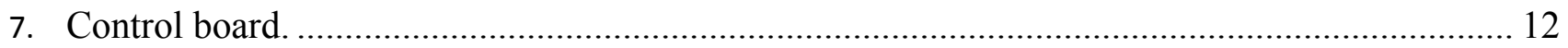

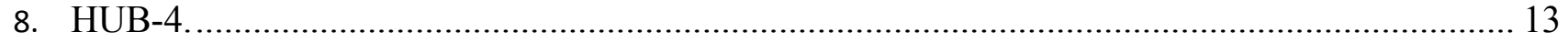

9. Commercial MATE remote control panel and display [15] ............................................... 14

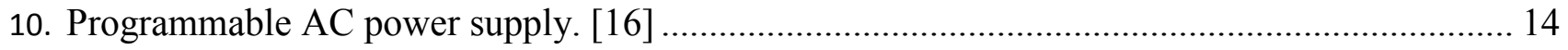

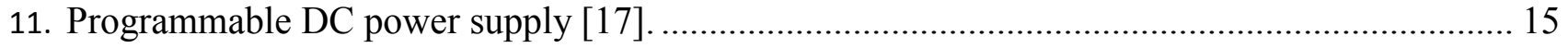

12. Series-connected lead-acid batteries from WSU Power Quality Laboratory. ........................... 16

13. Grid-tie inverter system in WSU Power Quality Laboratory. ............................................... 18

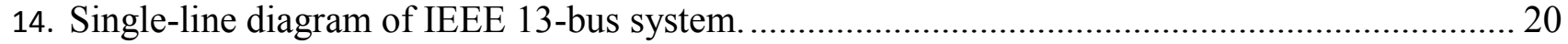

15. IEEE 13-bus model on commercial distribution power flow software................................... 21

16. Efficiency of inverter with resistive load while discharging. .............................................. 28

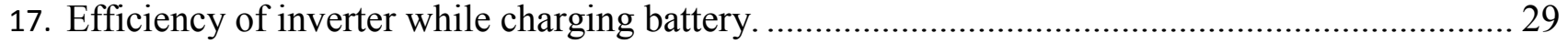

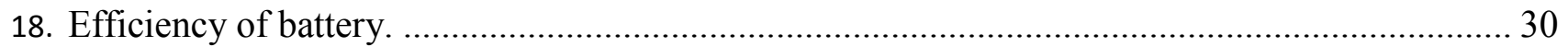

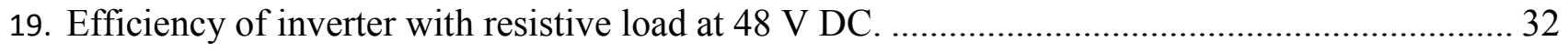

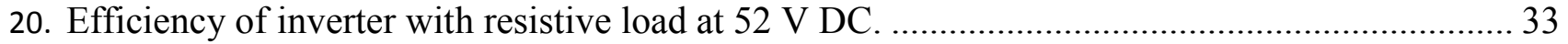

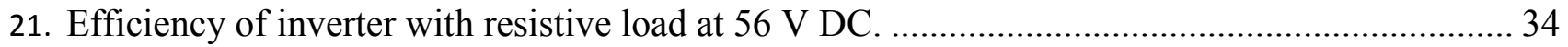

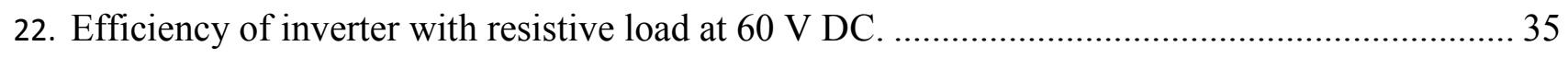

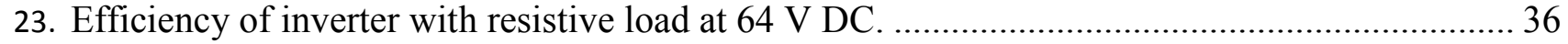

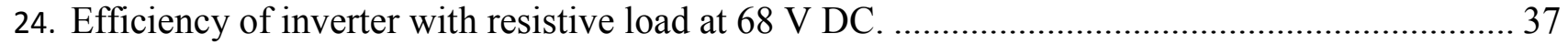

25. Efficiency of inverter with resistive load at various voltage inputs........................................ 38

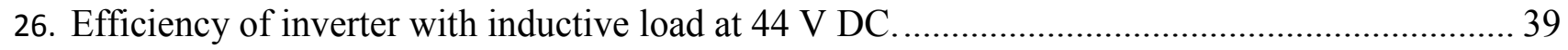

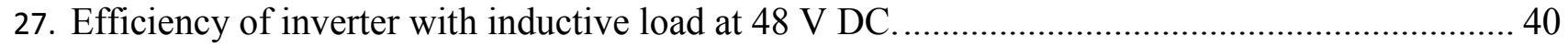

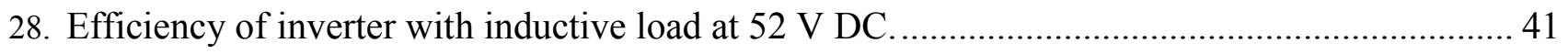




\section{LIST OF FIGURES (Continued)}

Figure

Page

29. Efficiency of inverter with inductive load at 56 V DC ........................................................ 42

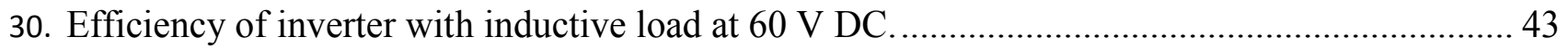

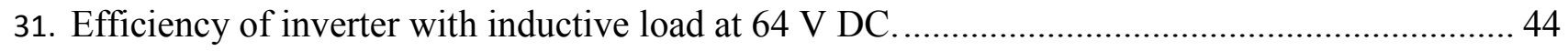

32. Efficiency of inverter with inductive load at 68 V DC...................................................... 45

33. Efficiency of inverter with inductive load at various voltage inputs. ...................................... 46

34. Efficiency of inverter with resistive and inductive loads at $48 \mathrm{~V} \mathrm{DC}$....................................47

35. Efficiency of inverter with resistive and inductive loads at $52 \mathrm{~V} \mathrm{DC}$................................... 47

36. Efficiency of inverter with resistive and inductive loads at 56 V DC. .................................. 47

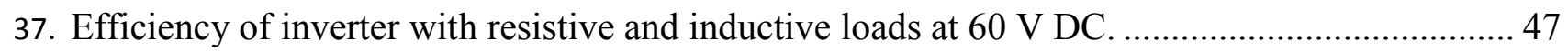

38. Efficiency of inverter with resistive and inductive loads at 64 V DC. .................................... 47

39. Efficiency of inverter with resistive and inductive loads at $68 \mathrm{~V} \mathrm{DC}$................................... 47

40. Diagram of connections for steady-state analysis when energy is passing through.................. 48

41. Performance of inverter with inductive load connected to grid while selling power to grid at $44 \mathrm{~V}$ DC. 53

42. Efficiency of inverter with inductive load connected to grid while selling power to grid at $44 \mathrm{~V}$

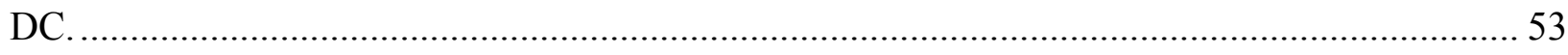

43. Performance of inverter with inductive load connected to grid while selling power to grid at $48 \mathrm{~V}$ DC.

44. Efficiency of inverter with inductive load connected to grid while selling power to grid at $48 \mathrm{~V}$ DC. 55

45. Performance of inverter with inductive load connected to grid while selling power to grid at $52 \mathrm{~V}$ DC.

46. Performance of inverter with inductive load connected to grid while selling power to grid at $52 \mathrm{~V}$ DC. 56

47. Performance of inverter with inductive load connected to grid while selling power to grid at $56 \mathrm{~V}$ DC. 


\section{LIST OF FIGURES (Continued)}

Figure

Page

48. Efficiency of inverter with inductive load connected to grid while selling power to grid at $56 \mathrm{~V}$

DC. 57

49. Performance of inverter with inductive load connected to grid while selling power to grid at $60 \mathrm{~V}$

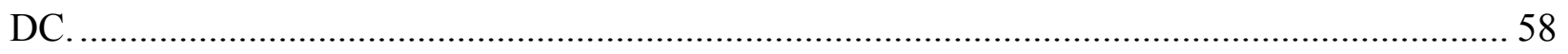

50. Efficiency of inverter with inductive load connected to grid while selling power to grid at $60 \mathrm{~V}$ DC.

51. Performance of inverter with inductive load connected to grid while selling power to grid at $64 \mathrm{~V}$ DC.

52. Efficiency of inverter with inductive load connected to grid while selling power to grid at $64 \mathrm{~V}$ DC

53. Performance of inverter with inductive load connected to grid while selling power to grid at $68 \mathrm{~V}$ DC.

54. Efficiency of inverter with inductive load connected to grid while selling power to grid at $68 \mathrm{~V}$ DC.

55. Performance of inverter with inductive load connected to output terminals while selling power to grid at $48 \mathrm{~V} \mathrm{DC}$.

56. Efficiency of inverter with inductive load connected to output terminals while selling power to grid at $48 \mathrm{~V} \mathrm{DC}$

57. Performance of inverter with inductive load connected to output terminals while selling power to grid at $52 \mathrm{~V} \mathrm{DC}$.

58. Efficiency of inverter with inductive load connected to output terminals while selling power to grid at $52 \mathrm{~V} \mathrm{DC}$.

59. Performance of inverter with inductive load connected to output terminals while selling power to grid at $56 \mathrm{~V} \mathrm{DC}$.

60. Efficiency of inverter with inductive load connected to output terminals while selling power to grid at $56 \mathrm{~V} \mathrm{DC}$. 


\section{LIST OF TABLES}

Table

Page

1. REQUIRED PARTS FOR FLEXWARE 500 (GRID-TIE) SYSTEM................................... 17

2. PERFORMANCE OF INVERTER WITH RESISTIVE LOAD WHILE DISCHARGING ....... 28

3. PERFORMANCE OF INVERTER WHILE CHARGING BATTERY ................................... 29

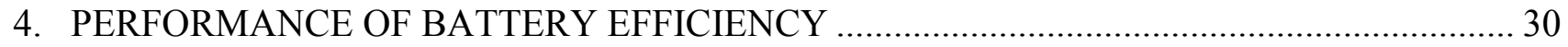

5. PERFORMANCE OF INVERTER WITH RESISTIVE LOAD AT 48 V DC .......................... 32

6. PERFORMANCE OF INVERTER WITH RESISTIVE LOAD AT 52 V DC ......................... 33

7. PERFORMANCE OF INVERTER WITH RESISTIVE LOAD AT 56 V DC ......................... 34

8. PERFORMANCE OF INVERTER WITH RESISTIVE LOAD AT 60 V DC ......................... 35

9. PERFORMANCE OF INVERTER WITH RESISTIVE LOAD AT 64 V DC......................... 36

10. PERFORMANCE OF INVERTER WITH RESISTIVE LOAD AT 68 V DC ......................... 37

11. PERFORMANCE OF INVERTER WITH INDUCTIVE LOAD AT 44 V DC ........................ 39

12. PERFORMANCE OF INVERTER WITH INDUCTIVE LOAD AT 48 V DC ....................... 40

13. PERFORMANCE OF INVERTER WITH INDUCTIVE LOAD AT 52 V DC ....................... 41

14. PERFORMANCE OF INVERTER WITH INDUCTIVE LOAD AT 56 V DC ........................ 42

15. PERFORMANCE OF INVERTER WITH INDUCTIVE LOAD AT 60 V DC ........................ 43

16. PERFORMANCE OF INVERTER WITH INDUCTIVE LOAD AT 64 V DC ....................... 44

17. PERFORMANCE OF INVERTER WITH INDUCTIVE LOAD AT 68 V DC ....................... 45

18. PERFORMANCE OF INVERTER WHEN ACTING AS PASS-THROUGH ........................ 49

19. PERFORMANCE OF INVERTER WITH INDUCTIVE LOAD CONNECTED TO GRID

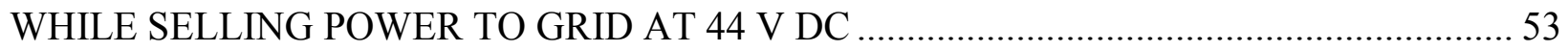

20. PERFORMANCE OF INVERTER WITH INDUCTIVE LOAD CONNECTED TO GRID

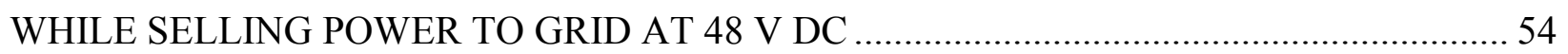

21. PERFORMANCE OF INVERTER WITH INDUCTIVE LOAD CONNECTED TO GRID WHILE SELLING POWER TO GRID AT 52 V DC ....................................................... 55

22. PERFORMANCE OF INVERTER WITH INDUCTIVE LOAD CONNECTED TO GRID WHILE SELLING POWER TO GRID AT 56 V DC 
Table

23. PERFORMANCE OF INVERTER WITH INDUCTIVE LOAD CONNECTED TO GRID WHILE SELLING POWER TO GRID AT 60 V DC ............................................................ 58

24. PERFORMANCE OF INVERTER WITH INDUCTIVE LOAD CONNECTED TO GRID

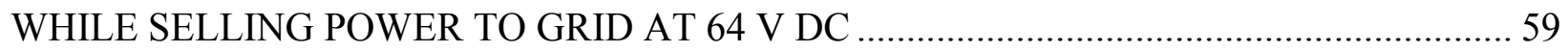

25. PERFORMANCE OF INVERTER WITH INDUCTIVE LOAD CONNECTED TO GRID WHILE SELLING POWER TO GRID AT $68 \mathrm{~V}$ DC....

26. PERFORMANCE OF INVERTER WITH INDUCTIVE LOAD CONNECTED TO OUTPUT TERMINALS WHILE SELLING POWER TO GRID AT 48 V DC

27. PERFORMANCE OF INVERTER WITH INDUCTIVE LOAD CONNECTED TO OUTPUT TERMINALS WHILE SELLING POWER TO GRID AT $52 \mathrm{~V}$ DC

28. PERFORMANCE OF INVERTER WITH INDUCTIVE LOAD CONNECTED TO OUTPUT TERMINALS WHILE SELLING POWER TO GRID AT 56 V DC

29. PERFORMANCE OF INVERTER WITH INDUCTIVE LOAD CONNECTED TO OUTPUT TERMINALS AND GRID WHILE SELLING POWER TO GRID AT 48 V DC.. 65

30. PERFORMANCE OF INVERTER DURING VOLTAGE SAG.

31. PERFORMANCE OF INVERTER DURING VOLTAGE SAG WITH LOAD CONNECTED TO OUPUT TERMINALS WHILE SELLING POWER TO GRID

32. AVERAGE VALUES OF GRID VOLTAGE, OUTPUT POWER OF INVERTER . 74

33. VOLTAGE DROP OF EACH PHASE OF 13-BUS SYSTEM DURING VOLTAGE SAG

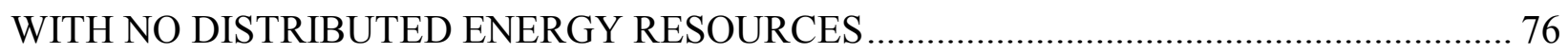

34. VOLTAGE DROP OF GRID WHEN 5\% OF DR SUPPLYING POWER AT BUS 680 ........... 78

35. VOLTAGE DROP OF GRID WHEN 10\% OF DR SUPPLYING POWER AT BUS 680 AND GIRD VOLTAGE IS $123.42 \mathrm{~V}$

36. VOLTAGE DROP OF GRID WHEN 5\% OF DR SUPPLYING POWER AT BUS 680 AND GRID VOLTAGE IS $120.10 \mathrm{~V}$

37. VOLTAGE DROP OF GRID WHEN 10\% OF DR SUPPLYING POWER AT BUS 680 AND GRID VOLTAGE IS $120.10 \mathrm{~V}$ 
38. VOLTAGE DROP OF GRID WHEN 5\% OF DR SUPPLYING POWER AT BUS 680 AND

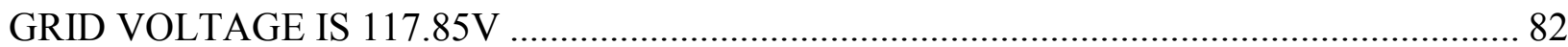

39. VOLTAGE DROP OF GRID WHEN 10\% OF DR SUPPLYING POWER AT BUS 680 AND GRID VOLTAGE IS $117.85 \mathrm{~V}$ 


\section{LIST OF ABRIVATIONS/NOMANCLATURE}

$\mathrm{AC}$

ANSI

CSP

DC

DG

DR

EPS

IEEE

KW

KWH Kilowatt Hour

MW

MWH Megawatt Hour

PCC

PV

PWM

WSU

Direct Current

Kilowatt

Megawatt

Photovoltaic
Alternating Current

American National Standards Institute

Concentrating Solar Power

Distributed Generation

Distributed Energy Resource(s)

Electric Power System

Institute of Electrical and Electronics Engineers

Point of Common Coupling

Pulse-Width-Modulation

Wichita State University 


\section{CHAPTER 1}

\subsection{INTRODUCTION}

Currently, nonconventional energy sources, such as solar and wind, are the fastest growing in the electrical industry. Solar energy can be generated in two ways: (1) using the photovoltaic (PV) method by converting solar radiation into direct current electricity at the atomic level with semiconductors, and (2) using concentrating solar power (CSP), also known as solar thermal power plants. Parabolic troughs, solar dishes, and solar power towers are three ways to generate power by using solar thermal power plants. The PV method generates electricity in the form of direct current (DC), and CSP method generates electricity in the form of alternating current (AC). According to the U.S. Energy Information Administration, the total domestic photovoltaic module shipment in 2009 was $601 \mathrm{MW}$, which is $14.66 \%$ more than in 2008, and these numbers are increasing year to year [1]. When it comes to wind energy, wind turbines produce anywhere less than 100 kilowatt hours(KWH) (power for a single home or small business) to 5 megawatt hours(MWH) (power for commercial enterprises), and 34,296 MW of wind power was available by 2009 [2]. Most wind power generation is through commercial turbines; therefore, these plants generate AC voltage.

An inverter is a device that can convert DC energy into AC energy. Some residential small wind turbines and photovoltaic panels need inverters because they generate DC power, which needs to be converted into AC power in order to sell it back to the grid or use it for electrical appliances. Occasionally, PV panels or residential small wind turbines are connected to batteries that store the energy for later use by using inverters

The main purpose of this dissertation was to determine the performance of the inverter under steady-state and transient-state conditions, and then develop a power flow model that 
would be useful for power system operators and planners to determine how much high penetration of distributed photovoltaic energy would affect their power systems.

An inverter was purchased, and both steady-state analysis and transient-state analyses were performed on the inverter. Steady-state analysis is useful to determine the performance of the inverter at different available energy situations, and transient-state analysis is useful to determine the behavior of the inverter if there is voltage drop or voltage sag on the grid side of the inverter. Using the transient-state analysis results, a mathematical equation was developed, which led to the development of a model used in power flow software. In this dissertation, commercial distribution power flow software was used to test the model developed on a 13-bus system. Results show how the inverter might be used as a source for reactive and real power to support voltage on a distribution system.

These test results are useful for analyzing the inverter behavior in order for power system operators and planners to regulate the active power and reactive power flow if $5 \%$ to $10 \%$ of renewable energy penetrates into their neighborhoods in the near future.

\subsection{Organization of Dissertation}

Chapter 1 provides an introduction to this dissertation. Chapter 2 reviews the literature as well as the equipment and electrical connections for steady-state analysis and transient-state analysis. Chapter 3 examines the modeling analysis software and IEEE standards. Chapters 4 and 5 discuss the steady-state analysis test results and transient-state test results, respectively. Chapter 6 derives the active power flow mathematical equation. Chapter 7 shows results of the distribution system simulator. Chapter 8 concludes the dissertation and presents suggestions for future work. 


\section{CHAPTER 2}

\section{LITERATURE REVIEW AND METHODOLOGY}

\subsection{Literature Review}

World War II was the time of development for the motor generator set [3], which was the only technology that could convert DC into AC. Graham Tripp invented the early electronic inverter, and this unit used mechanical vibrators to oscillate DC power into square wave AC power. In the early 1960s, mechanical vibrators were replaced by transistors [3]. The main drawback of this inverter was that it generated square waves and, therefore, was only useful for resistive loads but not reactive loads. Later on, the introduction of modified sine wave technology now makes this inverter useful for reactive loads as well.

There are three types of inverters. The oldest technology is square wave technology, which is cheaper but provides poor power quality and the reason why this technology is not used in commercial inverters. The second type of inverter is the modified sine wave inverter, which is economical but still has some problems with power quality. The third type of inverter is the sine wave inverter, which has clean output but is more expensive.

Most research work on inverter-grid interaction has been done on microgrids. A microgrid power system can operate in either autonomous mode or grid-connected mode [4]. In the autonomous mode, a microgrid can be connected to a local energy source, such as a solar panel or batteries, and also to the load via an inverter so that it can operate autonomously when energy is available from solar panels or batteries; if not connected in this manner, the microgrid can operate by connecting to the grid. One paper published in the IEEE Transactions discusses analysis and modeling of the autonomous operation of a microgrid [4]. A state-space model is 
presented in this paper. The model is subdivided into three submodels: inverter, networks, and loads. This system was analyzed by using eigenvalues and their sensitivity to different states [4]. Another IEEE Transactions paper [5] provides test results from Sandia National Laboratories on inverter compatibility with the power system or smart grid. These results prove that the inverter's output power quality is better than that of the local utility and a satisfactory response from protection circuits.

Gurdjian and Maxwell [6] verified the test results of two $100 \mathrm{KW}$ photovoltaic generating systems in the Fort Davis, Texas, area connected to the local distribution system via a pulse-width-modulation (PWM) inverter. They compared the test results with IEEE 519-1992 standards, where the output power quality of the inverter was found to be within these standards. When the inverter alone was connected to the circuit rather than when the solar panels and inverter were connected, the voltage distortion was higher but still within the standards. This paper did not discuss the reason why the voltage distortion was high when the inverter alone was connected to the circuit.

In the laboratory, Woyte et al. [7] verified test results on the islanding protection function of a photovoltaic inverter. According to their results, simple islanding protection methods are likely to fail if the small inverters (10 W to $200 \mathrm{~W})$ are loaded with considerable amounts of capacitive loads.

Kotsoopoulous et al. [8] tested zero-crossing distortion in inverters connected between the grid and PV panels. According to the authors, if the number of inverters connected to a smart grid is increased, there will be more chance for harmonic distortion in the grid because resonance will occur between the inverter capacitance and the grid impedance. They observed zerocrossing distortion from different kinds of inverters because of their designs. These distortions 
are avoidable with four-quadrant topologies and control, but this will increase the cost of the inverter. With a single inverter, the small harmonic effects are within the standards considered in this paper.

Enders et al. [9] discussed typical problems of the inverter. According to the authors, harmonic and radio frequency emissions, overvoltage at the end of PV line, islanding after disconnection, resonance effects, and DC current injection are common disturbances or dangers. Overvoltage, voltage sags, switching transient effects, short circuits in the grid, transients, and line-coupled data transfer are common effects to equipment. "The main aim of the tests was to develop suitable measurements against disturbances and risks and to get a base for new testparameters for PV inverters" [9].

This dissertation work will explain whether an inverter will supply reactive power or not, and what factors influence this supply of reactive power. The paper also explains the behavior of the renewable energy inverter for a voltage spike in the system and how the inverter will behave for voltage sags.

\subsection{Methodology}

\subsubsection{Steady-State Analysis}

The purpose of steady-state analysis in this dissertation was to determine the efficiency of the batteries and the inverter system. The inverter was analyzed in three ways. In the first method, batteries were connected to the inverter on the DC side, the resistive or inductive load was connected on the load side of the inverter, and the grid terminals of the inverter were disconnected. In the second method, the inverter AC terminals were connected to the grid, and the load terminals of the inverter were disconnected from the load analyzing the inverter while charging the batteries. The third method involved connecting the programmable DC supply (a 
controllable DC source that acts like a solar panel simulator) on the DC side of the inverter, connecting the load on the load terminals of the inverter, and disconnecting the inverter completely from the grid.

\subsubsection{Determining Inverter Efficiency}

In the first two methods, the efficiency of the inverter was calculated as the ratio of output power to input power. Here, there are two types of efficiency. The first occurs when the inverter is rectifying $\mathrm{AC}$ to $\mathrm{DC}$. In this case, $\mathrm{AC}$ side readings can be taken from the MATE (a complete system controller and display for the inverter), DC voltage can be read from the MATE, and DC current can be read from an ammeter connected between the inverter and batteries.

The second type of efficiency is when the inverter is inverting DC into AC. Here, the batteries begin fully charged, and then energy is discharged into a resistive load via two inverters connected in parallel. Inverters can handle a maximum power of $7200 \mathrm{~W}$. For safety and the life of batteries in this study, the discharge power was limited to $3600 \mathrm{~W}$ from the batteries, even though they can discharge power closer to $4500 \mathrm{~W}$. If the load was increased to more than 4600 $\mathrm{W}$, then the battery voltage was too low (around $42 \mathrm{~V}$ ) for the inverter to continue operating.

The inverter was programmed to stop discharging at a particular level of battery voltage. After the power was discharged, the load was increased, and readings were taken at every $600 \mathrm{~W}$ of load. When rectifying energy (from AC to DC), the batteries began fully discharged and then were charged at different power levels. Readings were taken from the MATE using WattPlot software (which is the most comprehensive software for monitoring performance data from a commercial renewable energy system), an ammeter to measure the DC current, and a power quality analyzer. When converting energy from $\mathrm{AC}$ to $\mathrm{DC}$, batteries take energy from the grid. In 
this condition, batteries are completely discharged and then are recharged by using the inverter. The amount of the current flow can be controlled by using the MATE; therefore, readings were taken while charging the batteries at different current flows. Figure 1 shows the test equipment connections of the inverter as well as power flow in the circuit for the first two steady-state analysis methods.

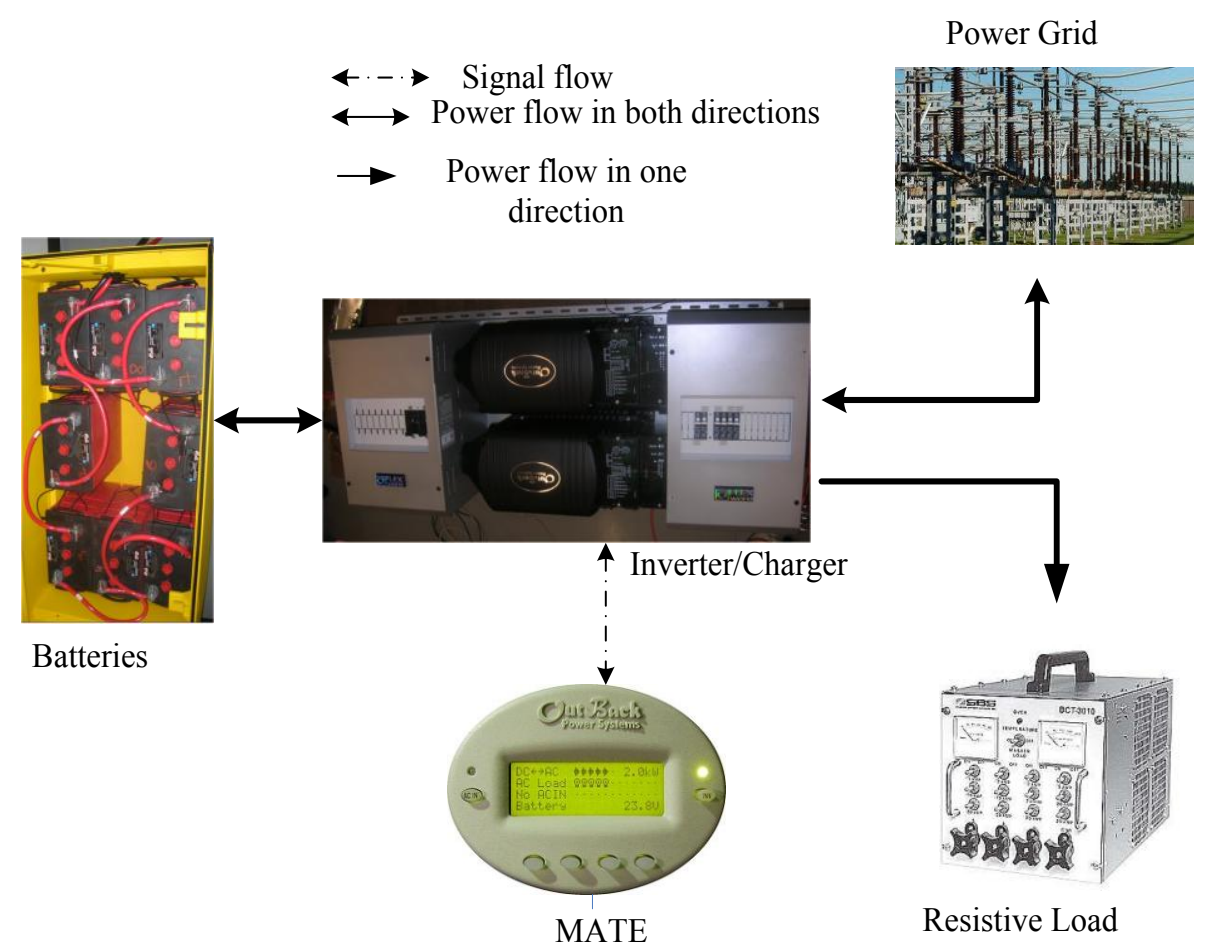

Figure 1. Steady-state analysis of inverter with batteries.

The third method of steady-state analysis was conducted by connecting a programmable DC supply (a controllable DC source that acts like a solar panel simulator) on the DC side of the inverter instead of using batteries; connecting a resistive, or inductive load, on the load terminals of the inverter; and disconnecting the inverter completely from the grid. Therefore, the energy consumed by the load was supplied by the programmable DC supply. According to the manufacturer, the inverter can operate from $42 \mathrm{~V}$ to $68 \mathrm{~V}$ on the $\mathrm{DC}$ side. Therefore, $44 \mathrm{~V}$ was supplied on the DC side, a variable resistive load was connected on the AC load side, and 
readings were taken at different load levels. Once resistive load readings were taken at different load levels, then variable inductive load readings were taken. The same experiment was repeated for the following voltages: $48,52,56,60,64$, and 68 on the DC side, with both resistive and inductive loads, and readings were collected at different load points. Figure 2 shows the test equipment connection of a steady-state analysis with the programmable DC supply.

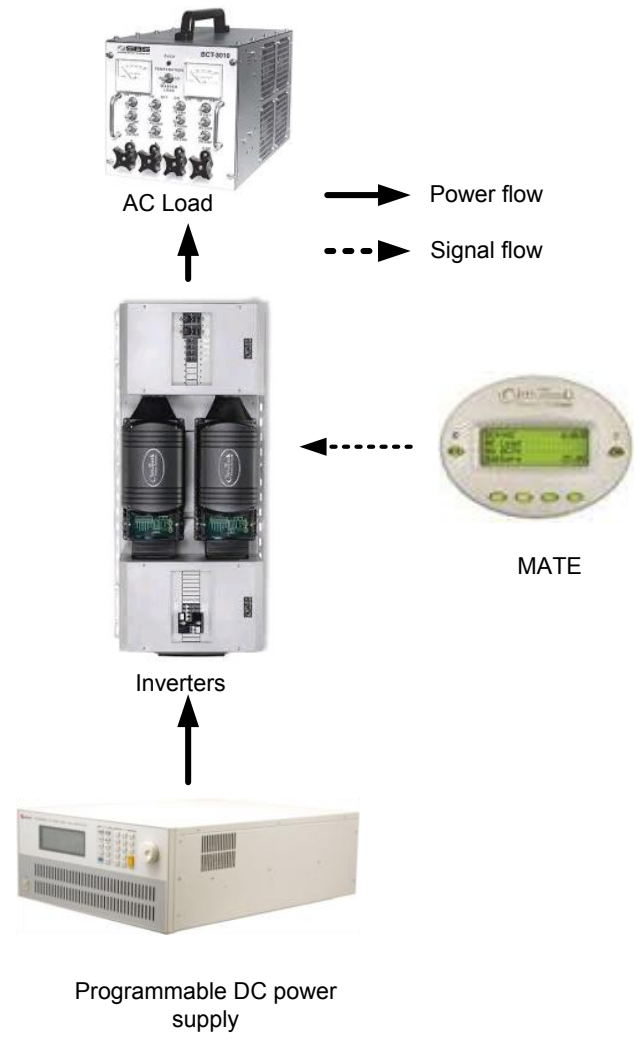

Figure 2. Test equipment connections for steady-state analysis.

\subsubsection{Determining Battery Efficiency}

The efficiency of the batteries is the ratio of output to input energy. According to specifications for the eight Rolls S-460 batteries in the Wichita State University (WSU) Power Quality Laboratory, each can store $466 \mathrm{amp}$ hours (Ah) with a 100-hour rate, $350 \mathrm{Ah}$ with a 20hour rate, and 126 Ah with a 1-hour rate [10]. From these energy storage values, each battery can deliver $2.796 \mathrm{KW}$ of energy when discharging at the rate of 100 hours of discharge time, 2.1 
KW of energy with a 20-hour discharge time, and $0.756 \mathrm{KW}$ of energy with a 1-hour discharge time. According to the recommended specifications, this battery can deliver $2.1 \mathrm{KW}$ of energy at 350 Ah with 20 hours discharge time, and for the experiment in this research, eight batteries were connected in series, so that the total energy storage capacity was $16.8 \mathrm{KW}$. For a longer life, lead-acid batteries should not be discharged below $50 \%$ of capacity, so only $8.4 \mathrm{KW}$ of energy was discharged from the system in the laboratory.

\subsubsection{Transient-State Analysis}

Transient-state analysis was performed in three ways. First, an inverter was connected to a programmable DC supply on the DC side of the inverter, and the AC terminals were connected to a programmable AC supply. The programmable AC supply was used for spike, sag, and surge susceptibility tests (acting like a grid), and nothing was connected to the load terminals of the inverter. The programmable AC supply voltage was controlled by virtual programming software. Then a constant inductive load, inverter, and programmable AC supply were connected at one node. Therefore, the load acted as a load on the grid, and load terminals of the inverter were kept open. Then voltage drops were created on the grid by using virtual programming software, and the readings were noted. The same test was repeated at different DC input voltages.

In the second method, a constant inductive load was connected at the load terminals of the inverter with a programmable DC supply to the DC terminals of the inverter and a programmable AC supply to the grid terminals of the inverter. By creating voltage drops on the grid side of the inverter, readings were taken. The same experiment was repeated at different DC input voltages.

In the third method, voltage sags were generated on the grid side of the inverter by using virtual programming software, which simulated disturbances of the grid in order to find 
determine how the inverter would react to faults on the grid. Some load was connected to the grid, but nothing was connected to the inverter load terminals. Readings were noted. The same test was repeated by connecting a load at the load terminals of the inverter and removing the load from the grid. Figure 3 shows the equipment connections for transient-state analysis tests.

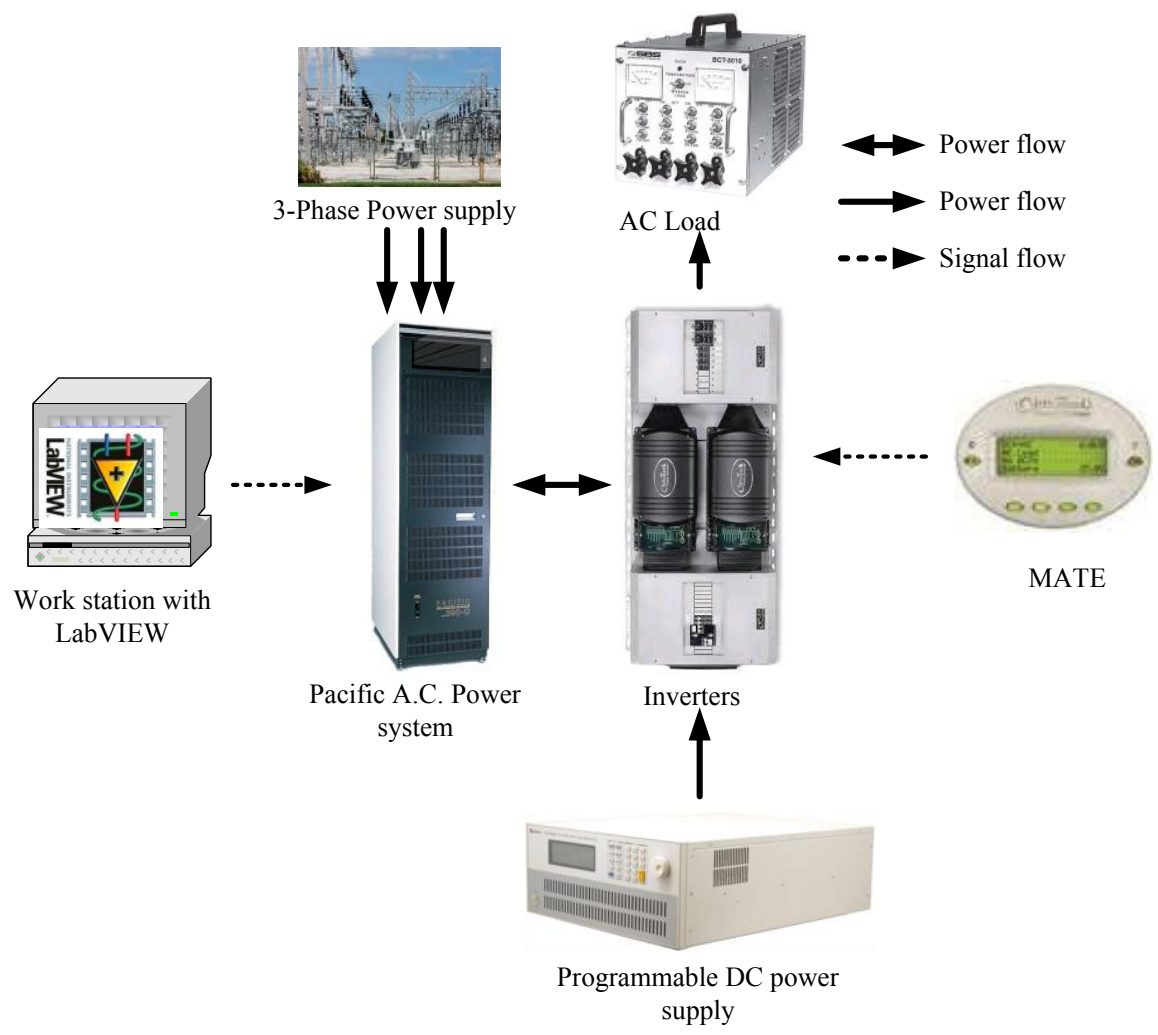

Figure 3. Equipment connections for transient-state analysis.

\subsubsection{Equipment}

In this study, a commercial grid-tie 3600-Watt 48VDC/120VAC inverter was tested. According to the manufacturer, this system will deliver 30 amps of AC RMS current and 45 amps of DC current. Typical efficiency of the system is $93 \%$, overload capacity is 6000 VA surge, $5000 \mathrm{VA}$ for 5 seconds, and $4000 \mathrm{VA}$ for 30 minutes [11]. This system can also operate in a $42 \mathrm{~V}$ to $68 \mathrm{~V}$ of $\mathrm{DC}$ voltage range, $58 \mathrm{~Hz}$ to $62 \mathrm{~Hz}$ frequency range, and $80 \mathrm{~V}$ to $150 \mathrm{~V} \mathrm{AC}$ voltage range [11]. 


\section{Inverter}

An "inverter is a DC to AC sine wave inverter, battery charger, and AC transfer switch housed within tough, die-cast aluminum" [12]. Each inverter has its own communication network for control to allow for the connection of inverters in series or parallel. Figure 4 shows a commercial GVFX3648 inverter.

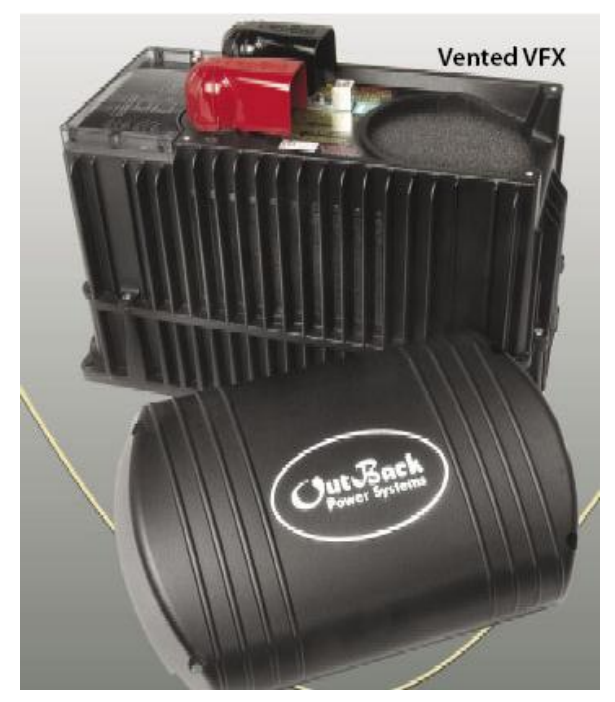

Figure 4. Commercial GVFX3648 inverter [11].

Two GVFX inverters connected in parallel are located in the WSU Power Quality Laboratory. Their DC output voltage is $48 \mathrm{~V}$, their AC output voltage is $120 \mathrm{~V}$, and their input AC voltage is $120 \mathrm{~V}$. The DC terminals are connected to either batteries or a programmable DC supply, and the AC terminals are connected to a programmable AC supply (acting as a grid). Other AC output terminals are connected to the load. If this inverter system is connected to solar panels via a charge controller (a device that collects power from PV panels, conditions it, and supplies it to batteries), and if the panels are generating more power than the load, then the inverters will supply excess power to the grid. If the panels are generating less power than the load, then the inverters will draw power from the grid. 
The inverter consists of a transformer, field effect transistor (FET) board, control board, AC assembly board, and temperature sensor. The transformer is useful to step up the voltage from $48 \mathrm{~V}$ to $120 \mathrm{~V}$ or to step down the voltage from $120 \mathrm{~V}$ to $48 \mathrm{~V}$.

The FET board, connected directly to the battery terminals, handles high currents to and from the battery; therefore, it contains the drive and over-current protection circuits [13]. "The control board is the 'brain' of the inverter; it contains all the processing power as well as the unit's memory" [13]. The AC assembly board is useful to connect the I/O terminals. The temperature sensor is useful in turning on the fan when the transformer becomes hot. Figures 5 6, and 7 show the FET board, AC assembly board, and control board, respectively.

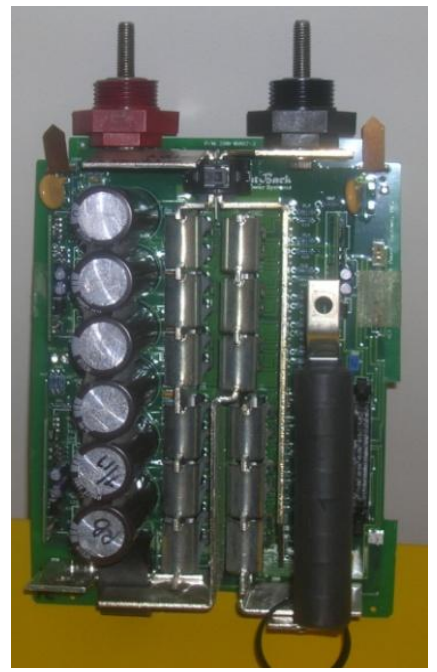

Figure 5. FET board.

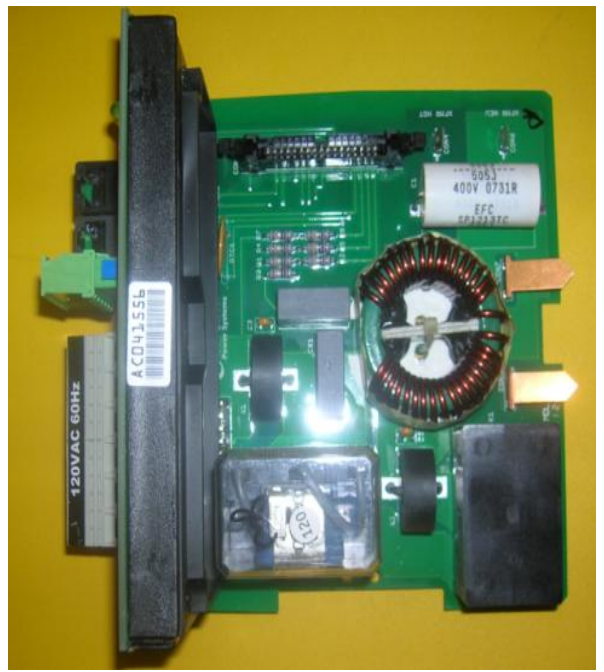

Figure 6. AC assembly board.

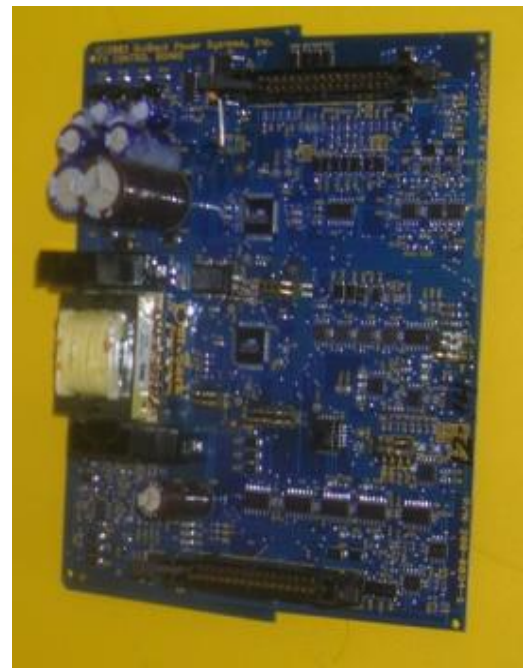

Figure 7. Control board.

\section{HUB}

The HUB is a communication manager between the MATE and the commercial power inverter. The HUB will allow connecting up to ten commercial power conversion devices to the MATE in order to send a command to them. Two kinds of hubs are available. The first, HUB-4, will control any combination of four commercial power inverters and chargers by using a MATE via an eight-wire CAT5 with RJ45 modular jack [14]. The other, HUB-10, will control up to ten 
FX-series inverters or chargers and MX60 charge controllers, or up to eight FX-series inverters/chargers. The power supply to the HUB comes from any FX-series inverters/chargers or MX60 charge controllers. Figure 8 shows a HUB-4.
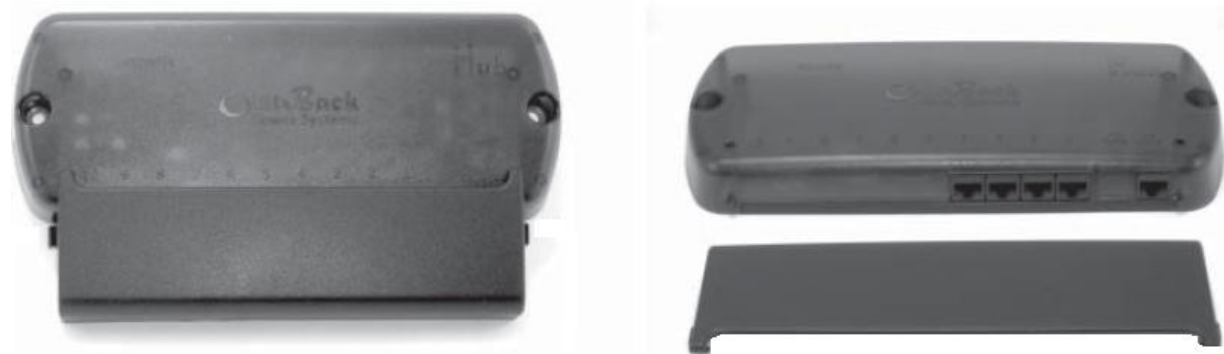

Figure 8. HUB-4.

\section{MATE}

All commercial converters, inverters, and MX60 charge controllers are controlled, configured, and monitored by using a MATE [14]. A single MATE can operate and monitor multiple inverters and MX60 charge controllers [14]. The MATE is connected to commercial components via the HUB with an Ethernet cable. The MATE has an RS232 opto-isolated DB9 serial communication port for computer interface in order for a computer to send a command directly to the MATE by using compatible programs like WattPlot, WinVerter, etc. Also, it has an RJ45 port so it can easily communicate with the inverter using an Ethernet cable via the HUB. The MATE consists of a four-line, 80-character LCD display to show the status of the system, six backlit silicone membrane keys, and two LED indicators to show the status of the AC grid connection and inverters [15]. The MATE obtains power from the inverters via the HUB. By using the MATE, commands (start, stop, change the input current, etc.) can be sent to the inverter. Figure 9 shows a picture of a commercial MATE. 


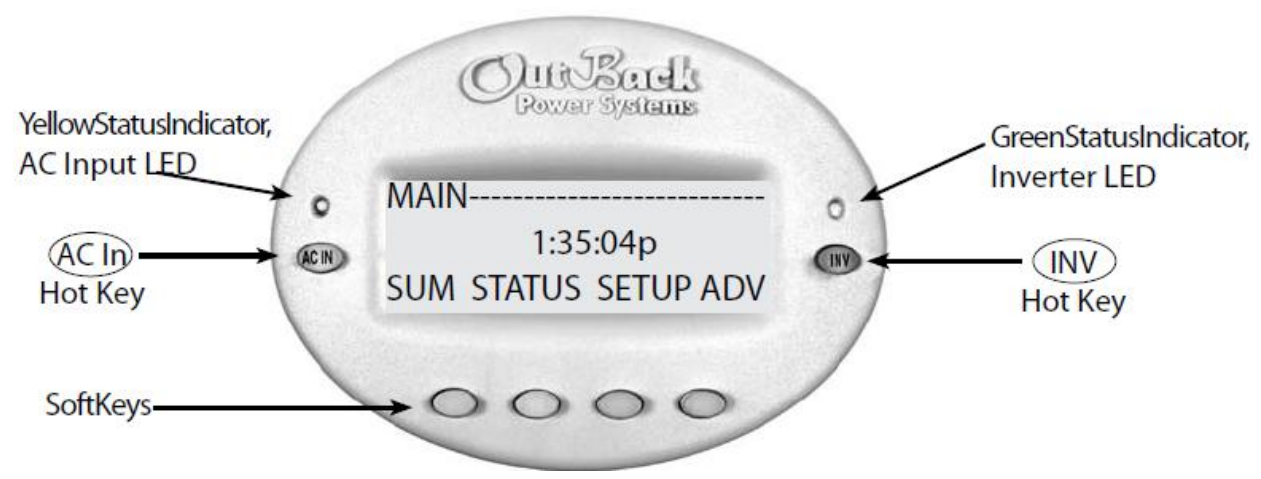

Figure 9. Commercial MATE remote control panel and display [15].

\section{Programmable AC Supply}

The 6 KVA single- and three-phase programmable AC power supply with a frequency range from $45 \mathrm{~Hz}$ to $5000 \mathrm{~Hz}$ [16] is used for spike, sag, and surge susceptibility tests. In this study, this power supply was used as a grid for the laboratory experiment. This unit is able to supply as well as consume electrical energy. The output voltage and frequency of this system can be controlled by virtual programming software. Output of this unit is either single phase or three phases but requires three-phase supply. The programmable AC supply is shown in Figure 10.

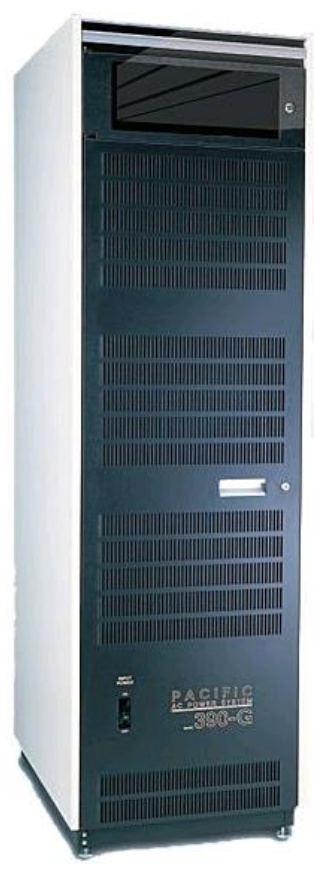

Figure 10. Programmable AC power supply. [16] 


\section{Programmable DC Power Supply}

The programmable DC power supply is a solar array simulator used to simulate solar panels. Output voltage rating of this unit is $0 \mathrm{~V}$ to $100 \mathrm{~V}$, a current rating of $0 \mathrm{~A}$ to $100 \mathrm{~A}$, and a power rating of $5000 \mathrm{~W}$. Output settings and measured values can be seen in the LCD panel attached on the front side of the unit. The input voltage rating is $190 \mathrm{~V}$ to $250 \mathrm{~V}$ line to line for a three-phase four-wire delta-connected system, or $329 \mathrm{~V}$ to $433 \mathrm{~V}$ line to line for a three-phase five-wire star-connected system, with an input frequency range of $47 \mathrm{~Hz}$ to $63 \mathrm{~Hz}$ and maximum input current of 16 A per phase for a star-connected AC power supply or 27 A for a deltaconnected AC power supply. This power supply has an RS-232C port to connect with a PC for a remote-control operation, and if there is more than one unit, an RS-485 port for series or paralleldata transmission between different units. It always maintains constant voltage at the output terminals. Figure 11 shows a programmable DC power supply.

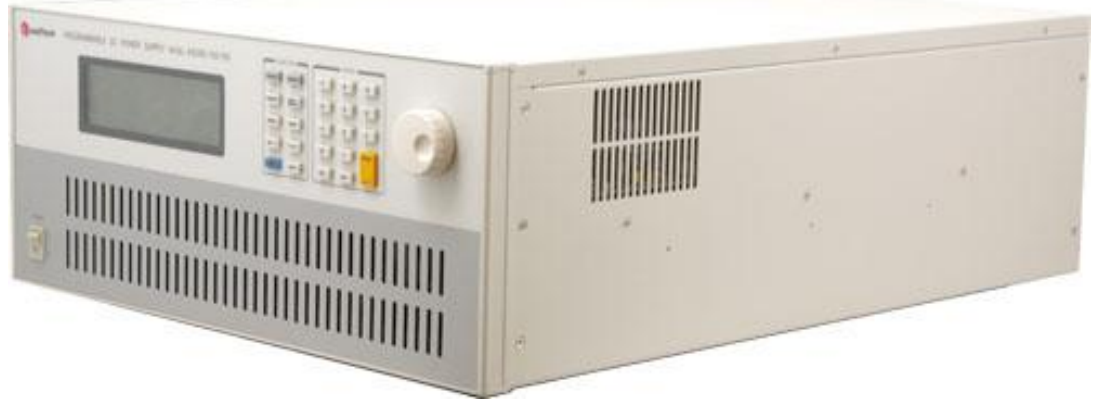

Figure 11. Programmable DC power supply [17].

\section{WattPlot Software}

WattPlot software is used to control, monitor, and record the performance data of the inverter. The MATE is connected to a PC serial port through an RS 232 cable. Three types of operation options are available with WattPlot software: local operation, remote TCP/IP 
operation, and remote file operation [18]. For this study, the local operation, which allowed monitoring of the inverter operation, input, and output, was used.

\section{Lead-Acid Batteries}

In a lead-acid battery, lead dioxide acts as the cathode (negative plate), and a sponge metallic lead acts as the anode (positive plate). Sulfuric acid is the electrolyte [19]. Here, a number of positive plates are connected together, and a number of negative plates are connected together, in order to obtain the required output voltage and current. Positive plates are always in between negative plates so there will be an $\mathrm{N}+1$ negative plate if there are $\mathrm{N}$ positive plates. Eight lead-acid batteries were used to produce $48 \mathrm{~V}$. Figure 12 shows the eight batteries connected in series in the Power Quality Laboratory.

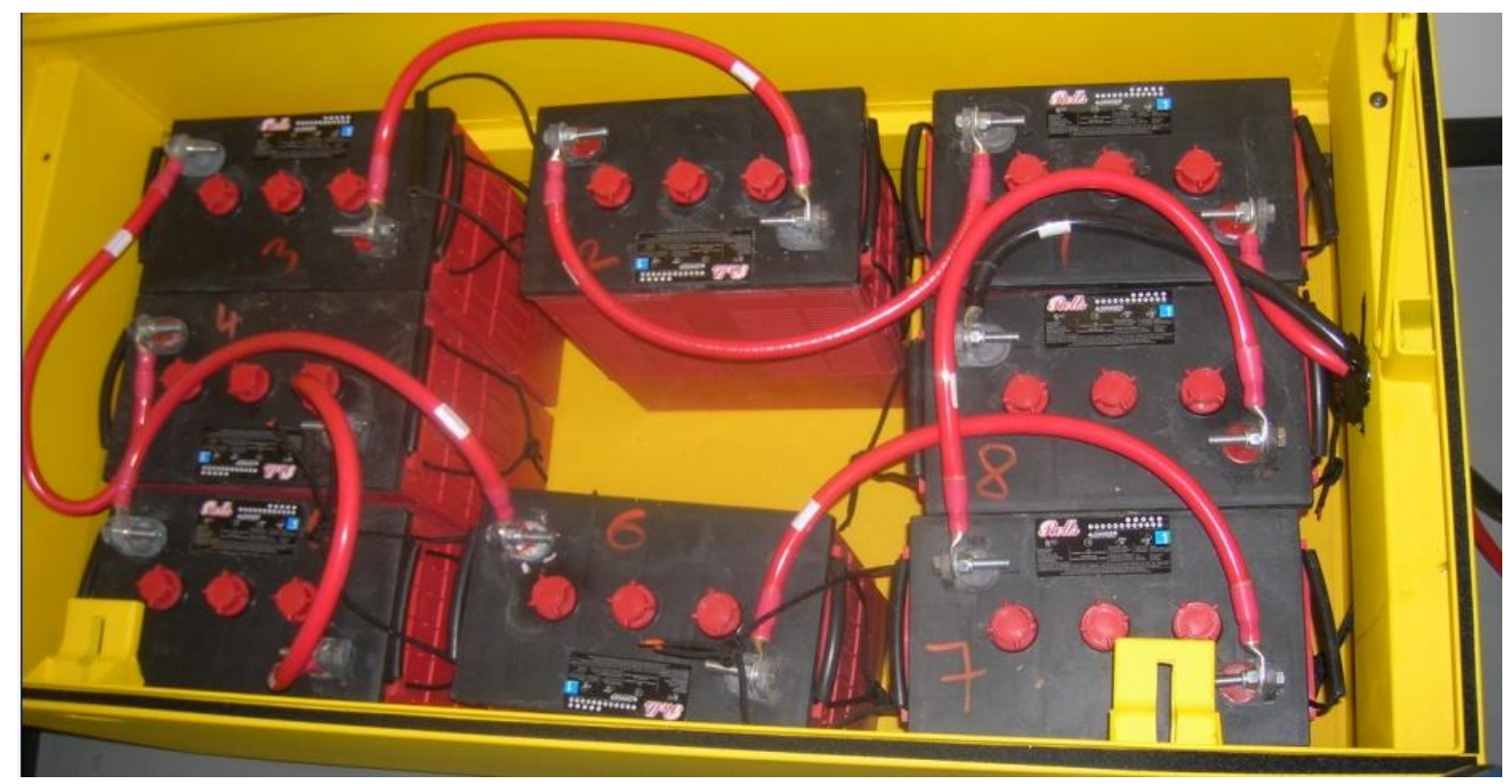

Figure 12. Series-connected lead-acid batteries from WSU Power Quality Laboratory.

Additional parts, listed in Table 1, were needed to complete this smart grid system. 
TABLE 1

REQUIRED PARTS FOR FLEXWARE 500 (GRID-TIE) SYSTEM

\begin{tabular}{|l|l|}
\hline \multicolumn{1}{|c|}{ Part Name } & \multicolumn{1}{c|}{ Description } \\
\hline FW500-DC & $\begin{array}{l}\text { DC breaker enclosure to protect DC breaker and keep DC wiring } \\
\text { inside enclosure. }\end{array}$ \\
\hline FW500-AC & $\begin{array}{l}\text { AC breaker enclosure to protect AC breaker and keep AC wiring } \\
\text { inside enclosure. }\end{array}$ \\
\hline FW-BBS & Bus to connect two DC breakers. \\
\hline OBDC-125 Breaker & DC breaker to disconnect or connect batteries to inverter. \\
\hline FW-IOB-D-120/240VAC & AC breaker to disconnect or connect power supply. \\
\hline FLEXware Mounting Plate & Useful plate for mounting inverter and breakers \\
\hline Surge Protector & $\begin{array}{l}\text { Designed to protect sensitive components from excessively high } \\
\text { voltage like electrical storms. }\end{array}$ \\
\hline
\end{tabular}

\subsubsection{Steady-State Test Connections}

Eight six-volt batteries were connected in series, in order to obtain $48 \mathrm{~V}$ of output voltage. These batteries were connected to the DC terminals of two parallel inverters through over-current circuit breakers. Six terminals were located on the AC side of the inverter-two terminals for $\mathrm{AC}$ input, two terminals for $\mathrm{AC}$ output, and two terminals for ground. $\mathrm{AC}$ input terminals were connected to the power supply via $\mathrm{AC}$ breakers, and $\mathrm{AC}$ output terminals were connected to the load via other breakers. The input and output terminals of the inverters were connected to surge protectors to protect them from excessive high voltage [20]. There were two communication ports-RJ45 and RJ11. The MATE was connected to the inverter by an RJ45 cable and to the computer by an RS-232 cable to communicate with the software.

The second part of the test connections was the same as for the first part of the steadystate analysis. The only difference was in replacing the batteries with the programmable DC supply. Figure 13 shows the complete grid-tie system in the WSU Power Quality Laboratory. 


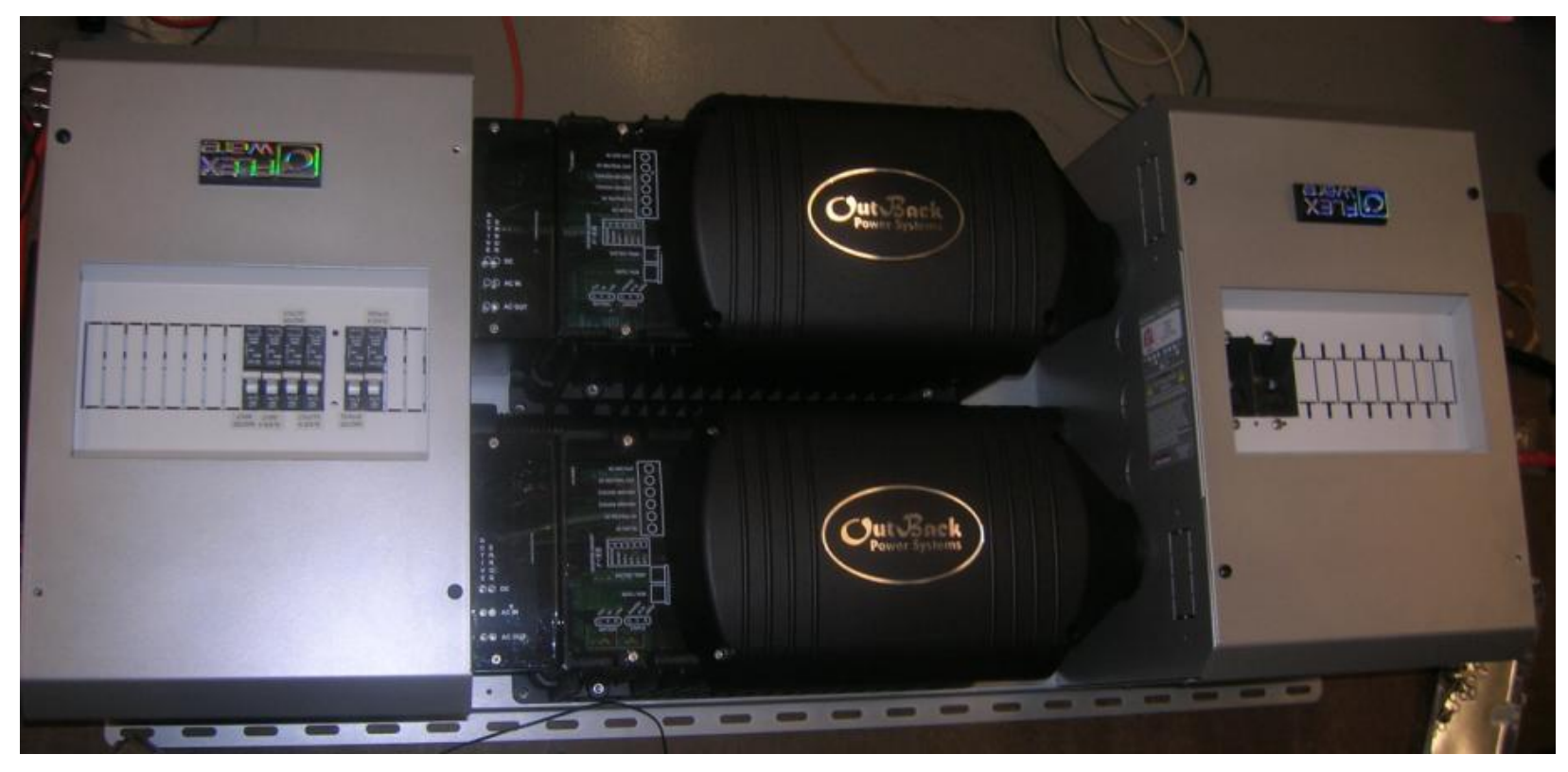

Figure 13. Grid-tie inverter system in WSU Power Quality Laboratory. 


\section{CHAPTER 3}

\section{IEEE TEST SYSTEMS AND POWER FLOW SOFTWARE}

Steady-state analysis is useful for analyzing the performance of an inverter. It is possible to analyze the efficiency of the inverter with both resistive and inductive loads and to determine if it is supplying reactive power to the load.

Transient-state analysis is useful for analyzing the behavior of an inverter when connected to the grid, and when there are voltage drops and voltage sags on the grid. Power system planners and developers are interested in how a high penetration of distributed energy resources (DR) will affect the system. Therefore, it is necessary to develop a model of how much power the distribution resource is going to inject into the grid for voltage drops. To obtain those results, a test was conducted in this study by connecting DC terminals of the inverter to a programmable DC supply, by connecting $\mathrm{AC}$ terminals of the inverter to the programmable $\mathrm{AC}$ supply, and keeping the load terminals open. The results of this test are discussed in Chapter 5. Readings were taken at different voltage levels on the grid side, and the same test was repeated with the same connections at different DC voltages.

The results obtained had a nonlinear relation between the grid voltage and power supplied by the inverter, so to linearize the relation, regression analysis was used. Regression analysis explains how the dependent variable changes with respect to independent variable. The resultant model was used in IEEE 13 bus system.

\subsection{IEEE 13-Bus System}

Results were analyzed using an IEEE 13-bus system, which is a radial distribution feeder with 13 nodes and a common set of data for programmers and end users to verify the correctness of solutions [21]. The loads used in this model were spot loads and uniformly distributed. Some 
of the loads were single phase and some were three-phase unbalanced loads. All loads were a combination of constant power, constant current, and constant impedance loads. This type of system used underground lines as well as overhead lines for power distribution. It had $1158 \mathrm{KW}$ of load and 606 KVAr of reactive power on Phase A, $973 \mathrm{KW}$ of active power and $627 \mathrm{KVAr}$ of reactive power on Phase $\mathrm{B}$, and $1135 \mathrm{KW}$ of active power and753 KVAr of reactive power on Phase C. It also consisted of a distributed load of $17 \mathrm{KW}$ active power and $10 \mathrm{KVAr}$ reactive power on Phase A, $66 \mathrm{KW}$ of active power and $38 \mathrm{KVAr}$ of reactive power on Phase B, and $117 \mathrm{KW}$ of active power and $68 \mathrm{KVAr}$ of reactive power on Phase C. Figure 14 shows a singleline diagram of the IEEE 13-bus system.

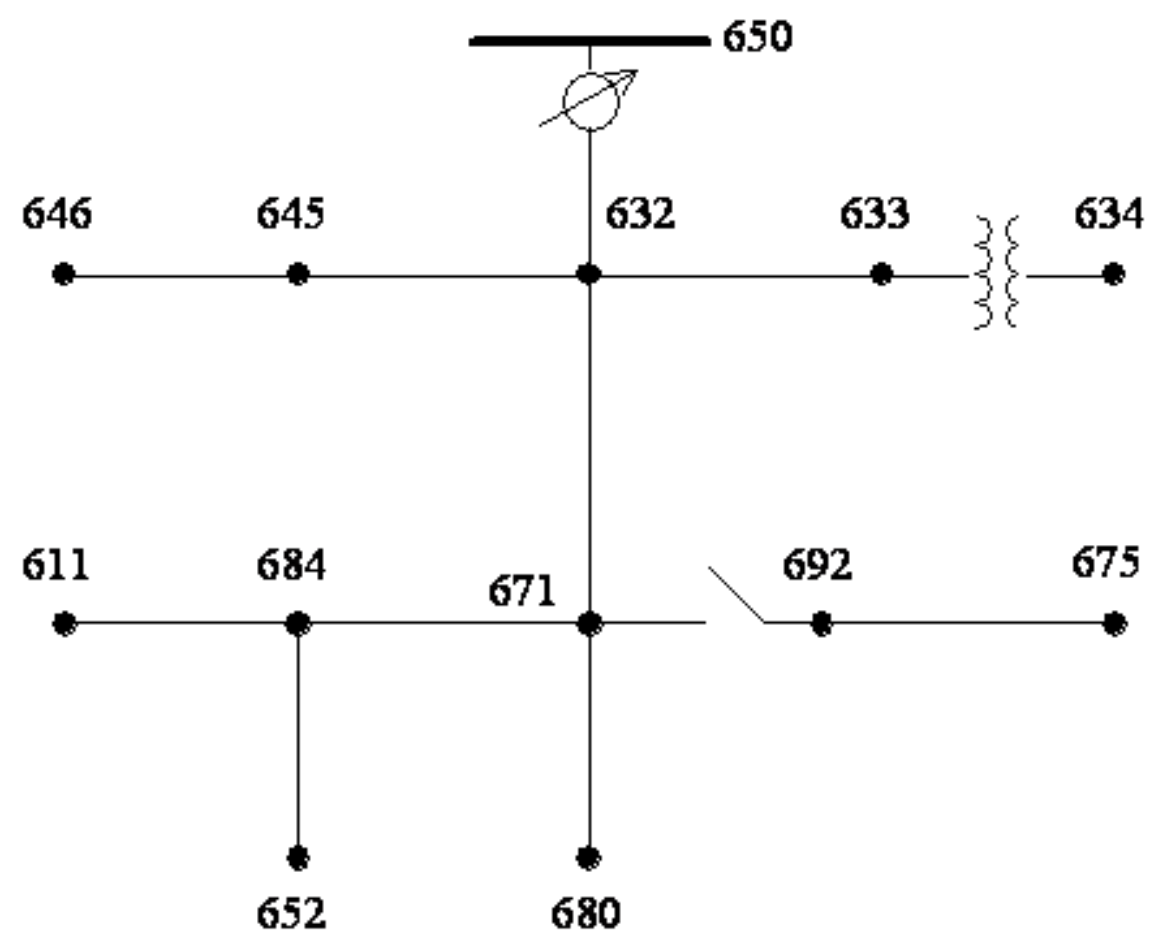

Figure 14. Single-line diagram of IEEE 13-bus system.

\subsection{Commercial Distribution Power Flow Software}

Commercially distributed power flow software was used to analyze the data from the experiments. Using this software enabled power flow modeling, voltage drop modeling, 
reliability analysis, short circuit calculations, fault current calculations, and arc flash hazard analysis [22]. Figure 15 shows the IEEE 13-bus system modeled on commercial distribution power flow software.

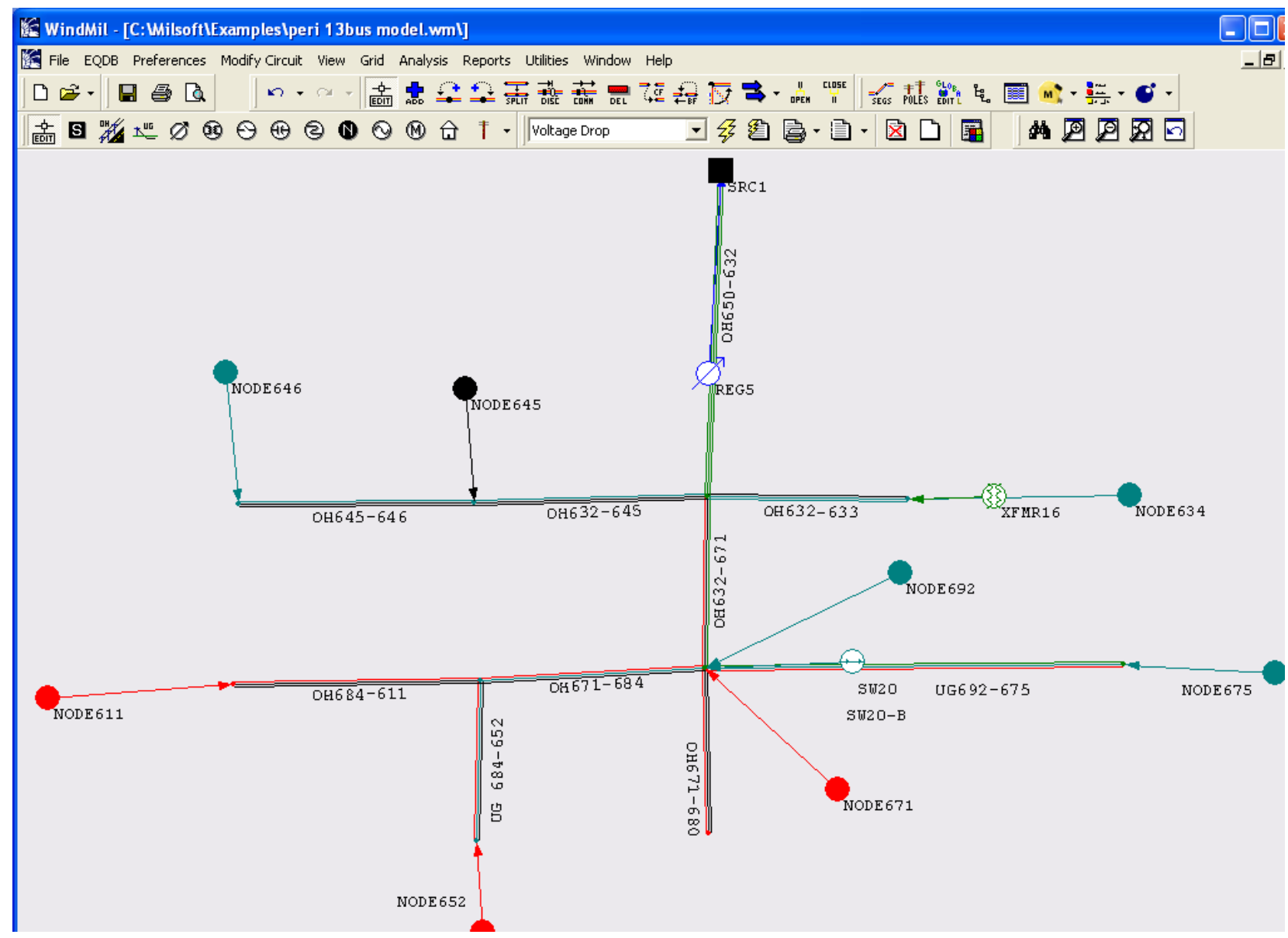

Figure 15. IEEE 13-bus model on commercial distribution power flow software.

The total load on this system was around $3550 \mathrm{KW}$, and losses on the system were close to $116 \mathrm{KW}$. The WSU Power Quality Laboratory has a 3600 VA inverter, with selling power between $0 \mathrm{~W}$ and $3600 \mathrm{~W}$, depending on the DC source voltage and AC grid voltage. Readings from the experiment were taken while maintaining constant DC voltage on the DC side and creating a voltage sag on the AC side. Also, a load was connected at the node where the inverter and grid came together. This test was repeated at different DC voltages. A nonlinear relation was 
found between the grid voltage drop and power supplied by the inverter, and regression analysis was used to make this linear. Test results were from different DC voltages, so using the regression analysis equation created a large error value in relation to real test results and the results from the regression analysis equation. The error was high at extreme DC source voltages $-44 \mathrm{~V}$ and $68 \mathrm{~V}$. Most of the time, the inverter operated between $46 \mathrm{~V}$ and $52 \mathrm{~V}$; therefore, to minimize the error, the average value of the inverter output at various DC voltages - $48,52,56,60$, and $64-$ was used. Then the error was limited to $20 \%$ in 33 out of 34 cases, and only one case error was close to $31.4 \%$. Even at the $44 \mathrm{~V}$ DC supply, the error was limited to $18 \%$ in three of six cases, $25 \%$ in one case, $35 \%$ in one case, and $56 \%$ in another case.

\subsection{IEEE 1547 Standards}

IEEE 1547 standards typically discuss how the smart grid should react to problems in the main grid. Inverters are designed to obey both UL 1741 standards and IEEE 1547 standards. According to UL 1741 standards, distributed generation (DG) must maintain standards in voltage flicker/variation, harmonics/waveform distortion, frequency variation, power factor variation, safety/protection related to the public, islanding, relay protection, DC bias, thermocycling, power quality, power storage, and magnetic inrush currents. Therefore, companies that manufacture inverters must keep these standards in mind. According to these standards, if there is a notch in the voltage that is higher than the standard value, then the inverter automatically stops discharging the energy to the grid.

Currently in the world, many kinds of distributed energy resources are available—solar arrays, wind turbines, micro turbines, fuel cells, gas fired turbines, and energy storage technologies, to name a few [23]. There are three ways to connect DR to an electric power 
system (EPS): with synchronous generators, with asynchronous generators, and with static inverters [23]. Most DR use static inverter to connect to an EPS.

The EPS is a redial system, and power flows in only one direction. If a DR is located at the end of the system or somewhere in the line, it may introduce a two-way power flow that may interfere with the voltage regulation on the EPS. Voltage regulations may occur in two ways: (1) if a DR is injecting active power into the EPS, then the load current will be offset, the voltage drop in the line will be reduced, and a voltage rise will occur in the line, and (2) if the DR consumes reactive power or supply reactive power, then this would lead to a voltage change on the Area EPS [23].

This chapter discusses the IEEE 1547 standards for connecting distributed energy resources to the EPS. According to this standard, "The functions of the interconnection system hardware and software that affect the Area EPS are required to meet this [1547] standard regardless of their location on the EPS. The DR shall not actively regulate the voltage at the point of common coupling (PCC). The DR shall not cause the Area EPS service voltage at other Local EPSs to go outside the requirements of ANSI C84.1-1995, Range A" [23]. The DR must not regulate the EPS voltage by supplying or consuming reactive power. The DR voltage must follow the Area EPS and must not influence the EPS voltage. Sometimes an EPS operator can request a constant power factor from the DR; in that case, reactive power will change with respect to active power generation [23].

The American National Standard Institute (ANSI) C84.1-2011 (a revision of ANSI C84.1-2006) aims to achieve economical and practical operation and design, encourage the understanding of the voltage associated with the power and utilization equipment, set up uniform categorization in the field of voltages, encourage regularity of equipment voltage ratings and 
tolerances, provide a channel for potential development and design of equipment to accomplish the best possible conformance with the need of users [24].

According to IEEE Std. 1547-2003 4.2.3, the DR device must not supply energy to the EPS when the EPS voltage goes out of range, which is $88 \%$ to $110 \%$, of nominal voltage [23].

IEEE Std. 1547-2003 5.1.2 stipulates that if the DR system is less than or equal to 500 KVA, then when paralleling the DR system with the EPS, it is important to ensure that the difference in frequency (difference between EPS frequency and DR system frequency) is less than or equal to $0.3 \mathrm{~Hz}$, that the voltage difference is less than or equal to $10 \%$, and the that difference in phase angle is less than or equal to $20^{\circ}$. If the DR system is between $501 \mathrm{KVA}$ and $1500 \mathrm{KVA}$, then the frequency difference must not be more than $0.2 \mathrm{~Hz}$, the voltage difference must not be more than $5 \%$, and the phase angle difference must not be more than $15^{\circ}$. If the DR system is between $1501 \mathrm{KVA}$ and $10 \mathrm{MVA}$, then the frequency difference must be limited to 0.1 $\mathrm{Hz}$, the voltage difference must be limited to $3 \%$, and the phase angle difference must be limited to $10^{\circ}[23]$.

IEEE Std. 1547-2003 4.1.5 says "The DR shall not energize the Area EPS when the Area EPS is de-energized" [23].

According to IEEE Std. 1547-2003 4.1.8.2, "The interconnection system shall have the capability to withstand voltage and current surges in accordance with the environments defined in (IEEE Std. C62.41.2 ${ }^{\mathrm{TM}}-2002$ [B48] or IEEE Std C37.90.1 ${ }^{\mathrm{TM}}-2002$ [B42]) as applicable" [23]. Usage of semiconductor devices are increased in the power system, and these devices are more sensitive to voltage surges. Electrical circuits are designed to supply energy without damaging any equipment in the system. The DR system must maintain the same standard of performance as the other equipment in the power system. 
IEEE Std. 1547-2003 4.1.8.3 stipulates that "The interconnection system parallelingdevice shall be capable of withstanding $220 \%$ of the interconnection system rated voltage" [23]. The maximum allowable operating voltage on any system is $110 \%$ of its normal voltage [23]. If the Area EPS system with the DR system is isolated from the main EPS and is being paralleled to the main EPS, then the voltage on any one of those systems could be $180^{\circ}$ out of phase, and both voltages might be at their peak values $(110 \%)$. Operating at $60 \mathrm{~Hz}$ may lead to a long-term steady-state voltage of $220 \%$, so the paralleling device must be capable of withstanding $220 \%$.

IEEE Std. 1547-2003 4.2 says that "Abnormal conditions can arise on the Area EPS that requires a response from the connected DR. This response contributes to the safety of utility maintenance personnel and the general public, as well as the avoidance of damage to connected equipment, including the DR. All voltage and frequency parameters specified in these subclauses shall be met at the PCC, unless otherwise stated" [23]. According to IEEE standard 1547-2003 4.2.1, the DR unit, which is connected to the EPS, must cease energy to the EPS [23]. If there is a fault on the Area EPS and the circuit has stopped energizing, then any other source connected to the Area EPS must not supply any energy for the safety of equipment and workers. IEEE Standard 1547-2003 4.2.1 says that the DR unit must not supply any energy to the EPS prior to reclosure by the Area EPS [23]. Most faults on the transmission system (70\% to 95\%) are transient in nature, so most of the protecting system will attempt to reclose the circuit to establish the power supply to that area. According to IEEE standard1547-2003 4.2.1, the DR system must not attempt to supply energy prior to the Area EPS [23].

IEEE Std. 15474.2 .3 states that if the local EPS voltage range is less than $50 \%$ of base voltage, then the DR system must cease energy to the EPS in less than 0.16 seconds. If the voltage range is $50 \%$ to $88 \%$ of the base voltage, then the DR system must cease energy in less 
than 2 seconds. If the EPS voltage is $110 \%$ to $120 \%$ of the base voltage, then the clearing time is 1 second. If the EPS voltage is $120 \%$ of the base voltage, then the clearing time for the DR system is 0.16 seconds. This clearing time is the maximum clearing time if the DR system is below $30 \mathrm{KW}$, and this clearing time is the default clearing time if the system is above $30 \mathrm{KW}$ [23].

According to IEEE Std. 1547-2003 4.2.4, if EPS frequency is above $60.5 \mathrm{~Hz}$ or below $59.3 \mathrm{~Hz}$, then the maximum clearing time for the DR system to cease energy, which is less than $30 \mathrm{KW}$, is 0.16 seconds. If the DR system is above $30 \mathrm{KW}$, then the default clearing time is 0.16 seconds, if the EPS system frequency is above $60.5 \mathrm{~Hz}$ or below $57 \mathrm{~Hz}$. If the DR system is above $30 \mathrm{KW}$ and the EPS frequency is between $59.8 \mathrm{~Hz}$ and $57 \mathrm{~Hz}$, then the default clearing time can be adjustable between 0.16 seconds and 300 seconds [23]

IEEE Std. 1547-2003 4.2.6 states that the DR unit must not reconnect to the Area EPS immediately after the disturbance. The DR system interconnection with the EPS must maintain an adjustable delay (or a fixed time delay) until the Area EPS is restored to the steady-state values or within the acceptable range [23].

According to IEEE Std. 1547-2003 4.1.3, while connecting the DR unit to the Area EPS, it should not cause voltage fluctuations greater than $\pm 5 \%$ of normal voltage, and according to IEEE 154-2003 4.3.2, it must not create any objectionable flicker for other customers in that area [23].

IEEE Std. 1547-2003 4.3 states that the DR unit must not inject DC current more than $0.5 \%$ of the rated output current into the EPS [23], or the DC current will produce DC offset in the voltage waveform, which will lead to significant saturation in the magnetic components. A flux offset of $10 \%$ to $20 \%$ will result in profound saturation at the peak of one polarity of the flux 
wave, which leads to drastic increases in exciting currents, and exciting currents are highly distorted and will lead to even-order harmonics in the output [23].

IEEE Std. 1547-2003 4.3.3 states that if the DR unit is serving balanced loads, then the harmonic current injection into the EPS must be less than $4 \%$ for harmonics below the $11^{\text {th }}$ harmonic, $2 \%$ for the $11^{\text {th }}$ to $17^{\text {th }}$ harmonics, $1.5 \%$ for the $17^{\text {th }}$ to $23^{\text {rd }}$ harmonics, $0.6 \%$ for the $23^{\text {rd }}$ to $35^{\text {th }}$ harmonics, and $0.3 \%$ for the $35^{\text {th }}$ harmonics and above [23].

According to IEEE Std. 1547-2003 4.4.1, "For an unintentional island in which DR energizes a portion of the Area EPS through the PCC, the DR interconnection system shall detect the island and cease to energize the Area EPS within two seconds of the formation of an island" [23].

All of the above IEEE standards explain how the distribution resource should react when there is a problem in the electric power system. The laboratory's inverter was used in some of the distribution resources where DC power was generated. Therefore, the above IEEE standards explain how the inverter should react to all changes appearing on the grid. Here we are able to see the performance of the inverter and also checked some of the IEEE standards of the inverter. 


\section{CHAPTER 4}

\section{STEADY-STATE TEST RESULTS}

Table 2 shows the steady-state test results of the inverter while discharging. In this part of the experiment, only resistive loads were used. Efficiencies might change a little with inductive or capacitive loads. All AC measurements were taken from a Fluke 435 power quality analyzer. The DC voltage was from the MATE, and the DC current was from a multimeter. Figure 16 graphs the output power (X-axis) versus efficiency (Y-axis) of the inverter while discharging.

TABLE 2

PERFORMANCE OF INVERTER WITH RESISTIVE LOAD WHILE DISCHARGING

\begin{tabular}{|c|c|c|c|c|c|c|c|}
\hline $\begin{array}{c}\text { DC Voltage } \\
\text { (Volt) }\end{array}$ & $\begin{array}{c}\text { DC } \\
\text { Current } \\
\text { (Ampere) }\end{array}$ & $\begin{array}{c}\text { DC } \\
\text { Power } \\
\text { (Watt) }\end{array}$ & $\begin{array}{c}\text { AC Voltage } \\
\text { (Volt) }\end{array}$ & $\begin{array}{c}\text { AC } \\
\text { Current } \\
\text { (Amp) }\end{array}$ & $\begin{array}{c}\text { Frequency } \\
\text { (HZ) }\end{array}$ & $\begin{array}{c}\text { AC } \\
\text { Power } \\
\text { (Watt) }\end{array}$ & $\begin{array}{c}\text { Efficiency } \\
\text { (\%) }\end{array}$ \\
\hline 49.2 & 20.2 & 993.84 & 123.2 & 6 & 59.99 & 600 & 60.37 \\
\hline 49.2 & 29 & 1626.8 & 123.3 & 10 & 59.99 & 1200 & 73.76 \\
\hline 49.2 & 47.2 & 2322.24 & 123.1 & 16 & 59.99 & 1800 & 77.51 \\
\hline 48 & 58.4 & 2803.2 & 122.6 & 20 & 59.99 & 2400 & 85.61 \\
\hline 47.2 & 78.6 & 3709.92 & 122 & 26 & 59.99 & 3000 & 80.86 \\
\hline 46 & 89.9 & 4135.4 & 121.7 & 30 & 59.99 & 3600 & 87.05 \\
\hline
\end{tabular}

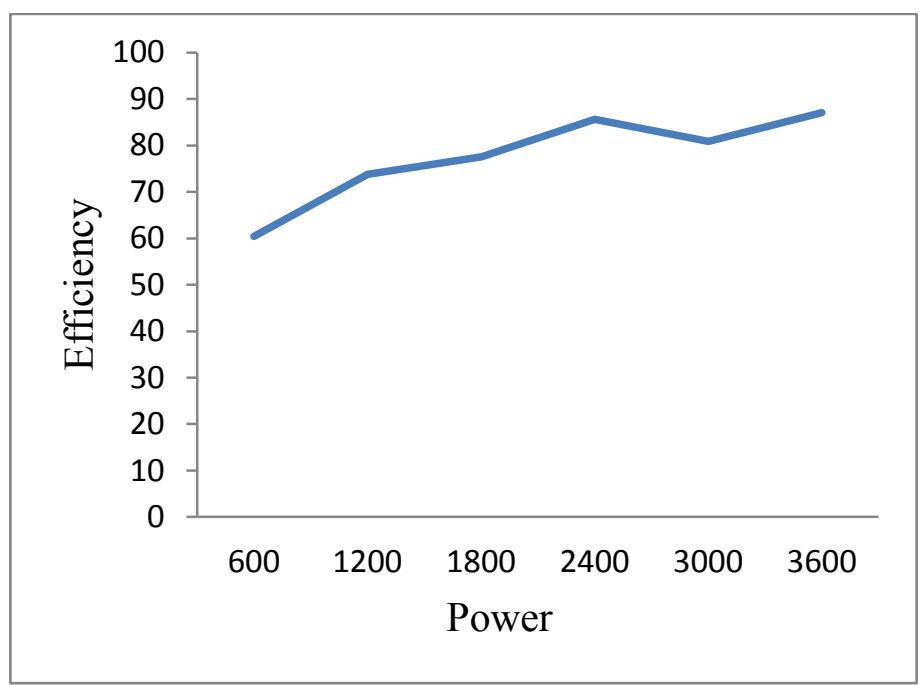

Figure 16. Efficiency of inverter with resistive load while discharging. 
Table 3 shows the steady-state test results of the inverter while charging the battery. From Table 3, it can be concluded that efficiency is low when the inverter is discharging a lower value of power compared to discharging a rated power. In other words, the inverter performed better when discharging a rated power. Figure 17 shows a graph of output power (X-axis) versus efficiency (Y-axis) of the inverter when it was charging the battery.

TABLE 3

PERFORMANCE OF INVERTER WHILE CHARGING BATTERY

\begin{tabular}{|c|c|c|c|c|c|c|c|c|c|}
\hline $\begin{array}{c}\mathbf{V}_{\text {RMS }} \text { of } \\
\text { Master } \\
\text { (Volts) }\end{array}$ & $\begin{array}{c}\mathbf{I}_{\text {RMs of }} \\
\text { Master } \\
\text { (Amps) }\end{array}$ & $\begin{array}{c}\text { Master } \\
\text { Power } \\
\text { Factor }\end{array}$ & $\begin{array}{c}\mathbf{V}_{\text {RMS }} \text { of } \\
\text { Slave } \\
\text { (Volts) }\end{array}$ & $\begin{array}{c}\mathbf{I}_{\text {RMs of }} \\
\text { Slave } \\
\text { (Amps) }\end{array}$ & $\begin{array}{c}\text { Slave } \\
\text { Power } \\
\text { Factor }\end{array}$ & $\begin{array}{c}\text { Total AC } \\
\text { Power } \\
\text { (Watt) }\end{array}$ & $\begin{array}{c}\text { DC } \\
\text { Power } \\
\text { (Watt) }\end{array}$ & $\begin{array}{c}\text { DC } \\
\text { Voltage } \\
\text { (Volts) }\end{array}$ & Efficiency \\
\hline 121 & 5 & 0.93 & 121.8 & 5 & 0.93 & 1129.0 & 600 & 52.4 & 53.31 \\
\hline 120.3 & 6 & 0.94 & 121.6 & 6 & 0.94 & 1364.3 & 1200 & 53.2 & 87.95 \\
\hline 119.4 & 9 & 0.96 & 121.2 & 9 & 0.96 & 2078.8 & 1800 & 54 & 86.58 \\
\hline 118.1 & 12 & 0.97 & 120.2 & 12 & 0.97 & 2773.8 & 2400 & 54.4 & 86.52 \\
\hline 116.9 & 14 & 0.98 & 119.6 & 15 & 0.98 & 3362 & 3000 & 55.2 & 89.23 \\
\hline 115.1 & 18 & 0.99 & 119.5 & 16 & 0.97 & 3869.7 & 3400 & 56 & 87.86 \\
\hline
\end{tabular}

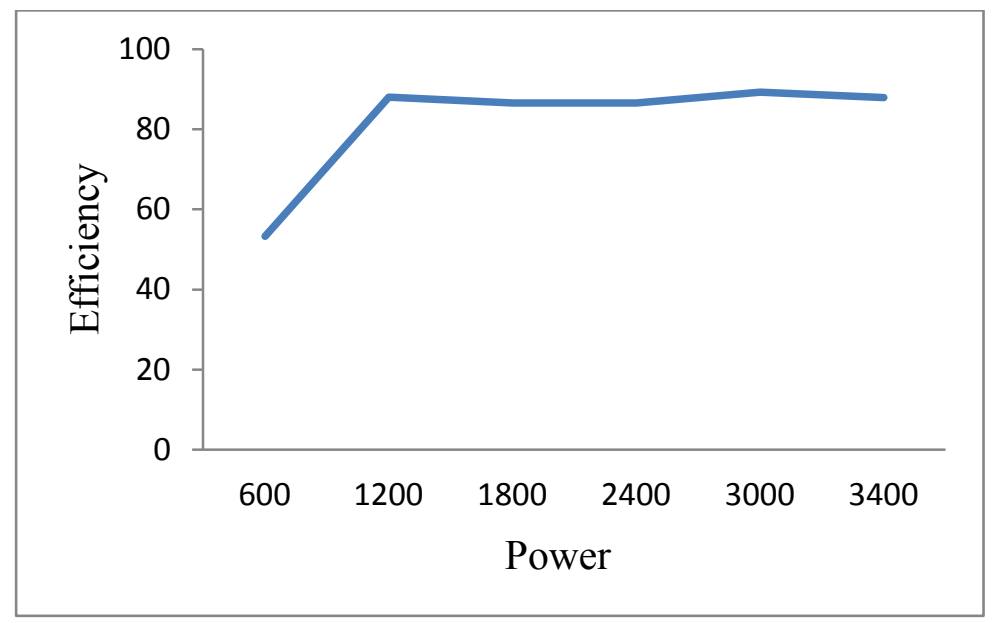

Figure 17. Efficiency of inverter while charging battery.

Table 4 and Figure 18 show test results for battery efficiency. The battery was fully charged and then discharged through the inverter into varying resistive loads until the battery 
voltage reached $46 \mathrm{~V}$. The energy to recharge the battery was then measured. When the battery was connected to the $1200 \mathrm{~W}$ load, it discharged $6.58 \mathrm{KW}$ of energy and required $9.86 \mathrm{KW}$ of energy to recharge. When the battery was connected to a $2400 \mathrm{~W}$ resistive load, it discharged 4.16 KW of energy and required 7.2 KW of energy to recharge. When $3600 \mathrm{~W}$ of resistive load was connected to the battery, it discharged $1.907 \mathrm{KW}$ of energy and required $4.377 \mathrm{KW}$ of energy to recharge. From Table 4, it can be seen that battery efficiency depends on how fast it discharges energy. Efficiency is reduced if the battery discharges quickly.

TABLE 4

PERFORMANCE OF BATTERY EFFICIENCY

\begin{tabular}{|c|c|c|c|}
\hline $\begin{array}{c}\text { Discharge Load } \\
\text { (W) }\end{array}$ & $\begin{array}{c}\text { Output Energy } \\
(\mathbf{K W})\end{array}$ & $\begin{array}{c}\text { Input Energy } \\
(\mathbf{K W})\end{array}$ & $\begin{array}{c}\text { Efficiency } \\
(\mathbf{\%})\end{array}$ \\
\hline 1200 & 6.58 & 9.86 & 66.73 \\
\hline 2400 & 4.16 & 7.2 & 57.77 \\
\hline 3600 & 1.907 & 4.377 & 43.56 \\
\hline
\end{tabular}

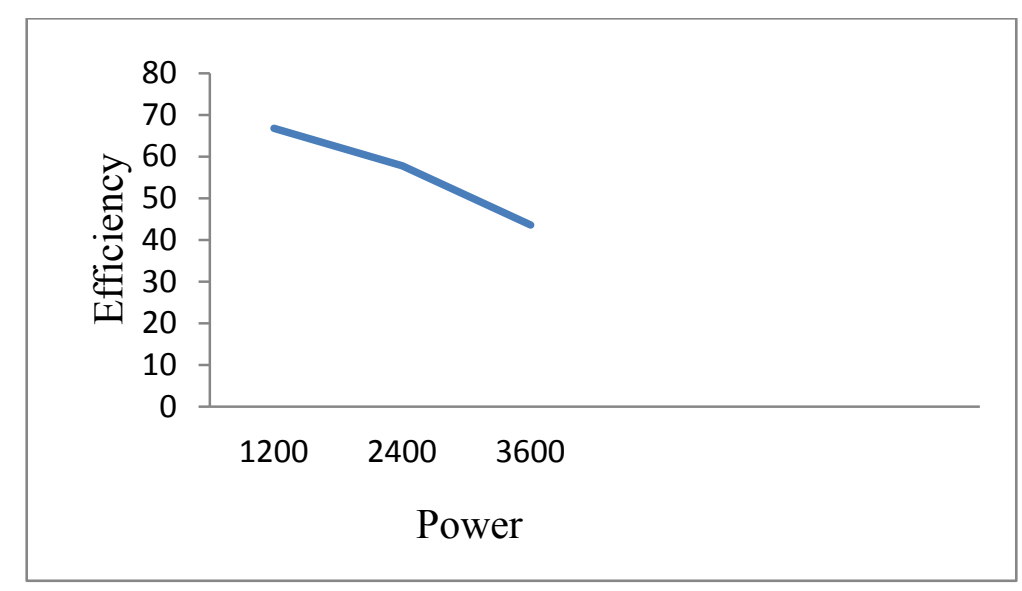

Figure 18. Efficiency of battery.

\subsection{Steady-State Analysis with Programmable DC Supply}

Tables 5 to 17 show data for the steady-state analysis at different DC voltages with different load levels. $\mathrm{V}_{\mathrm{DC}}$ refers to the $\mathrm{DC}$ voltage given to the $\mathrm{DC}$ terminals of the inverter 
from the programmable DC supply and is measured from the programmable DC supply, $\mathrm{I}_{\mathrm{DC}}$ is the DC current supplied to the inverter and measured by an ammeter, $\mathrm{P}_{\mathrm{DC}}$ is the DC power that is the product of DC voltage and $\mathrm{DC}$ current, $\mathrm{V}_{\mathrm{AC}}$ is $\mathrm{AC}$ voltage at the load terminals of the inverter, $\mathrm{I}_{\mathrm{AC}}$ is the $\mathrm{AC}$ current, and $\mathrm{P}_{\mathrm{AC}}$ is the $\mathrm{AC}$ power supplied to the load. All quantities were measured by a Fluke power quality analyzer. "Losses" refers to power losses in the inverter, which is the difference between $\mathrm{AC}$ power and $\mathrm{DC}$ power $\left(\mathrm{P}_{\mathrm{DC}}-\mathrm{P}_{\mathrm{AC}}\right)$, and "efficiency" is efficiency of the inverter, which is the ratio of output power to input power $\left(\mathrm{P}_{\mathrm{AC}} / \mathrm{P}_{\mathrm{DC}}\right)$.

The results shown in Table 5 were obtained by supplying $48 \mathrm{~V}$ of power on the DC side of the inverter, connecting the resistive load to the load terminals, and keeping the $\mathrm{AC}$ grid terminals open. The no-load losses of the inverter were $57.58 \mathrm{~W}$, and the full load losses were 443.99 W. The no-load losses were responsible for hysteresis and eddy current losses in the transformer of the inverter, and full-load losses were responsible for iron and copper losses in the inverter and power losses in the electronic components of the inverter. Maximum efficiency of the inverter was $90.05 \%$, which is at half the rating of the inverter (rating of the inverter is 3,600 VA), and the lowest efficiency was $81.59 \%$, which is when the inverter was loaded with a very small amount. One observation that can be seen in Table 5, as well as in other Tables 6 to 17, is that when the load increased, voltage on the load side increased until it approached the midpoint of inverter capacity, and then it decreased. Figure 19 shows the performance graph of the inverter at $48 \mathrm{~V}$ on the DC side. No-load efficiency was not considered in this graph. 
TABLE 5

PERFORMANCE OF INVERTER WITH RESISTIVE LOAD AT 48 V DC

\begin{tabular}{|c|c|c|c|c|c|c|c|}
\hline $\mathbf{V}_{\mathbf{D C}}$ & $\mathbf{I}_{\mathbf{D C}}$ & $\mathbf{P}_{\mathbf{D C}}$ & $\mathbf{P}_{\mathbf{A C}}$ & $\mathbf{V}_{\mathbf{A C}}$ & $\mathbf{I}_{\mathbf{A C}}$ & Losses & Efficiency \\
\hline 47.99 & 1.2 & 57.58 & 0 & 121.2 & 0 & 57.58 & 0 \\
\hline 47.99 & 8.3 & 398.31 & 325 & 122.2 & 2.5 & 73.31 & 81.59 \\
\hline 47.99 & 15.8 & 758.24 & 650 & 124.1 & 5.25 & 108.24 & 85.75 \\
\hline 47.99 & 23.1 & 1108.56 & 975 & 124.6 & 8 & 133.56 & 87.95 \\
\hline 47.99 & 30.6 & 1468.49 & 1300 & 124.4 & 10.5 & 168.49 & 88.52 \\
\hline 47.99 & 37.6 & 1804.42 & 1625 & 123.5 & 13 & 179.42 & 90.05 \\
\hline 47.99 & 44.8 & 2149.95 & 1925 & 123.3 & 15.75 & 224.95 & 89.53 \\
\hline 47.99 & 51.6 & 2476.28 & 2225 & 122.4 & 18 & 251.28 & 89.85 \\
\hline 47.99 & 60.1 & 2884.19 & 2575 & 123.6 & 21 & 309.19 & 89.27 \\
\hline 47.99 & 67 & 3215.33 & 2875 & 122.7 & 23.25 & 340.33 & 89.41 \\
\hline 47.99 & 73.6 & 3532.06 & 3150 & 121.9 & 25.75 & 382.06 & 89.18 \\
\hline 47.99 & 80.1 & 3843.99 & 3400 & 121.1 & 28 & 443.99 & 88.44 \\
\hline
\end{tabular}



Figure 19. Efficiency of inverter with resistive load at $48 \mathrm{~V}$ DC.

Table 6 shows performance of the inverter when the input voltage was $52 \mathrm{~V}$ on the DC side. Under this condition, the maximum efficiency was $90.16 \%$ and occurred as the inverter was loaded close to $50 \%$ of its rating. Mostly electrical equipment is designed to obtain maximum efficiency around half of its rating. The lowest efficiency of the inverter occurred at a very low 
load, or $82.25 \%$. Figure 20 shows the performance graph of the inverter at $52 \mathrm{~V}$ on the DC side. No-load efficiency was not considered in this graph.

TABLE 6

PERFORMANCE OF INVERTER WITH RESISTIVE LOAD AT 52 V DC

\begin{tabular}{|c|c|c|c|c|c|c|c|}
\hline $\mathbf{V}_{\mathbf{D C}}$ & $\mathbf{I}_{\mathbf{D C}}$ & $\mathbf{P}_{\mathbf{D C}}$ & $\mathbf{P}_{\mathbf{A C}}$ & $\mathbf{V}_{\mathbf{A C}}$ & $\mathbf{I}_{\mathbf{A C}}$ & Losses & Efficiency \\
\hline 51.99 & 0.9 & 46.791 & 0 & 121.9 & 0 & 46.791 & 0 \\
\hline 51.99 & 7.6 & 395.124 & 325 & 123.1 & 2.5 & 70.124 & 82.25 \\
\hline 51.99 & 14.4 & 748.656 & 650 & 124.3 & 5.25 & 98.656 & 86.82 \\
\hline 51.99 & 21.4 & 1112.59 & 1000 & 125 & 8 & 112.586 & 89.88 \\
\hline 51.99 & 28.4 & 1476.52 & 1325 & 124.7 & 10.5 & 151.516 & 89.73 \\
\hline 51.99 & 35.2 & 1830.05 & 1650 & 124.6 & 13.25 & 180.048 & 90.16 \\
\hline 51.99 & 42 & 2183.58 & 1950 & 124.4 & 15.75 & 233.58 & 89.3 \\
\hline 51.99 & 48.9 & 2542.31 & 2275 & 124.2 & 18.5 & 267.311 & 89.48 \\
\hline 51.99 & 55.3 & 2875.05 & 2575 & 123.3 & 20.75 & 300.047 & 89.56 \\
\hline 51.99 & 62.8 & 3264.97 & 2925 & 123.9 & 23.5 & 339.972 & 89.58 \\
\hline 51.99 & 69.2 & 3597.71 & 3200 & 123 & 26 & 397.708 & 89.94 \\
\hline 51.99 & 75.4 & 3920.05 & 3450 & 121.5 & 28.25 & 470.046 & 88 \\
\hline
\end{tabular}

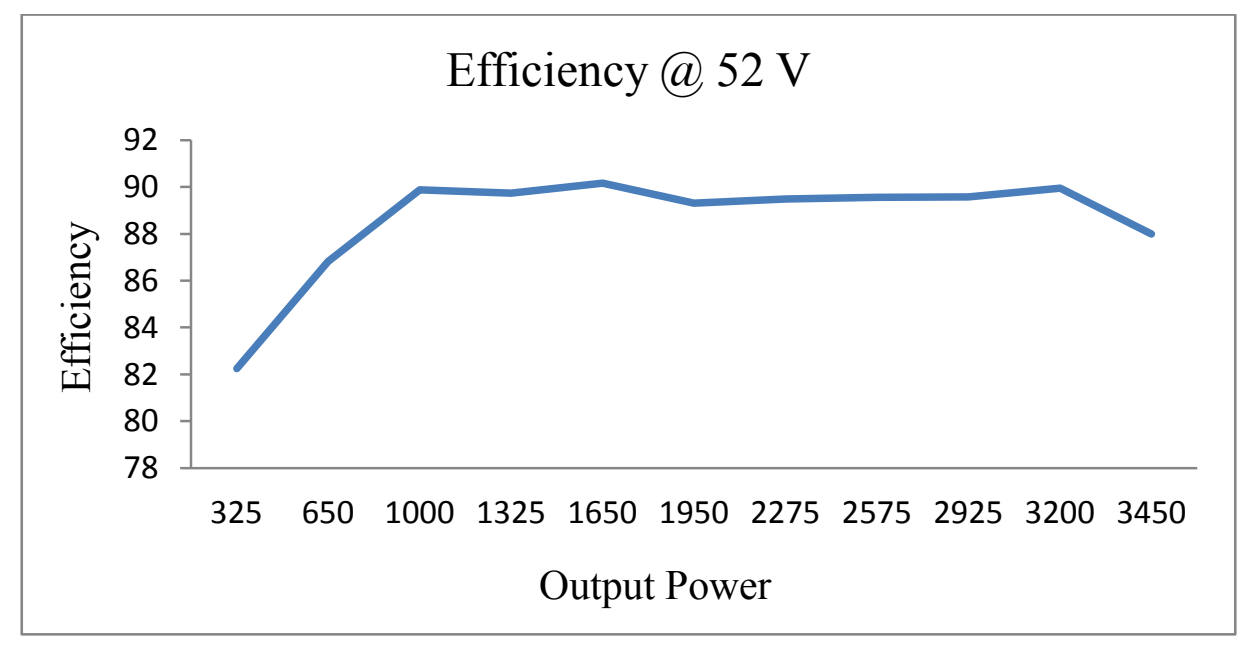

Figure 20. Efficiency of inverter with resistive load at $52 \mathrm{~V}$ DC.

Table 7 shows performance of the inverter charger when it was discharging energy from a DC source through a resistive load at $56 \mathrm{~V}$. Maximum efficiency of the inverter was $89.45 \%$, 
which appears to be close to a full load, and low efficiency was $84.34 \%$, which is a very low load. Figure 21 shows the performance graph of the inverter when DC voltage was $56 \mathrm{~V}$.

TABLE 7

PERFORMANCE OF INVERTER WITH RESISTIVE LOAD AT 56 V DC

\begin{tabular}{|c|c|c|c|c|c|c|c|}
\hline $\mathbf{V}_{\mathbf{D C}}$ & $\mathbf{I}_{\mathbf{D C}}$ & $\mathbf{P}_{\mathbf{D C}}$ & $\mathbf{P}_{\mathbf{A C}}$ & $\mathbf{V}_{\mathbf{A C}}$ & $\mathbf{I}_{\mathbf{A C}}$ & Losses & Efficiency \\
\hline 55.99 & 0.7 & 39.193 & 0 & 122 & 0 & 39.193 & 0 \\
\hline 55.99 & 7.3 & 408.727 & 325 & 124.8 & 2.75 & 83.727 & 84.34 \\
\hline 55.99 & 11.5 & 643.885 & 550 & 125 & 4.5 & 93.885 & 84.41 \\
\hline 55.99 & 18 & 1007.82 & 900 & 125.2 & 7 & 107.82 & 89.3 \\
\hline 55.99 & 26.6 & 1489.33 & 1325 & 125.2 & 10.5 & 164.334 & 88.96 \\
\hline 55.99 & 33 & 1847.67 & 1650 & 125.1 & 13.25 & 197.67 & 89.3 \\
\hline 55.99 & 39.5 & 2211.61 & 1975 & 125 & 15.75 & 236.605 & 89.3 \\
\hline 55.99 & 46.1 & 2581.14 & 2300 & 124.8 & 18.5 & 281.139 & 89.1 \\
\hline 55.99 & 52.6 & 2945.07 & 2625 & 124.7 & 21 & 320.074 & 89.13 \\
\hline 55.99 & 58.4 & 3269.82 & 2925 & 123.8 & 23.5 & 344.816 & 89.45 \\
\hline 55.99 & 64.3 & 3600.16 & 3200 & 122.9 & 26 & 400.157 & 88.88 \\
\hline 55.99 & 70.1 & 3924.9 & 3475 & 122.1 & 28.5 & 449.899 & 88.53 \\
\hline
\end{tabular}

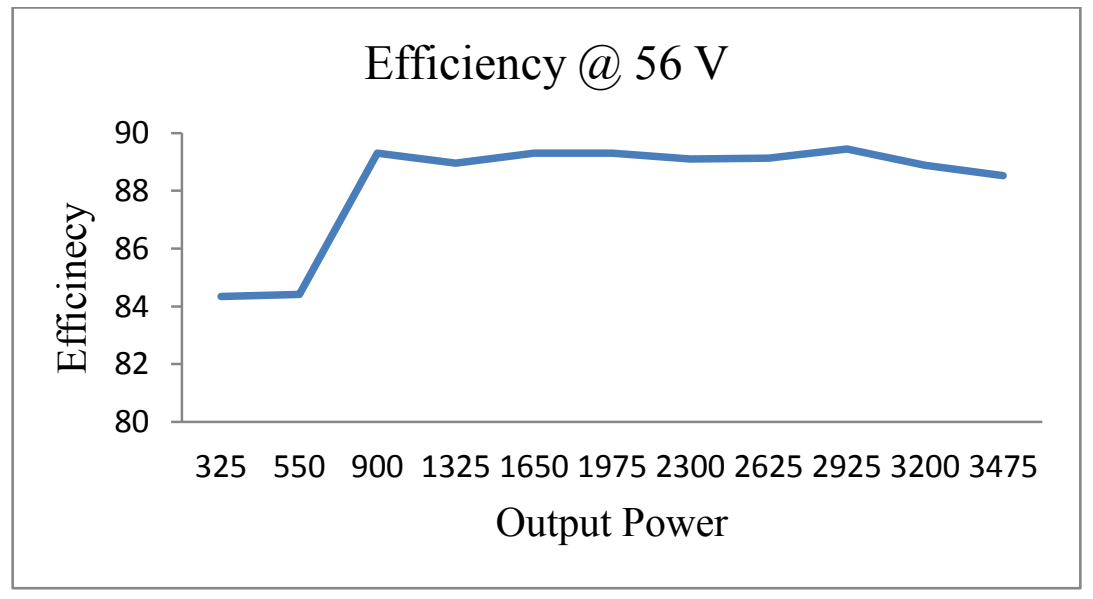

Figure 21. Efficiency of inverter with resistive load at $56 \mathrm{~V}$ DC.

Table 8 shows performance of the inverter when the DC supply voltage is $60 \mathrm{~V}$. Maximum efficiency of the inverter was $89.35 \%$ at $2650 \mathrm{~W}$ of load, and low efficiency of the 
inverter was $78.21 \%$ at $325 \mathrm{~W}$ of load. Figure 22 shows the performance graph of the inverter at $60 \mathrm{~V}$ DC.

TABLE 8

PERFORMANCE OF INVERTER WITH RESISTIVE LOAD AT $60 \mathrm{~V}$ DC

\begin{tabular}{|c|c|c|c|c|c|c|c|}
\hline $\mathbf{V}_{\mathbf{D C}}$ & $\mathbf{I}_{\mathbf{D C}}$ & $\mathbf{P}_{\mathbf{D C}}$ & $\mathbf{P}_{\mathbf{A C}}$ & $\mathbf{V}_{\mathbf{A C}}$ & $\mathbf{I}_{\mathbf{A C}}$ & Losses & Efficiency \\
\hline 59.99 & 0.7 & 41.993 & 0 & 121.8 & 0 & 41.993 & 0 \\
\hline 59.99 & 6.9 & 413.931 & 325 & 123.7 & 2.5 & 88.931 & 78.51 \\
\hline 59.99 & 13.1 & 785.869 & 675 & 125.5 & 5.25 & 110.869 & 85.89 \\
\hline 59.99 & 19 & 1139.81 & 1000 & 125.4 & 8 & 139.81 & 87.73 \\
\hline 59.99 & 25 & 1499.75 & 1325 & 125.3 & 10.5 & 174.75 & 88.34 \\
\hline 59.99 & 31 & 1859.69 & 1650 & 125.2 & 13.25 & 209.69 & 88.72 \\
\hline 59.99 & 37 & 2219.63 & 1975 & 125.1 & 15.75 & 244.63 & 88.97 \\
\hline 59.99 & 43.2 & 2591.57 & 2300 & 125 & 18.5 & 291.568 & 88.74 \\
\hline 59.99 & 49.3 & 2957.51 & 2650 & 124.9 & 21.25 & 307.507 & 89.6 \\
\hline 59.99 & 55.5 & 3329.45 & 2975 & 124.8 & 23.75 & 354.445 & 89.35 \\
\hline 59.99 & 61.1 & 3665.39 & 3250 & 123.9 & 26.25 & 415.389 & 88.66 \\
\hline 59.99 & 66.6 & 3995.33 & 3525 & 123.1 & 28.5 & 470.334 & 88.22 \\
\hline
\end{tabular}

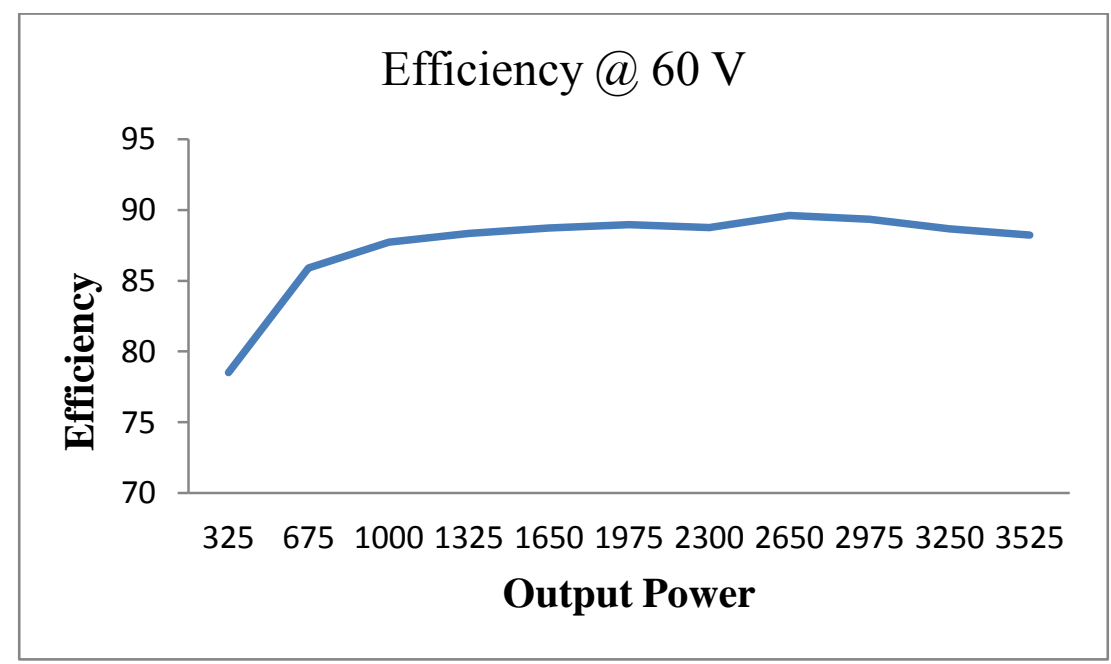

Figure 22. Efficiency of inverter with resistive load at $60 \mathrm{~V}$ DC.

Table 9 shows performance of the inverter when the DC voltage is at $64 \mathrm{~V}$ on one side and connected to a resistive load. Maximum efficiency of the inverter was $89.25 \%$ at $2975 \mathrm{~W}$ of 
load, and minimum efficiency of the inverter was around $79.35 \%$ at $325 \mathrm{~W}$ of load. Figure 23 shows the performance graph of the inverter at $64 \mathrm{~V}$.

TABLE 9

PERFORMANCE OF INVERTER WITH RESISTIVE LOAD AT 64 V DC

\begin{tabular}{|c|c|c|c|c|c|c|c|}
\hline $\mathbf{V}_{\mathbf{D C}}$ & $\mathbf{I}_{\mathbf{D C}}$ & $\mathbf{P}_{\mathbf{D C}}$ & $\mathbf{P}_{\mathbf{A C}}$ & $\mathbf{V}_{\mathbf{A C}}$ & $\mathbf{I}_{\mathbf{A C}}$ & Losses & Efficiency \\
\hline 63.99 & 0.7 & 44.793 & 0 & 121.8 & 0 & 44.793 & 0 \\
\hline 63.99 & 6.4 & 409.536 & 325 & 123.7 & 2.5 & 84.536 & 79.35 \\
\hline 63.99 & 12.5 & 799.875 & 675 & 124.5 & 5.25 & 124.875 & 84.38 \\
\hline 63.99 & 18 & 1151.82 & 1000 & 125.4 & 8 & 151.82 & 86.81 \\
\hline 63.99 & 23.3 & 1490.97 & 1325 & 125.3 & 10.5 & 165.967 & 88.86 \\
\hline 63.99 & 29 & 1855.71 & 1650 & 125.2 & 13.25 & 205.71 & 88.91 \\
\hline 63.99 & 34.7 & 2220.45 & 1975 & 125.1 & 15.75 & 245.453 & 88.94 \\
\hline 63.99 & 40.6 & 2597.99 & 2300 & 125 & 18.5 & 297.994 & 88.52 \\
\hline 63.99 & 46.4 & 2969.14 & 2650 & 125 & 21.25 & 319.136 & 89.25 \\
\hline 63.99 & 52.4 & 3353.08 & 2975 & 125 & 23.75 & 378.076 & 88.72 \\
\hline 63.99 & 58.4 & 3737.02 & 3250 & 125 & 26.25 & 487.016 & 86.96 \\
\hline 63.99 & 63.6 & 4069.76 & 3525 & 124.1 & 28.5 & 544.764 & 86.61 \\
\hline
\end{tabular}

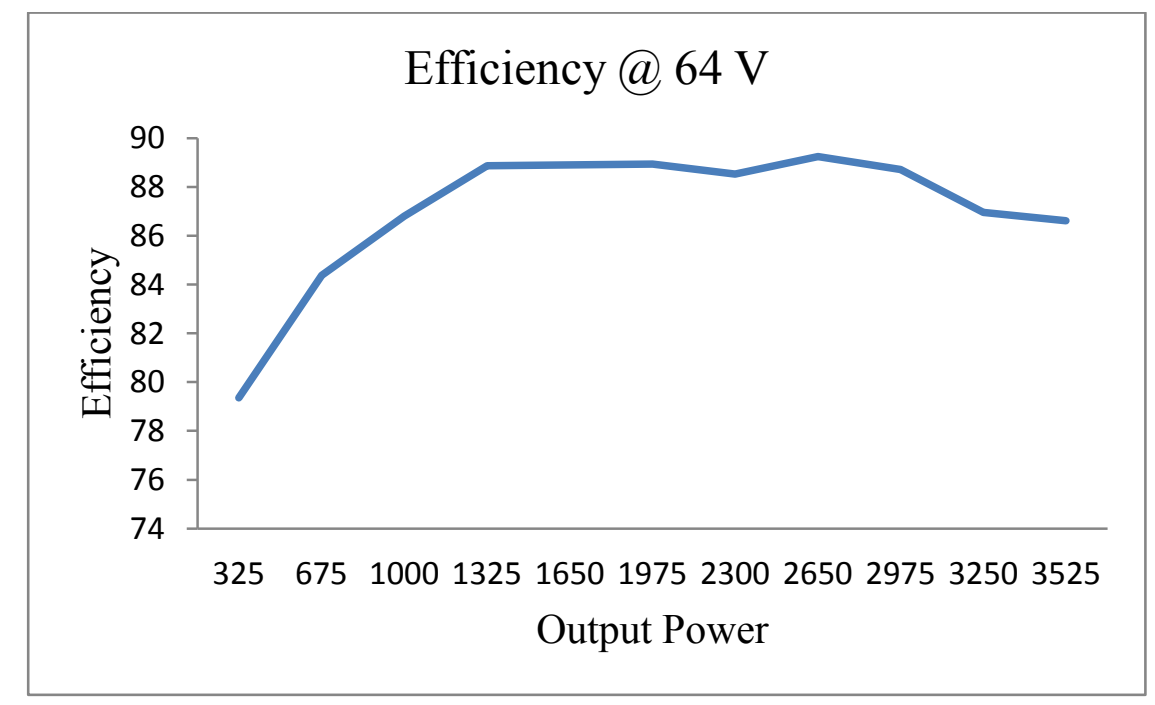

Figure 23. Efficiency of inverter with resistive load at $64 \mathrm{~V}$ DC.

Table 10 shows performance of the inverter when connected to a supply voltage of $68 \mathrm{~V}$ on the DC side. Maximum efficiency of the inverter was $89.05 \%$ at $2325 \mathrm{~W}$ of load, and 
minimum efficiency of the inverter was $78.36 \%$ at $325 \mathrm{~W}$ of load. Figure 24 shows the performance graph of the inverter at $68 \mathrm{~V}$.

TABLE 10

PERFORMANCE OF INVERTER WITH RESISTIVE LOAD AT 68 V DC

\begin{tabular}{|c|c|c|c|c|c|c|c|}
\hline $\mathbf{V}_{\mathbf{D C}}$ & $\mathbf{I}_{\mathbf{D C}}$ & $\mathbf{P}_{\mathbf{D C}}$ & $\mathbf{P}_{\mathbf{A C}}$ & $\mathbf{V}_{\mathbf{A C}}$ & $\mathbf{I}_{\mathbf{A C}}$ & Losses & Efficiency \\
\hline 67.99 & 0.7 & 47.593 & 0 & 121.7 & 0 & 47.593 & 0 \\
\hline 67.99 & 6.1 & 414.739 & 325 & 123.9 & 2.5 & 89.739 & 78.36 \\
\hline 67.99 & 11.6 & 788.684 & 650 & 125 & 5.25 & 138.684 & 82.41 \\
\hline 67.99 & 17.2 & 1169.43 & 1000 & 126.2 & 8 & 169.428 & 85.51 \\
\hline 67.99 & 22.4 & 1522.98 & 1350 & 126 & 10.75 & 172.976 & 88.64 \\
\hline 67.99 & 27.4 & 1692.93 & 1500 & 125 & 13.25 & 362.926 & 88.51 \\
\hline 67.99 & 32.8 & 2230.07 & 1975 & 125 & 15.75 & 255.072 & 88.56 \\
\hline 67.99 & 38.4 & 2610.82 & 2325 & 125 & 18.5 & 285.816 & 89.05 \\
\hline 67.99 & 43.9 & 2984.76 & 2650 & 125.1 & 21.25 & 334.761 & 88.78 \\
\hline 67.99 & 49.5 & 3365.51 & 2975 & 125.1 & 23.75 & 390.505 & 88.39 \\
\hline 67.99 & 55.2 & 3753.05 & 3300 & 125.1 & 26.4 & 453.048 & 87.92 \\
\hline 67.99 & 60.2 & 4093 & 3600 & 124.3 & 29 & 492.998 & 87.95 \\
\hline
\end{tabular}

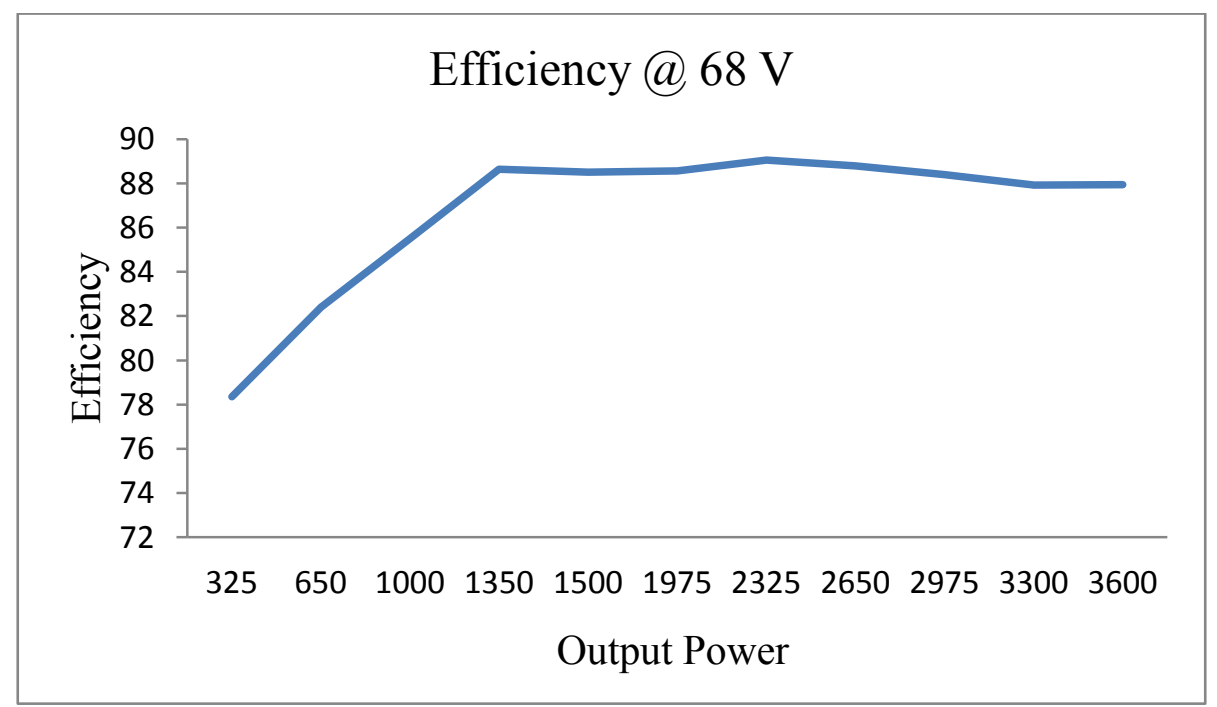

Figure 24. Efficiency of inverter with resistive load at $68 \mathrm{~V} \mathrm{DC}$.

Figure 25 shows performance of the inverter with resistive loads at different voltage inputs. From this graph, it can be concluded that the efficiency of the inverter was independent of the input voltage. 


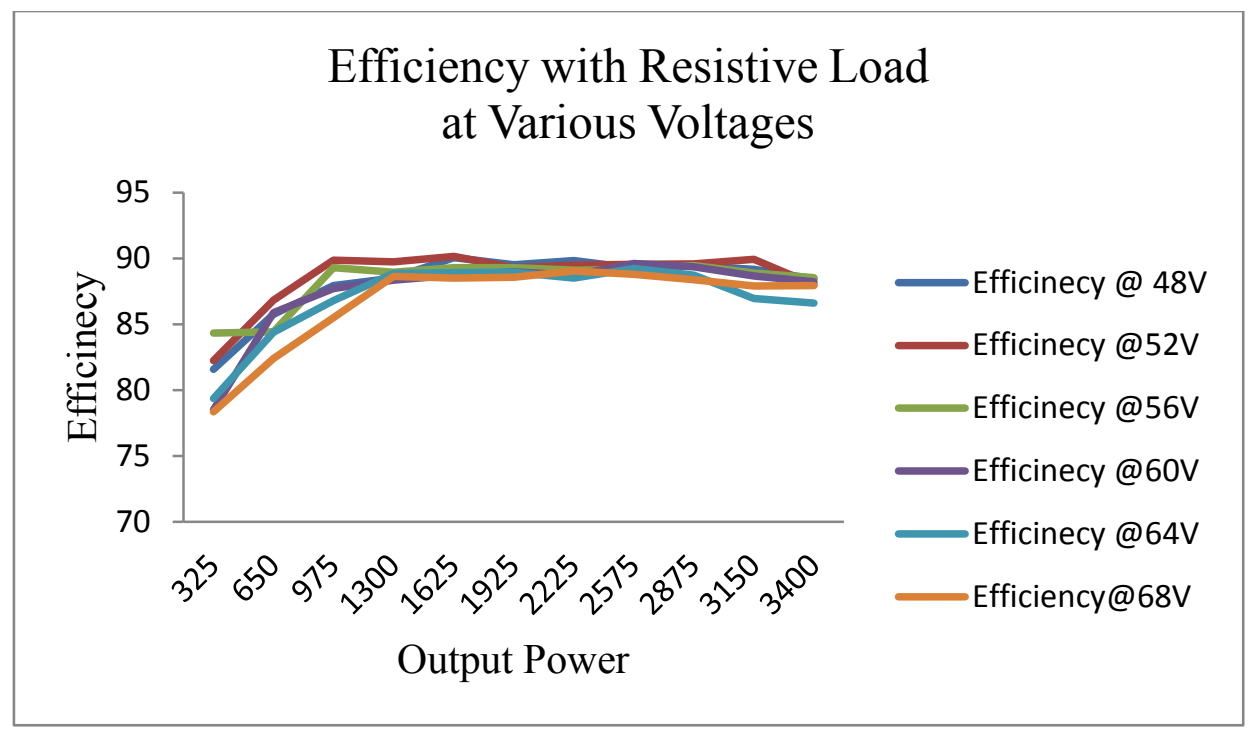

Figure 25. Efficiency of inverter with resistive load at various voltage inputs.

Tables 11 to Table 17 show the steady-state analysis of the inverter with inductive loads. Here, $\mathrm{V}_{\mathrm{DC}}$ is the voltage on the $\mathrm{DC}$ side of the inverter and is measured from the programmable power supply as well as the MATE, $\mathrm{I}_{\mathrm{DC}}$ is the DC current supplied to the inverter measured by an ammeter, $\mathrm{P}_{\mathrm{DC}}$ is the power supply on the $\mathrm{DC}$ side and measured from the programmable DC supply, $\mathrm{P}_{\mathrm{AC}}$ is the power supplied to the load, $\mathrm{V}_{\mathrm{AC}}$ is the voltage at the load terminals, $\mathrm{I}_{\mathrm{AC}}$ is the load current, P.F. is the power factor of the load, and $\mathrm{Q}_{\mathrm{AC}}$ is the reactive power supplied to the load. Electric fans and blowers were used as the inductive load. During this steady-state analysis, the inverter was not connected to the grid; therefore, all reactive power consumed by the load was supplied by the inverter, so the inverter was able to generate reactive power if necessary. Efficiency of the inverter was higher with resistive load than with inductive load, since the inverter was generating reactive power for the inductive loads.

Table 11 shows performance of the inverter with inductive load when the DC supply voltage was $44 \mathrm{~V}$. Here, the inverter indicated an error signal because the voltage was very low on the DC side (it needed $48 \mathrm{~V}$ ). If batteries were connected on the DC side, then once the 
energy started discharging from the battery, its voltage would decrease, and after a certain load on the inverter, it would stop discharging energy. But this study used a programmable DC supply, which maintained constant output voltage so that the inverter would not interrupt the power flow. The maximum efficiency of the inverter was $88.11 \%$ at $1500 \mathrm{~W}$ of load. Figure 26 shows the performance graph of the inverter at $44 \mathrm{~V}$ DC.

TABLE 11

PERFORMANCE OF INVERTER WITH INDUCTIVE LOAD AT 44 V DC

\begin{tabular}{|c|c|c|c|c|c|c|c|c|c|}
\hline $\mathbf{V}_{\mathbf{D C}}$ & \multicolumn{1}{|c|}{$\mathbf{I}_{\mathbf{D C}}$} & $\mathbf{P}_{\mathbf{D C}}$ & $\mathbf{P}_{\mathbf{A C}}$ & $\mathbf{V}_{\mathbf{A C}}$ & $\mathbf{I}_{\mathbf{A C}}$ & $\mathbf{P . F}$ & $\mathbf{Q}_{\mathbf{A C}}$ & Losses & Efficiency \\
\hline 43.99 & 5.8 & 255.142 & 175 & 120.5 & 2.25 & 0.71 & 175 & 80.142 & 68.58 \\
\hline 43.99 & 10.9 & 479.491 & 375 & 121.4 & 4.5 & 0.71 & 375 & 104.491 & 78.20 \\
\hline 43.99 & 15 & 659.85 & 575 & 121.1 & 6.5 & 0.71 & 575 & 84.85 & 87.14 \\
\hline 43.99 & 23.3 & 1024.967 & 900 & 122.9 & 9.5 & 0.77 & 750 & 124.967 & 87.80 \\
\hline 43.99 & 29.5 & 1297.705 & 1125 & 122.2 & 14.25 & 0.64 & 1350 & 172.705 & 86.69 \\
\hline 43.99 & 38.7 & 1702.413 & 1500 & 120.9 & 15.75 & 0.78 & 1200 & 202.413 & 88.11 \\
\hline 43.99 & 52.4 & 2305.076 & 1950 & 121.3 & 19.25 & 0.84 & 1275 & 355.076 & 84.59 \\
\hline
\end{tabular}

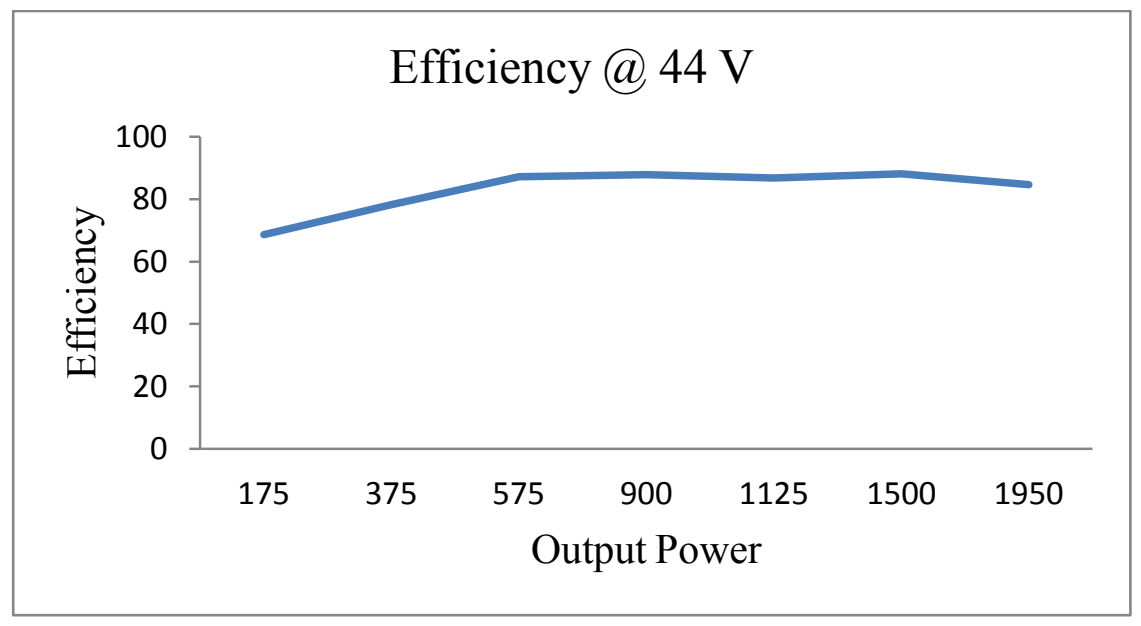

Figure 26. Efficiency of inverter with inductive load at $44 \mathrm{~V}$ DC.

Table 12 shows performance of the inverter with an inductive load when the DC supply voltage was $48 \mathrm{~V}$. Maximum efficiency of the inverter was $87.63 \%$ at $900 \mathrm{~W}$ of load, and minimum efficiency of the inverter was $77.17 \%$ at $200 \mathrm{~W}$ of load. The efficiency of the inverter 
was close to maximum once the load reached $1 / 6^{\text {th }}$ of its rating and then was maintained at the same level until a full load. Figure 27 shows the performance graph of the inverter at 48 V DC.

TABLE 12

PERFORMANCE OF INVERTER WITH INDUCTIVE LOAD AT 48 V DC

\begin{tabular}{|c|c|c|c|c|c|c|c|c|c|}
\hline $\mathbf{V}_{\mathbf{D C}}$ & $\mathbf{I}_{\mathbf{D C}}$ & $\mathbf{P}_{\mathbf{D C}}$ & $\mathbf{P}_{\mathbf{A C}}$ & $\mathbf{V}_{\mathbf{A C}}$ & $\mathbf{I}_{\mathbf{A C}}$ & $\mathbf{P . F}$ & $\mathbf{Q}_{\mathbf{A C}}$ & Losses & Efficiency \\
\hline 47.99 & 5.4 & 259.146 & 200 & 122.3 & 2.25 & 0.71 & 200 & 59.146 & 77.17 \\
\hline 47.99 & 9.8 & 470.302 & 375 & 121.8 & 4.5 & 0.71 & 400 & 95.302 & 79.73 \\
\hline 47.99 & 14 & 671.86 & 575 & 121.6 & 6.75 & 0.71 & 575 & 96.86 & 85.58 \\
\hline 47.99 & 21.4 & 1026.986 & 900 & 123 & 9.5 & 0.77 & 750 & 126.986 & 87.63 \\
\hline 47.99 & 27.2 & 1305.328 & 1125 & 122.6 & 14.5 & 0.64 & 1375 & 180.328 & 86.18 \\
\hline 47.99 & 36.3 & 1742.037 & 1525 & 121.7 & 16.25 & 0.78 & 1225 & 217.037 & 87.54 \\
\hline 47.99 & 48.5 & 2327.515 & 1975 & 122.4 & 19.25 & 0.84 & 1300 & 352.515 & 84.85 \\
\hline
\end{tabular}

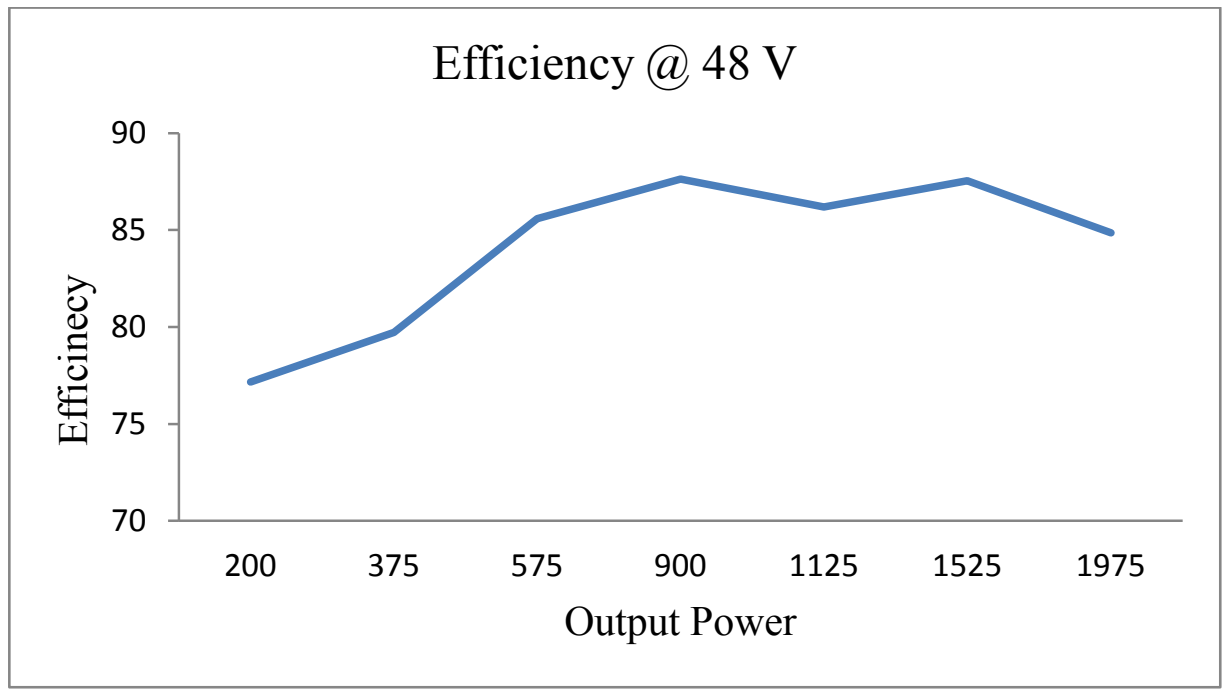

Figure 27. Efficiency of inverter with inductive load at 48 V DC.

Table 13 shows performance of the inverter discharging energy through an inductive load when the DC supply voltage was $52 \mathrm{~V}$. Maximum efficiency of the inverter was $89.33 \%$ at 2025 W of load. This is the maximum load possible in the WSU Power Quality Laboratory. The real maximum efficiency might have occurred at a different point if it was possible to continue to 
apply load. Minimum efficiency of the inverter was $75.42 \%$ at $200 \mathrm{~W}$ of load. Figure 28 shows the performance graph of the inverter at $52 \mathrm{~V} \mathrm{DC}$.

TABLE 13

PERFORMANCE OF INVERTER WITH INDUCTIVE LOAD AT 52 V DC

\begin{tabular}{|c|c|c|c|c|c|c|c|c|c|}
\hline $\mathbf{V}_{\mathbf{D C}}$ & $\mathbf{I}_{\mathbf{D C}}$ & $\mathbf{P}_{\mathbf{D C}}$ & $\mathbf{P}_{\mathbf{A C}}$ & $\mathbf{V}_{\mathbf{A C}}$ & $\mathbf{I}_{\mathbf{A C}}$ & $\mathbf{P . F}$ & $\mathbf{Q}_{\mathbf{A C}}$ & Losses & Efficiency \\
\hline 51.99 & 5.1 & 265.149 & 200 & 123.4 & 2.25 & 0.71 & 200 & 65.149 & 75.42 \\
\hline 51.99 & 9.1 & 473.109 & 375 & 122 & 4.5 & 0.71 & 375 & 98.109 & 79.26 \\
\hline 51.99 & 13.1 & 681.069 & 575 & 122 & 6.75 & 0.71 & 575 & 106.069 & 84.42 \\
\hline 51.99 & 20 & 1039.8 & 925 & 123.5 & 9.5 & 0.77 & 750 & 114.8 & 88.95 \\
\hline 51.99 & 25.4 & 1320.546 & 1125 & 123.5 & 14.5 & 0.64 & 1350 & 195.546 & 85.19 \\
\hline 51.99 & 33.3 & 1731.267 & 1525 & 122.4 & 16 & 0.79 & 1200 & 206.267 & 88.08 \\
\hline 51.99 & 43.6 & 2266.764 & 2025 & 123.2 & 19.5 & 0.84 & 1325 & 241.764 & 89.33 \\
\hline
\end{tabular}

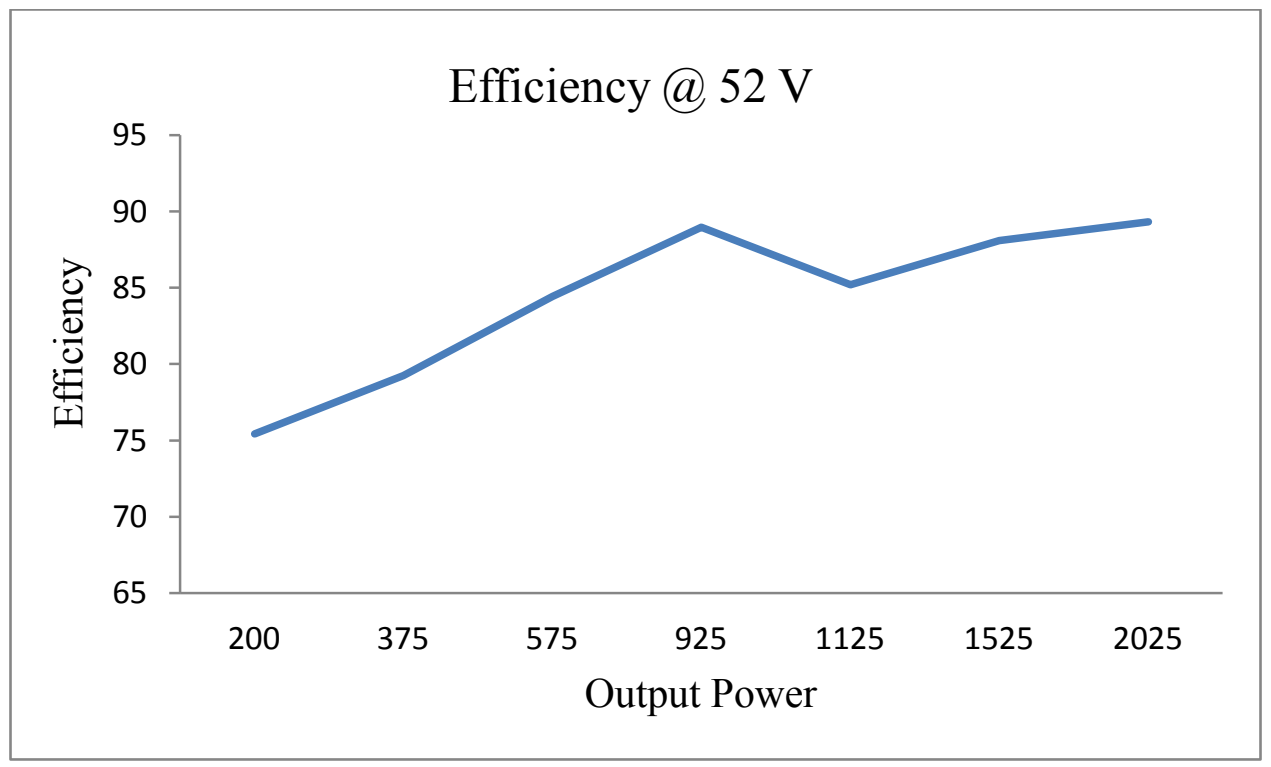

Figure 28. Efficiency of inverter with inductive load at $52 \mathrm{~V}$ DC.

Table 14 shows performance of the inverter when the DC supply voltage was $56 \mathrm{~V}$ and the inductive load was connected to the load terminals of the inverter. The maximum efficiency of the inverter was $88.86 \%$ at $2025 \mathrm{~W}$ of load, and the minimum efficiency of the inverter was $74.41 \%$ at $200 \mathrm{~W}$ of load. Figure 29 shows the performance graph of the inverter at $56 \mathrm{~V}$ DC. 
TABLE 14

PERFORMANCE OF INVERTER WITH INDUCTIVE LOAD AT 56 V DC

\begin{tabular}{|c|c|c|c|l|l|l|l|l|c|}
\hline $\mathbf{V}_{\mathbf{D C}}$ & $\mathbf{I}_{\mathbf{D C}}$ & $\mathbf{P}_{\mathbf{D C}}$ & $\mathbf{P}_{\mathbf{A C}}$ & $\mathbf{V}_{\mathbf{A C}}$ & $\mathbf{I}_{\mathbf{A C}}$ & $\mathbf{P . F}$ & $\mathbf{Q}_{\mathbf{A C}}$ & Losses & Efficiency \\
\hline 55.99 & 4.8 & 268.752 & 200 & 123 & 2.25 & 0.71 & 200 & 68.752 & 74.41 \\
\hline 55.99 & 8.5 & 475.915 & 375 & 122.3 & 4.5 & 0.71 & 375 & 100.915 & 78.79 \\
\hline 55.99 & 12.3 & 688.677 & 575 & 123 & 6.75 & 0.71 & 575 & 113.677 & 83.49 \\
\hline 55.99 & 18.8 & 1052.612 & 925 & 123.8 & 9.75 & 0.77 & 750 & 127.612 & 87.87 \\
\hline 55.99 & 24.1 & 1349.359 & 1125 & 124 & 14.75 & 0.64 & 1350 & 224.359 & 83.37 \\
\hline 55.99 & 31 & 1735.69 & 1525 & 122.3 & 16 & 0.79 & 1200 & 210.69 & 87.86 \\
\hline 55.99 & 40.7 & 2278.793 & 2025 & 123.7 & 20 & 0.84 & 1325 & 253.793 & 88.86 \\
\hline
\end{tabular}

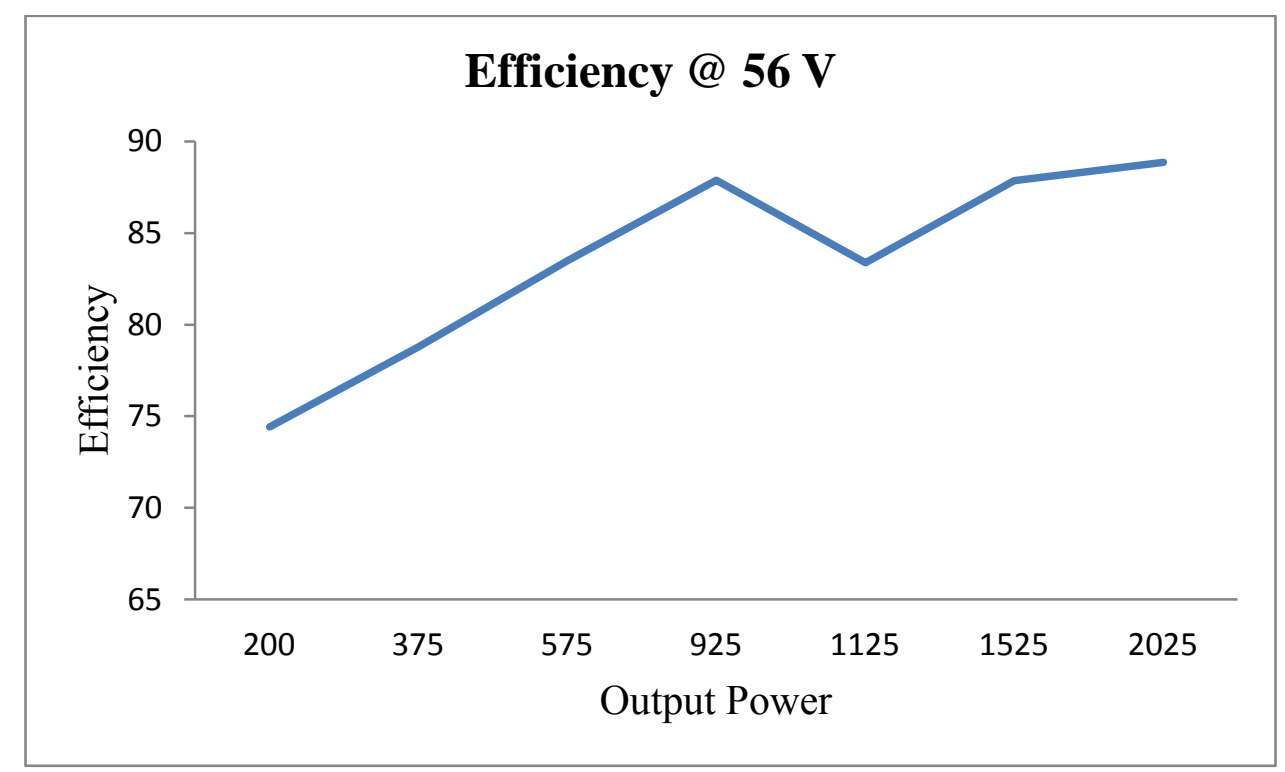

Figure 29. Efficiency of inverter with inductive load at $56 \mathrm{~V}$ DC.

Table 15 shows performance of the inverter discharging energy through an inductive load when the DC supply voltage is $60 \mathrm{~V}$. The maximum efficiency of the inverter was $88.36 \%$ at $2025 \mathrm{~W}$ of load, and minimum efficiency of the inverter was $74.08 \%$ at $200 \mathrm{~W}$ of load. Figure 30 shows the performance graph of the inverter at $60 \mathrm{~V} \mathrm{DC}$. 
TABLE 15

PERFORMANCE OF INVERTER WITH INDUCTIVE LOAD AT $60 \mathrm{~V}$ DC

\begin{tabular}{|c|c|c|c|c|c|c|c|c|c|}
\hline $\mathbf{V}_{\mathbf{D C}}$ & $\mathbf{I}_{\mathbf{D C}}$ & $\mathbf{P}_{\mathbf{D C}}$ & $\mathbf{P}_{\mathbf{A C}}$ & $\mathbf{V}_{\mathbf{A C}}$ & $\mathbf{I}_{\mathbf{A C}}$ & $\mathbf{P . F}$ & $\mathbf{Q}_{\mathbf{A C}}$ & Losses & Efficiency \\
\hline 59.99 & 4.5 & 269.955 & 200 & 123.8 & 2.25 & 0.71 & 200 & 69.955 & 74.08 \\
\hline 59.99 & 8 & 479.92 & 375 & 123.1 & 4.5 & 0.71 & 375 & 104.92 & 78.13 \\
\hline 59.99 & 11.6 & 695.884 & 575 & 123 & 6.75 & 0.71 & 575 & 120.884 & 82.62 \\
\hline 59.99 & 17.6 & 1055.824 & 925 & 124.1 & 9.5 & 0.77 & 750 & 130.824 & 87.60 \\
\hline 59.99 & 22.5 & 1349.775 & 1125 & 124 & 14.5 & 0.64 & 1350 & 224.775 & 83.34 \\
\hline 59.99 & 28.9 & 1733.711 & 1525 & 122.5 & 16 & 0.79 & 1200 & 208.711 & 87.96 \\
\hline 59.99 & 38.2 & 2291.618 & 2025 & 124.2 & 19.5 & 0.84 & 1325 & 266.618 & 88.36 \\
\hline
\end{tabular}

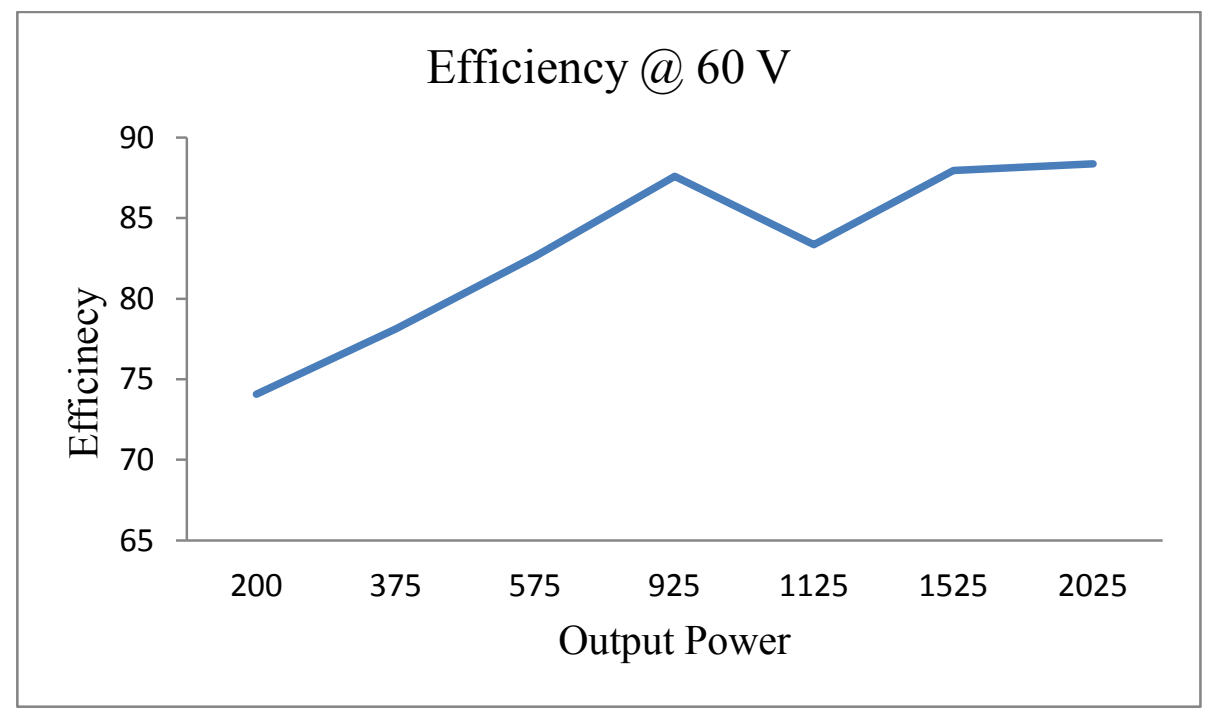

Figure 30. Efficiency of inverter with inductive load at $60 \mathrm{~V}$ DC.

Table 16 shows performance of the inverter discharging energy through an inductive load when the DC supply voltage was $64 \mathrm{~V}$. Maximum efficiency of the inverter was $87.41 \%$ at 2025 W of load, and minimum efficiency of the inverter was $67.94 \%$ at $200 \mathrm{~W}$ of load. Figure 31 shows the performance graph of the inverter at $64 \mathrm{~V}$ DC. 
TABLE 16

PERFORMANCE OF INVERTER WITH INDUCTIVE LOAD AT 64 V DC

\begin{tabular}{|c|c|c|c|c|c|c|c|c|c|}
\hline $\mathbf{V}_{\mathbf{D C}}$ & $\mathbf{I}_{\mathbf{D C}}$ & $\mathbf{P}_{\mathbf{D C}}$ & $\mathbf{P}_{\mathbf{A C}}$ & $\mathbf{V}_{\mathbf{A C}}$ & $\mathbf{I}_{\mathbf{A C}}$ & $\mathbf{P . F}$ & $\mathbf{Q}_{\mathbf{A C}}$ & Losses & Efficiency \\
\hline 63.99 & 4.6 & 294.354 & 200 & 123.6 & 2.25 & 0.71 & 200 & 94.354 & 67.94 \\
\hline 63.99 & 8 & 511.92 & 400 & 122.9 & 4.5 & 0.71 & 400 & 111.92 & 78.13 \\
\hline 63.99 & 11.3 & 723.087 & 575 & 122.9 & 9.25 & 0.71 & 575 & 148.087 & 79.52 \\
\hline 63.99 & 16.9 & 1081.431 & 925 & 124.1 & 12.25 & 0.76 & 775 & 156.431 & 85.53 \\
\hline 63.99 & 21.6 & 1382.184 & 1150 & 124.2 & 15 & 0.63 & 1450 & 232.184 & 83.20 \\
\hline 63.99 & 28.8 & 1842.912 & 1575 & 123.2 & 16.5 & 0.78 & 1275 & 267.912 & 85.46 \\
\hline 63.99 & 36.2 & 2316.438 & 2025 & 124.5 & 19.5 & 0.83 & 1350 & 291.438 & 87.41 \\
\hline
\end{tabular}

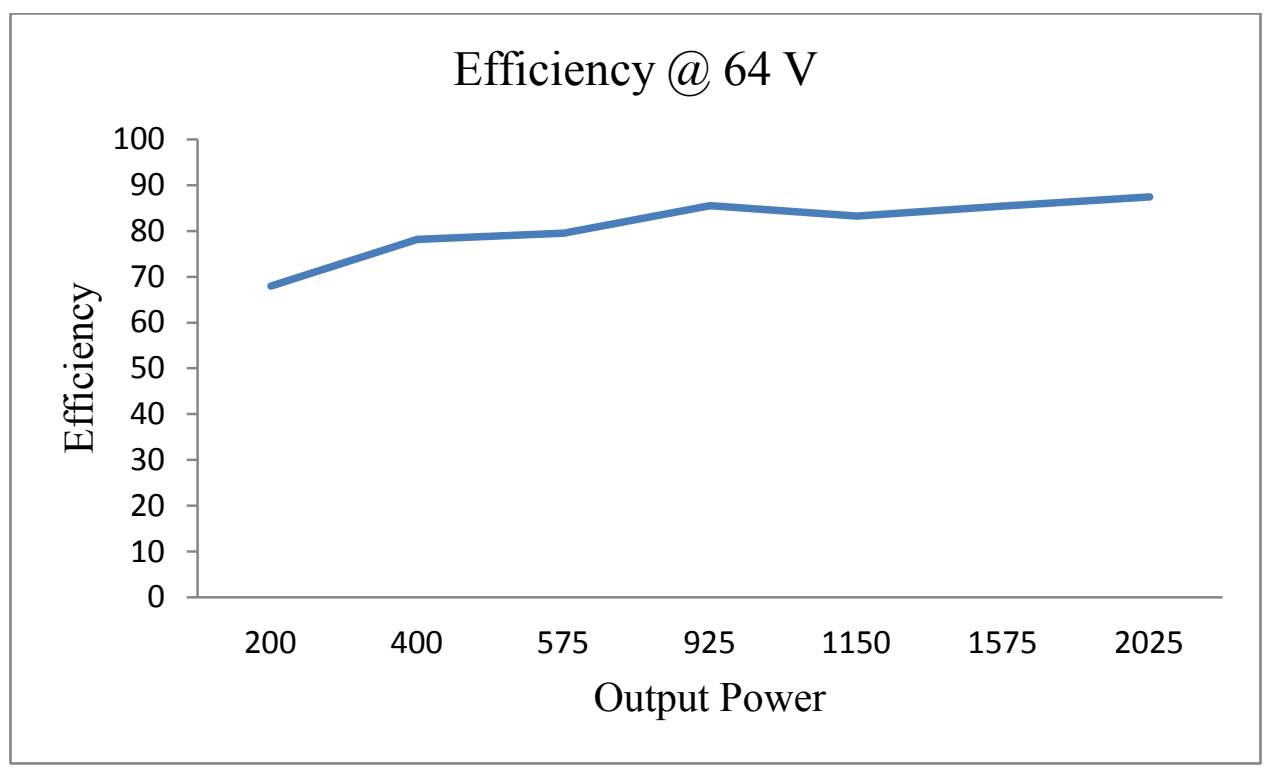

Figure 31. Efficiency of inverter with inductive load at $64 \mathrm{~V}$ DC.

Table 17 shows performance of the inverter discharging energy through an inductive load when the DC supply voltage was $60 \mathrm{~V}$. Maximum efficiency of the inverter was $86.76 \%$ at 1575 $\mathrm{W}$ of load, and minimum efficiency of the inverter was $70.03 \%$ at $200 \mathrm{~W}$ of load. Figure 32 shows the performance graph of the inverter at $68 \mathrm{~V}$ DC. 
TABLE 17

PERFORMANCE OF INVERTER WITH INDUCTIVE LOAD AT 68 V DC

\begin{tabular}{|c|c|c|c|c|c|c|c|c|c|}
\hline $\mathbf{V}_{\mathbf{D C}}$ & $\mathbf{I}_{\mathbf{D C}}$ & $\mathbf{P}_{\mathbf{D C}}$ & $\mathbf{P}_{\mathbf{A C}}$ & $\mathbf{V}_{\mathbf{A C}}$ & $\mathbf{I}_{\mathbf{A C}}$ & $\mathbf{P . F}$ & $\mathbf{Q}_{\mathbf{A C}}$ & Losses & Efficiency \\
\hline 67.99 & 4.2 & 285.558 & 200 & 123.5 & 2.25 & 0.71 & 200 & 85.558 & 70.03 \\
\hline 67.99 & 7.5 & 509.925 & 400 & 123.7 & 4.5 & 0.71 & 400 & 109.925 & 78.44 \\
\hline 67.99 & 10.6 & 720.694 & 575 & 123.4 & 9.25 & 0.71 & 575 & 145.694 & 79.78 \\
\hline 67.99 & 16.2 & 1101.438 & 925 & 124.9 & 9.75 & 0.77 & 775 & 176.438 & 83.91 \\
\hline 67.99 & 20.5 & 1393.795 & 1150 & 124.1 & 14.75 & 0.63 & 1450 & 243.795 & 82.50 \\
\hline 67.99 & 26.7 & 1815.333 & 1575 & 123.3 & 16 & 0.79 & 1275 & 240.333 & 86.76 \\
\hline 67.99 & 34.5 & 2345.655 & 2025 & 124.6 & 19.5 & 0.83 & 1350 & 320.655 & 86.32 \\
\hline
\end{tabular}

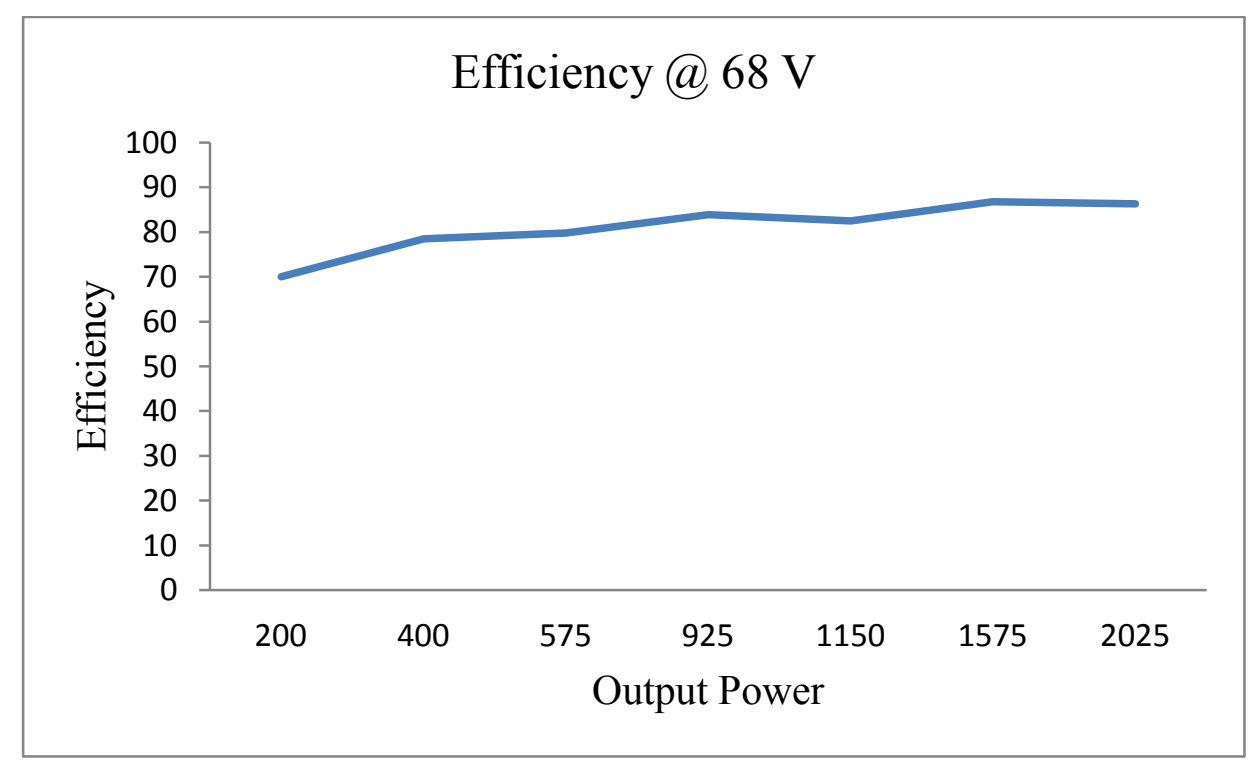

Figure 32. Efficiency of inverter with inductive load at $68 \mathrm{~V}$ DC.

Figure 33 shows performance of the inverter with inductive loads at different voltage inputs. From this graph, it can be concluded that the efficiency of the inverter was independent of the input voltage. 


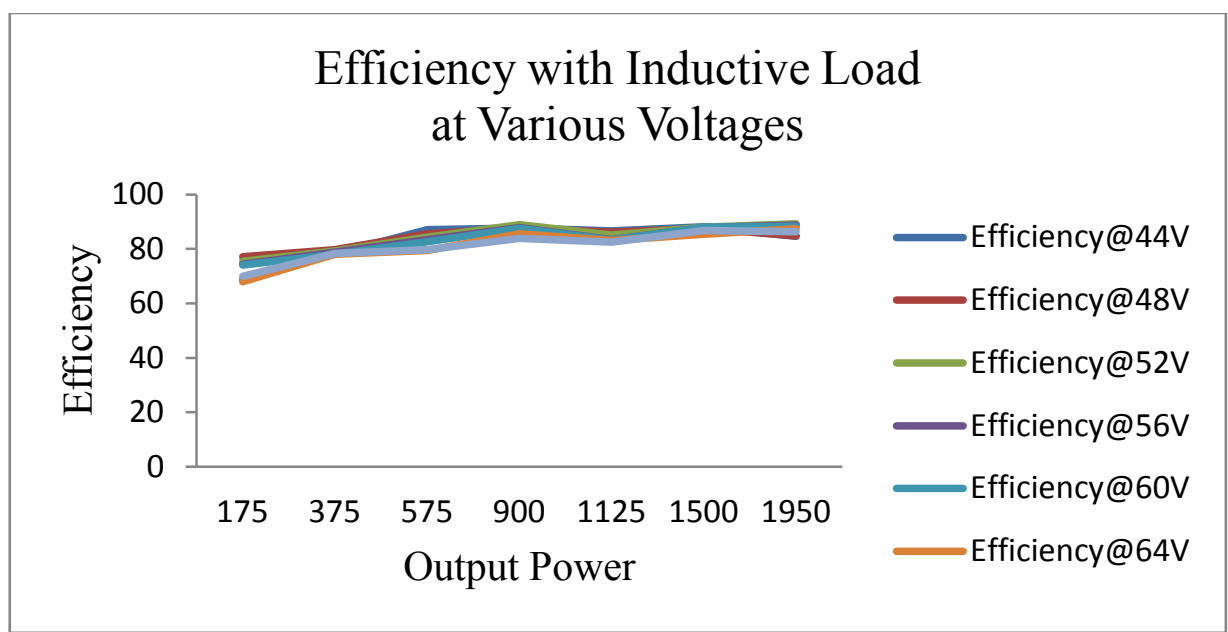

Figure 33. Efficiency of inverter with inductive load at various voltage inputs.

Figures 34 to 39 show graphs of the inverter's efficiency versus output power for both resistive and inductive loads at different load points and different voltage inputs on the DC side. It can be seen that the efficiency of the inverter with inductive loads is always less than the efficiency of the inverter with resistive loads, irrespective of voltage input. 


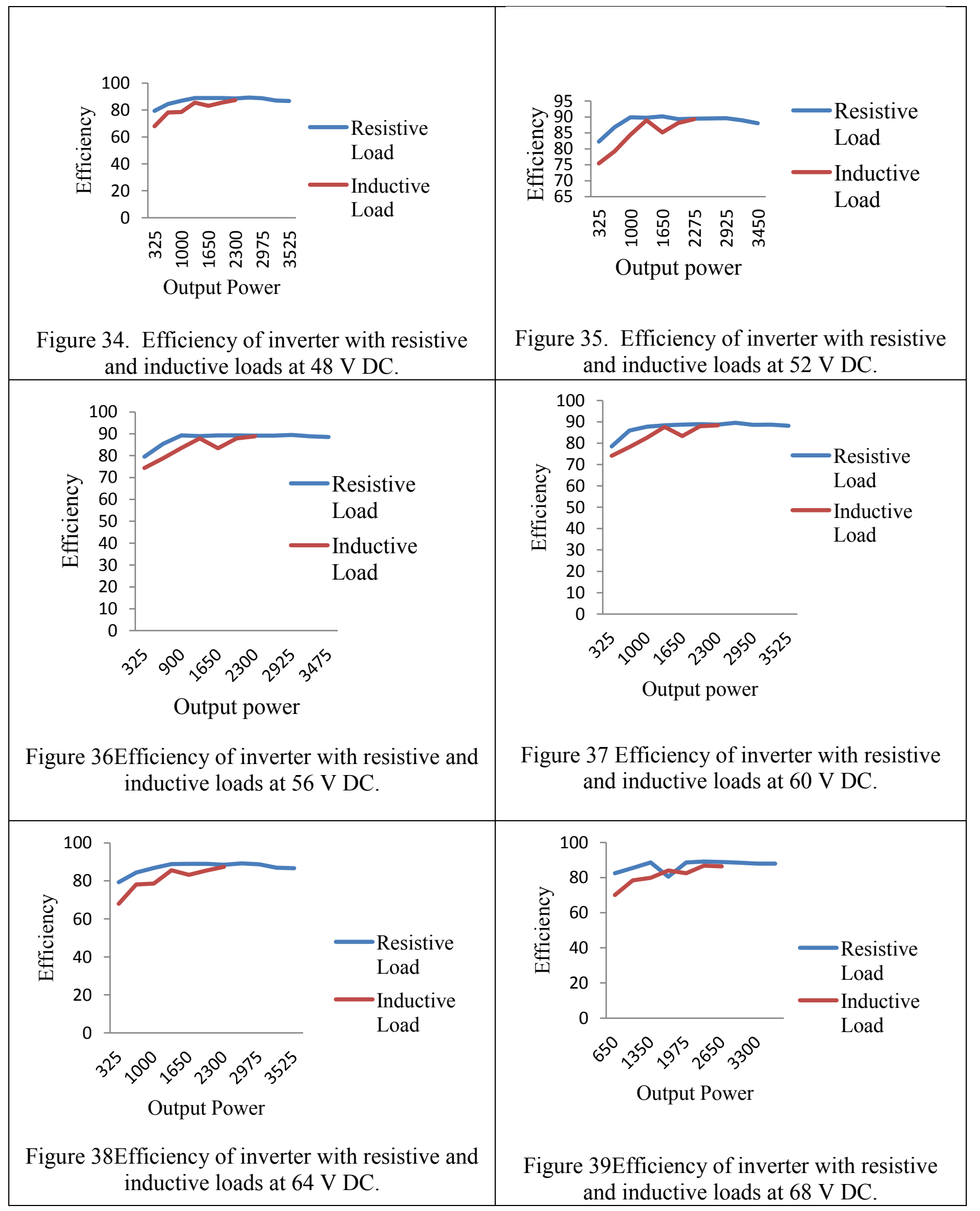




\subsection{Steady-State Analysis of Inverter When Acting as Pass-Through}

The purpose of this test case was to determine the efficiency of the inverter when acting as a pass-through. Figure 40 shows the connection diagram of this case. An inductive load was connected to the load terminals of the inverter, and AC terminals were connected to the grid. The inverter will not turn on without the DC source connected; therefore, the DC supply is useful to turn on the inverter but is not supplying any energy to the load.

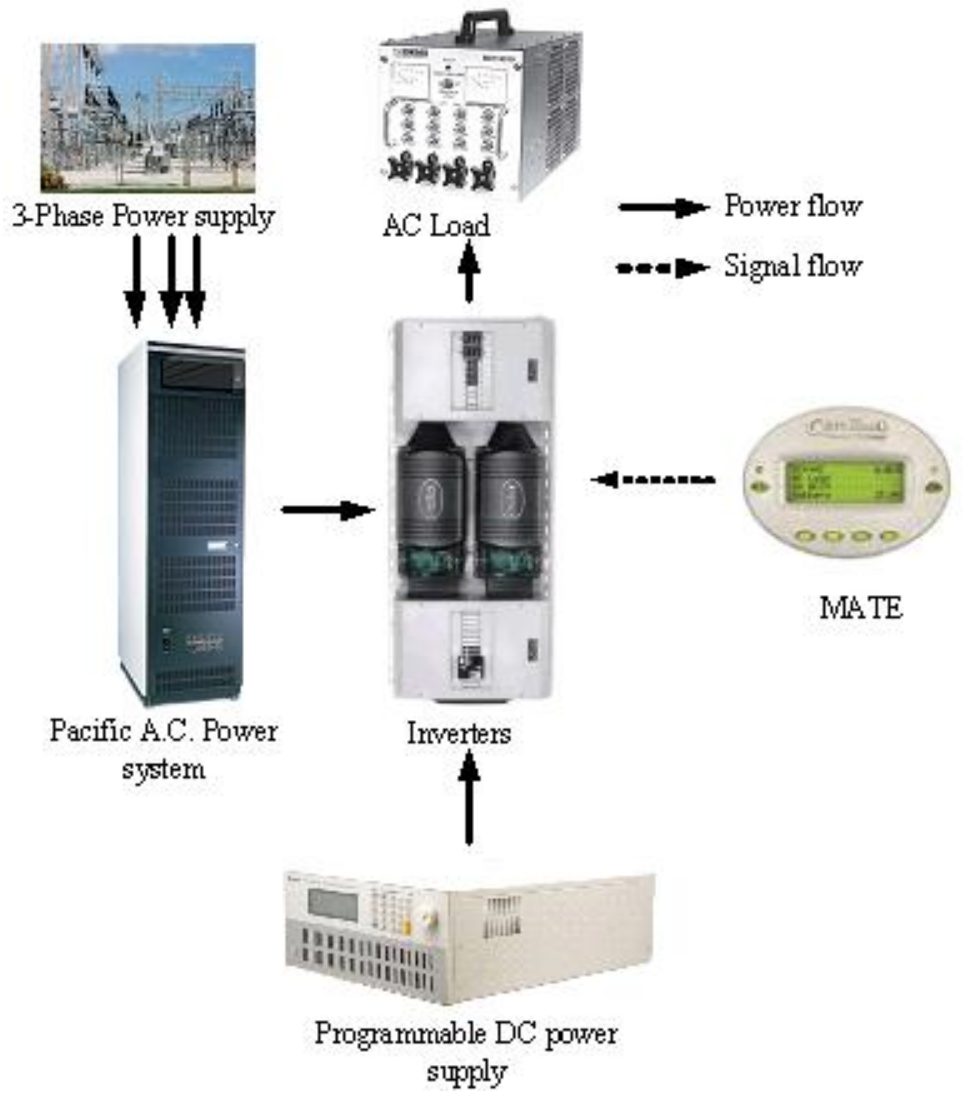

Figure 40 Diagram of connections for steady-state analysis when energy is passing through.

Table 18 shows the performance of the inverter when acting as a pass-through: $\mathrm{V}_{\mathrm{RMS}}$ of Grid is the root mean square voltage from the grid, Power from Grid is the active power supply from the grid, Grid Power Factor is the power factor of the power supply from the grid, $V_{\text {RMS }}$ of Load is the root mean square voltage across the load, Load Power is the power supply to the 
load, Reactive Power to Load is the reactive power supply to the load, Load Power Factor is the power factor of the load, DC Power is the power from the programmable DC power supply (the inverter will not turn on without a DC supply, which is supplying less than $10 \mathrm{~W}$ of power to the inverter), Input Power is the input power of the inverter from the grid source, and Efficiency is simply the efficiency of the inverter. From the data in Table 18, it can be seen that as the load increased, voltage across the load and voltage across the grid terminals decreased, the active power coming from the grid was directly going to the load, and there was some power loss in the inverter. In this case, efficiency of the inverter was high, since there was no power being inverted in the inverter; therefore, there would not be any power loss in the inverter's transformer, and all power losses in the inverter represented power losses in the power electronics components in the inverter.

TABLE 18

PERFORMANCE OF INVERTER WHEN ACTING AS PASS-THROUGH

\begin{tabular}{|l|c|c|c|c|c|c|c|c|c|c|}
\hline $\begin{array}{c}\mathbf{V}_{\text {rms }} \\
\text { of } \\
\text { Grid }\end{array}$ & $\begin{array}{c}\text { Power } \\
\text { from } \\
\text { Grid }\end{array}$ & $\begin{array}{c}\text { Reactive } \\
\text { Power } \\
\text { from } \\
\text { Grid }\end{array}$ & $\begin{array}{c}\text { Grid } \\
\text { Power } \\
\text { Factor }\end{array}$ & $\begin{array}{c}\mathbf{V}_{\text {RMS }} \\
\text { of } \\
\text { Load }\end{array}$ & $\begin{array}{c}\text { Load } \\
\text { Power } \\
\text { (Output) }\end{array}$ & $\begin{array}{c}\text { Reactive } \\
\text { Power to } \\
\text { Load }\end{array}$ & $\begin{array}{c}\text { Load } \\
\text { Power } \\
\text { Factor }\end{array}$ & $\begin{array}{c}\text { DC } \\
\text { Power }\end{array}$ & $\begin{array}{c}\text { Input } \\
\text { Power }\end{array}$ & Efficiency \\
\hline 123.9 & 200 & 200 & 0.71 & 123 & 200 & 200 & 0.71 & 9.56 & 209.56 & 95.44 \\
\hline 123.6 & 400 & 375 & 0.72 & 122 & 400 & 400 & 0.7 & 8.75 & 408.75 & 97.86 \\
\hline 123.4 & 600 & 575 & 0.72 & 121 & 575 & 575 & 0.71 & 8.71 & 608.71 & 94.46 \\
\hline 123.2 & 900 & 700 & 0.79 & 119.9 & 875 & 725 & 0.77 & 8.6 & 908.6 & 96.30 \\
\hline 123 & 1150 & 1250 & 0.68 & 118.8 & 1050 & 1250 & 0.65 & 8.62 & 1158.62 & 90.63 \\
\hline 122.6 & 1550 & 1175 & 0.8 & 117 & 1425 & 1125 & 0.78 & 8.56 & 1558.56 & 91.43 \\
\hline 122.1 & 2025 & 1175 & 0.86 & 116.2 & 1850 & 1175 & 0.84 & 8.54 & 2033.54 & 90.97 \\
\hline
\end{tabular}

From the steady-state analysis results, it can be concluded that the inverter was able to supply reactive power if the inverter is not connected to the grid; however, it was receiving reactive power from the grid when it was connected to the grid in order to supply reactive power 
to the load. Efficiency of the inverter was higher with the resistive load, compared to the inductive load, and efficiency of the inverter was independent of the input voltage on the DC side. When the inverter was acting as a pass-through, it required a DC supply to keep the inverter working; in this condition, the inverter was not supplying or consuming any reactive power. 


\section{CHAPTER 5}

\section{TRANSIENT-STATE ANALYSIS TEST RESULTS}

\subsection{Transient-State Analysis with Load Connected to Grid}

The aim of the transient-state analysis was to determine how the inverter would act during voltage sags (drops) on the grid side of the inverter, and to determine whether the inverter would supply reactive power to the grid or consume reactive power from the grid. The aim was also to determine how the system would react to voltage sags and voltage transients, if $5 \%$ to $10 \%$ of the total load of a neighborhood was connected through an inverter from a distributed energy resource.

In this test condition, DC terminals of the inverter were connected to a programmable DC supply, AC grid terminals were connected to a programmable AC supply acting as a grid, and load terminals of the inverter were kept open. The inverter was programmed using MATE. The voltage was set to sell the energy, but it was not possible to tell the inverter how much energy to sell. The amount of the selling energy was determined by voltage on both the DC side and the grid side. If the battery voltage was low, then the inverter assumed that the battery did not have enough energy and it would sell less energy. When the grid voltage was low, the inverter tried to sell more energy to the grid. Here, a programmable DC source was used on the DC side because it always maintained constant voltage on the DC side of the inverter. If the system had batteries on the DC side, then the battery voltage would decrease, and the MATE would send commands to the inverter and stop selling energy if battery voltage reached a lowest point. This test was conducted by reducing the grid voltage in small amounts (around $1.3 \mathrm{~V}$ per step) by sending a command to the programmable AC power supply through virtual programming software. The load and the inverter were connected to the same node. For the safety of the equipment, the 
discharge power was limited to $3,000 \mathrm{~W}$ when discharging the energy from the programmable DC supply.

Tables 19 to 26 show data of an inverter selling energy to the grid. $V_{\text {RMS }}$ No Load is the no-load voltage of the grid, $\mathrm{V}_{\mathrm{RMS}}$ No Inverter with Load is the grid voltage when some load is connected to the grid but the inverter is not connected (DR is not supplying any energy), $V_{\mathrm{RMS}}$ with Inverter and Load is the grid voltage when the inverter is selling energy to the grid and some load is connected to the grid, $\mathrm{DC}_{\text {Power }}$ is the power supplied to the inverter from the programmable DC supply, $\mathrm{P}_{\text {Inverter }}$ is the power supplied by the inverter to the grid, $\mathrm{Q}_{\text {Inverter }}$ is the reactive power supplied by the inverter and the negative sign (-) indicates that it is consuming instead of supplying, $\mathrm{P}_{\text {Source }}$ is the power supplied by the grid and the negative sign (-) indicates that it is buying power from the inverter, $\mathrm{Q}_{\text {source }}$ is the reactive power supplied by the grid, $\mathrm{P}_{\text {Load }}$ is the power consumed by the load which is connected to the grid, $\mathrm{Q}_{\text {load }}$ is the reactive power consumed by the load, and Load PF is the power factor of the load.

Table 19 shows performance of the inverter when selling power to the grid and supplying power to the load, which is connected at the grid, and the supply voltage is $44 \mathrm{~V}$ DC. The supply voltage on the $\mathrm{DC}$ side is $44 \mathrm{~V}$, but the normal required voltage of the inverter is $48 \mathrm{~V}$. Using MATE, the inverter was programmed to sell energy if the supplied DC voltage was above $42 \mathrm{~V}$. Here, the grid voltage was reduced by using virtual programming software. When the grid voltage was $122.9 \mathrm{~V}$ (first row, third column in Table 19), the inverter sold $1020 \mathrm{~W}$ of power, but the load needed $1180 \mathrm{~W}$ of power, so the remaining $160 \mathrm{~W}$ was obtained from the grid. When the grid voltage was reduced to $121.8 \mathrm{~V}$, the inverter started supplying more energy to the grid. The inverter was supplying $1340 \mathrm{~W}$ of power, the load was consuming $1140 \mathrm{~W}$ (here, a constant load was maintained throughout the test, but when the grid voltage was reduced 
automatically, the power supplied to the load is also fell from $1180 \mathrm{~W}$ to $1140 \mathrm{~W}$ ), and inverter was selling $200 \mathrm{~W}$ of power to the grid. From Table 19, it can be seen that as the grid voltage decreased, the power supplied by the inverter increased. Further reduction of the voltage after 117.6 $\mathrm{V}$ indicated that the inverter was disconnecting from the grid. Figure 41 is a graph of the voltage sag and power supply from the inverter, and Figure 42 shows the efficiency of the inverter during the voltage drop on the AC side.

TABLE 19

PERFORMANCE OF INVERTER WITH INDUCTIVE LOAD CONNECTED TO GRID WHILE SELLING POWER TO GRID AT 44 V DC

\begin{tabular}{|c|c|c|c|c|c|c|c|c|c|c|}
\hline $\begin{array}{c}\mathbf{V}_{\text {RMS }} \\
\text { No } \\
\text { Load }\end{array}$ & $\begin{array}{c}\mathbf{V}_{\text {RMS }} \\
\text { No Inverter } \\
\text { with Load }\end{array}$ & $\begin{array}{c}\mathbf{V}_{\text {RMS }} \\
\text { with Inverter } \\
\text { and Load }\end{array}$ & DC $_{\text {Power }}$ & $\mathbf{P}_{\text {Inverter }}$ & $\mathbf{Q}_{\text {Inverter }}$ & $\mathbf{P}_{\text {Source }}$ & $\mathbf{Q}_{\text {Source }}$ & $\mathbf{P}_{\text {Load }}$ & $\mathbf{Q}_{\text {Load }}$ & $\begin{array}{c}\text { Load } \\
\text { PF }\end{array}$ \\
\hline 122.9 & 121.2 & 122.9 & 1177 & 1020 & -70 & 160 & 1330 & 1180 & 1260 & 0.68 \\
\hline 121.4 & 119.7 & 121.8 & 1564.2 & 1340 & -90 & -200 & 1290 & 1140 & 1200 & 0.69 \\
\hline 119.4 & 117.8 & 120.6 & 1991 & 1640 & -90 & -540 & 1230 & 1100 & 1140 & 0.69 \\
\hline 117.9 & 116.4 & 119.4 & 2329.8 & 1950 & -120 & -870 & 1200 & 1080 & 1080 & 0.7 \\
\hline 116.2 & 114.5 & 118.3 & 2756.6 & 2270 & -70 & -1230 & 1110 & 1040 & 1040 & 0.71 \\
\hline 115.3 & 113.7 & 117.6 & 2862.2 & 2350 & -130 & -1310 & 1130 & 1040 & 1000 & 0.71 \\
\hline
\end{tabular}

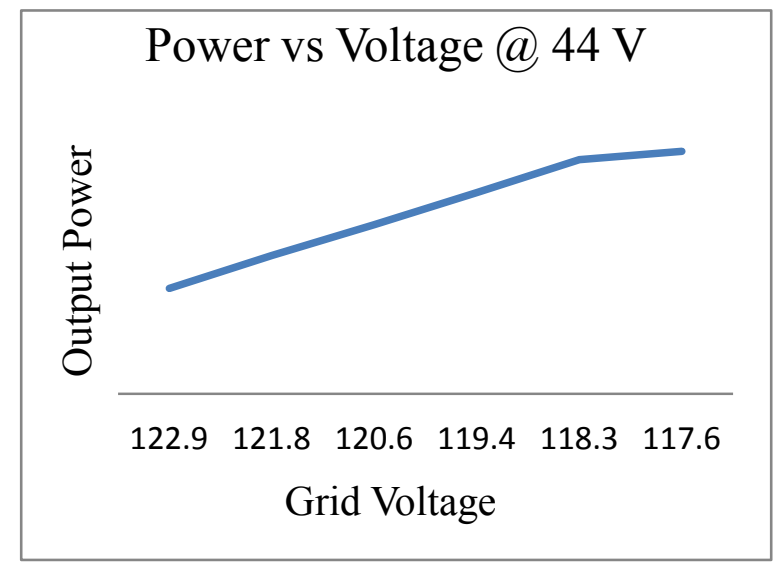

Figure 41 Performance of inverter with inductive load connected to grid while selling power to grid at $44 \mathrm{~V} \mathrm{DC}$.

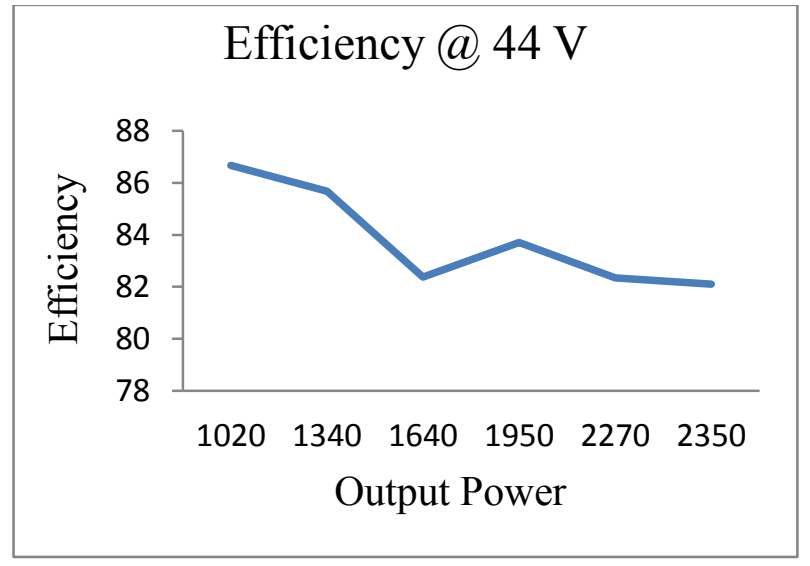

Figure 42 Efficiency of inverter with inductive load connected to grid while selling power to grid at $44 \mathrm{~V}$ DC. 
Table 20 shows performance of the inverter with an inductive load when the DC supply voltage was $48 \mathrm{~V}$. Since this voltage was higher than $44 \mathrm{~V}$, it was selling more energy. At normal grid voltage $(123.1 \mathrm{~V})$, all load power was supplied by the inverter. At very low grid voltage, or $117.7 \mathrm{~V}$, the inverter was supplying about $2460 \mathrm{~W}$ of active power. In all cases, the inverter was not supplying any reactive power but was consuming a small amount of reactive power. The reactive power consumed by the inverter varied between 110 var to 150 var. All reactive power consumed by the load was supplied by the grid. Figure 43 shows the relationship between the grid voltage and the output power of the inverter, and Figure 44 shows the efficiency of the inverter.

TABLE 20

PERFORMANCE OF INVERTER WITH INDUCTIVE LOAD CONNECTED TO GRID WHILE SELLING POWER TO GRID AT 48 V DC

\begin{tabular}{|c|c|c|c|c|c|c|c|c|c|c|}
\hline $\begin{array}{c}\mathbf{V}_{\text {RMS }} \\
\text { No } \\
\text { Load }\end{array}$ & $\begin{array}{c}\mathbf{V}_{\text {RMS }}^{\text {No Inverter }} \\
\text { with Load }\end{array}$ & $\begin{array}{c}\mathbf{V}_{\text {RMS }} \\
\text { with Inverter } \\
\text { and Load }\end{array}$ & $\mathbf{D C}_{\text {Power }}$ & $\mathbf{P}_{\text {Inverter }}$ & $\mathbf{Q}_{\text {Inverter }}$ & $\mathbf{P}_{\text {Source }}$ & $\mathbf{Q}_{\text {Source }}$ & $\mathbf{P}_{\text {Load }}$ & $\mathbf{Q}_{\text {Load }}$ & $\begin{array}{c}\text { Load } \\
\text { PF }\end{array}$ \\
\hline 122.9 & 121.2 & 123.1 & 1380 & 1180 & -130 & 0 & 1390 & 1180 & 1260 & 0.68 \\
\hline 121.4 & 119.7 & 122 & 1716 & 1490 & -140 & -350 & 1340 & 1140 & 1200 & 0.69 \\
\hline 119.4 & 117.8 & 120.8 & 2112 & 1760 & -110 & -660 & 1250 & 1100 & 1140 & 0.69 \\
\hline 118.6 & 117 & 120.1 & 2268 & 1880 & -110 & -800 & 1230 & 1080 & 1120 & 0.7 \\
\hline 117.9 & 116.4 & 119.5 & 2481.6 & 2060 & -120 & -980 & 1200 & 1080 & 1080 & 0.7 \\
\hline 117.1 & 115.3 & 119 & 2668.8 & 2220 & -140 & -1160 & 1200 & 1060 & 1060 & 0.71 \\
\hline 116.2 & 114.5 & 118.4 & 2815.2 & 2265 & -130 & -1225 & 1190 & 1040 & 1060 & 0.71 \\
\hline 115.3 & 113.7 & 117.7 & 3028.8 & 2460 & -150 & -1420 & 1150 & 1040 & 1000 & 0.72 \\
\hline
\end{tabular}




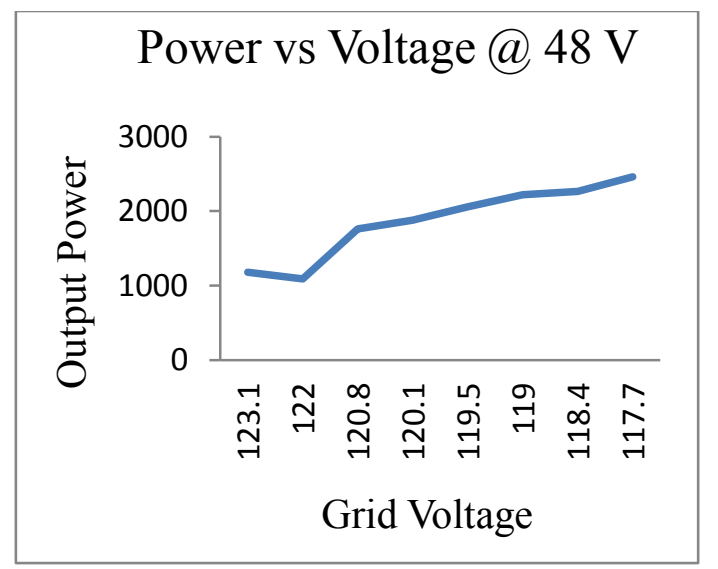

Figure 43. Performance of inverter with inductive load connected to grid while selling power to grid at $48 \mathrm{~V} \mathrm{DC}$.

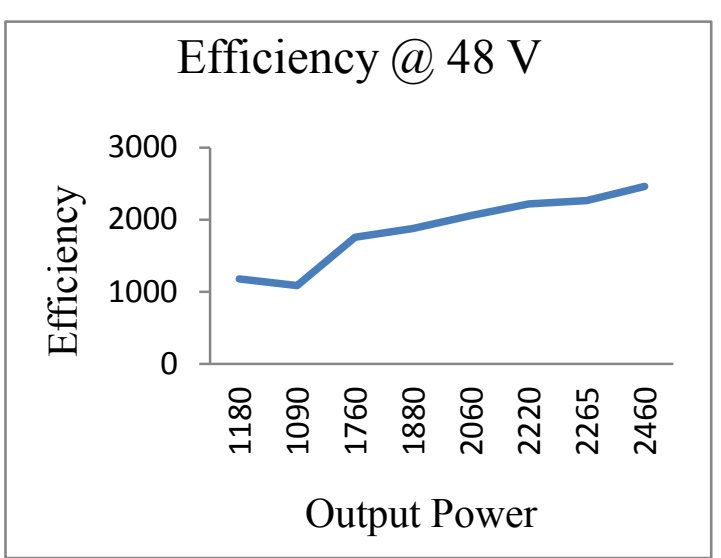

Figure 44Efficiency of inverter with inductive load connected to grid while selling power to grid at $48 \mathrm{~V} \mathrm{DC}$.

Table 21 shows performance of the inverter when the DC supply voltage as $52 \mathrm{~V}$ and was

connected to a constant inductive load. At full-grid voltage, the inverter sold $90 \mathrm{~W}$ of active power to the grid and at the same time consumed $140 \mathrm{VAr}$ of reactive power. As the grid voltage decreased, the inverter began selling more and more active power to the grid. When the grid voltage was $118 \mathrm{~V}$, the inverter was selling around $1600 \mathrm{~W}$ of active power. Figure 45 shows the performance graph of grid voltage versus power output of the inverter, and Figure 46 shows the efficiency of the inverter at $52 \mathrm{~V} \mathrm{DC}$.

TABLE 21

PERFORMANCE OF INVERTER WITH INDUCTIVE LOAD CONNECTED TO GRID WHILE SELLING POWER TO GRID AT 52 V DC

\begin{tabular}{|c|c|c|c|c|c|c|c|c|c|c|}
\hline $\begin{array}{c}\mathbf{V}_{\text {RMS }} \\
\text { No } \\
\text { Load }\end{array}$ & $\begin{array}{c}\mathbf{V}_{\text {RMS }} \\
\text { No Inverter } \\
\text { with Load }\end{array}$ & $\begin{array}{c}\mathbf{V}_{\text {RMS }} \\
\text { with Inverter } \\
\text { and Load }\end{array}$ & DC $_{\text {Power }}$ & $\mathbf{P}_{\text {Inverter }}$ & $\mathbf{Q}_{\text {Inverter }}$ & $\mathbf{P}_{\text {Source }}$ & $\mathbf{Q}_{\text {Source }}$ & $\mathbf{P}_{\text {Load }}$ & $\mathbf{Q}_{\text {Load }}$ & $\begin{array}{c}\text { Load } \\
\text { PF }\end{array}$ \\
\hline 122.9 & 121.2 & 123.2 & 1489.8 & 1270 & -140 & -90 & 1400 & 1180 & 1260 & 0.68 \\
\hline 121.4 & 119.7 & 122.1 & 1864.2 & 1560 & -210 & -420 & 1410 & 1140 & 1200 & 0.69 \\
\hline 119.4 & 117.8 & 120.9 & 2259.4 & 1930 & -160 & -830 & 1300 & 1100 & 1140 & 0.69 \\
\hline 118.6 & 117 & 120.3 & 2425.8 & 1990 & -140 & -910 & 1260 & 1080 & 1120 & 0.7 \\
\hline 117.9 & 116.4 & 119.8 & 2646.8 & 2170 & -160 & -1090 & 1240 & 1080 & 1080 & 0.7 \\
\hline 117.1 & 115.3 & 119.1 & 2862.6 & 2320 & -200 & -1260 & 1260 & 1060 & 1060 & 0.71 \\
\hline 116.2 & 114.5 & 118.5 & 2958.8 & 2390 & -70 & -1350 & 1130 & 1040 & 1060 & 0.71 \\
\hline 115.3 & 113.7 & 118 & 3268.2 & 2640 & -180 & -1600 & 1180 & 1040 & 1000 & 0.72 \\
\hline
\end{tabular}




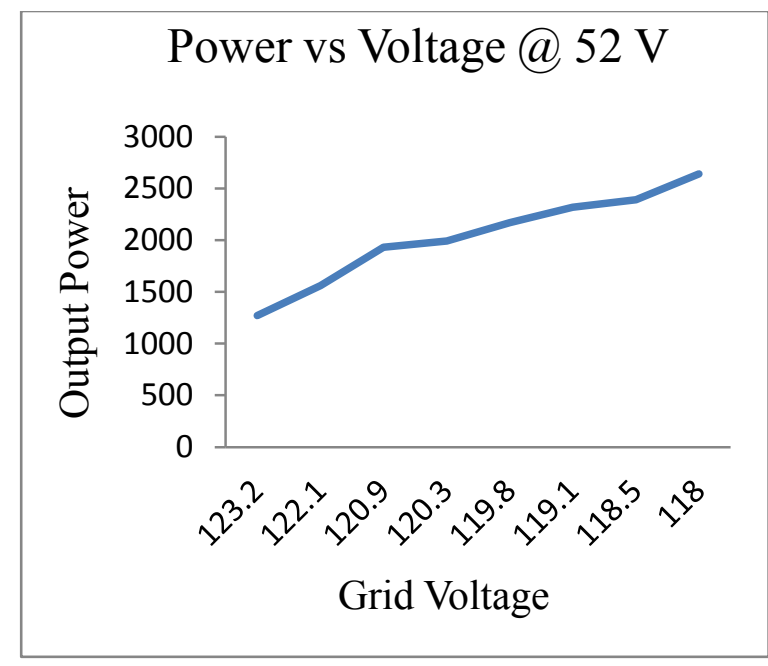

Figure 45. Performance of inverter with inductive load connected to grid while selling power to grid at $52 \mathrm{~V} \mathrm{DC}$.

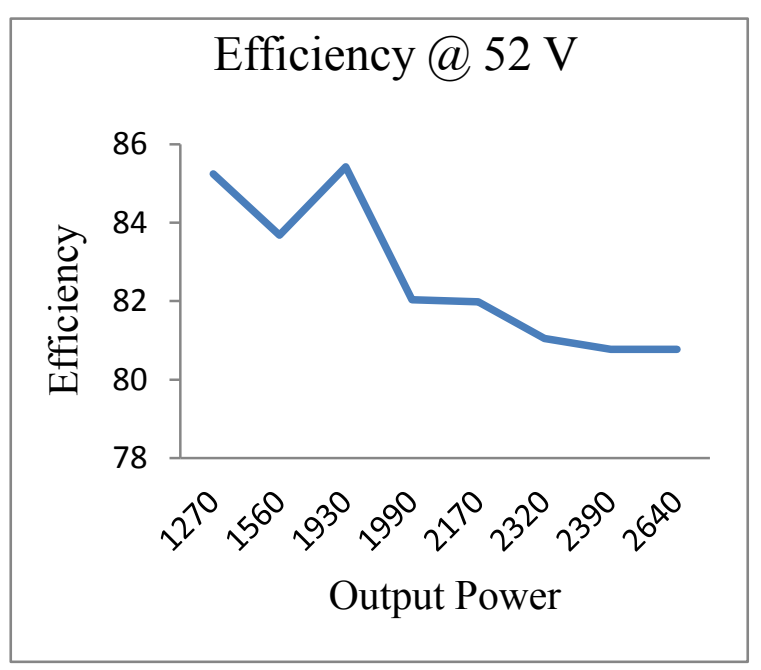

Figure 46 Performance of inverter with inductive load connected to grid while selling power to grid at $52 \mathrm{~V} \mathrm{DC}$.

Table 22 shows performance of the inverter when discharging energy through a constant inductive load and selling energy to the grid at $56 \mathrm{~V}$ of DC source voltage. At full-grid voltage, the inverter sold $180 \mathrm{~W}$ and consumed $140 \mathrm{VAr}$ of reactive power. When the grid voltage was 119.3 V, the inverter was selling around $1400 \mathrm{~W}$ of active power. Looking at the voltages at full load without and without the inverter, it can be seen that there is a voltage difference of almost 4 $\mathrm{V}$, thus indicating that the presence of a distribution energy resource means a large difference in grid voltage. Figure 47 shows the relationship between grid voltage and the output power of the inverter, and Figure 48 shows the efficiency of the inverter. 
TABLE 22

PERFORMANCE OF INVERTER WITH INDUCTIVE LOAD CONNECTED TO GRID WHILE SELLING POWER TO GRID AT 56 V DC

\begin{tabular}{|c|c|c|c|c|c|c|c|c|c|c|}
\hline $\begin{array}{c}\mathbf{V}_{\text {RMS }} \\
\text { No } \\
\text { Load }\end{array}$ & $\begin{array}{c}\mathbf{V}_{\text {RMS }} \\
\text { No Inverter } \\
\text { with Load }\end{array}$ & $\begin{array}{c}\mathbf{V}_{\text {RMS }} \\
\text { with Inverter } \\
\text { and Load }\end{array}$ & $\mathbf{D C}_{\text {Power }}$ & $\mathbf{P}_{\text {Inverter }}$ & $\mathbf{Q}_{\text {Inverter }}$ & $\mathbf{P}_{\text {Source }}$ & $\mathbf{Q}_{\text {Source }}$ & $\mathbf{P}_{\text {Load }}$ & $\mathbf{Q}_{\text {Load }}$ & $\begin{array}{c}\text { Load } \\
\mathbf{P F}\end{array}$ \\
\hline 122.9 & 121.2 & 123.3 & 1626.8 & 1360 & -140 & -180 & 1400 & 1180 & 1260 & 0.68 \\
\hline 121.4 & 119.7 & 122.2 & 2055.2 & 1700 & -180 & -560 & 1380 & 1140 & 1200 & 0.69 \\
\hline 119.4 & 117.8 & 121.1 & 2480.8 & 2030 & -220 & -930 & 1360 & 1100 & 1140 & 0.69 \\
\hline 118.6 & 117 & 120.5 & 2640.4 & 2100 & -140 & -1020 & 1260 & 1080 & 1120 & 0.7 \\
\hline 117.9 & 116.4 & 119.8 & 2819.6 & 2290 & -120 & -1210 & 1200 & 1080 & 1080 & 0.7 \\
\hline 117.1 & 115.3 & 119.3 & 3043.6 & 2460 & -150 & -1400 & 1210 & 1060 & 1060 & 0.71 \\
\hline
\end{tabular}

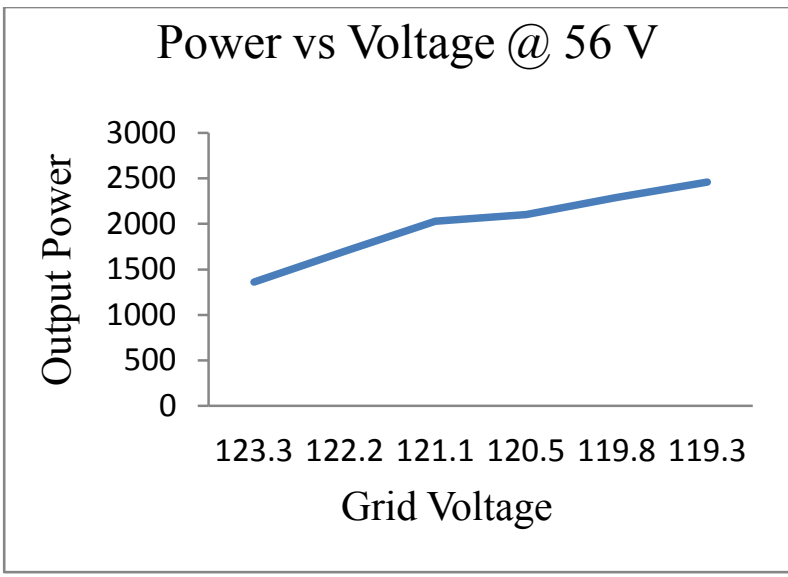

Figure 47. Performance of inverter with inductive load connected to grid while selling power to grid at $56 \mathrm{~V} \mathrm{DC}$.

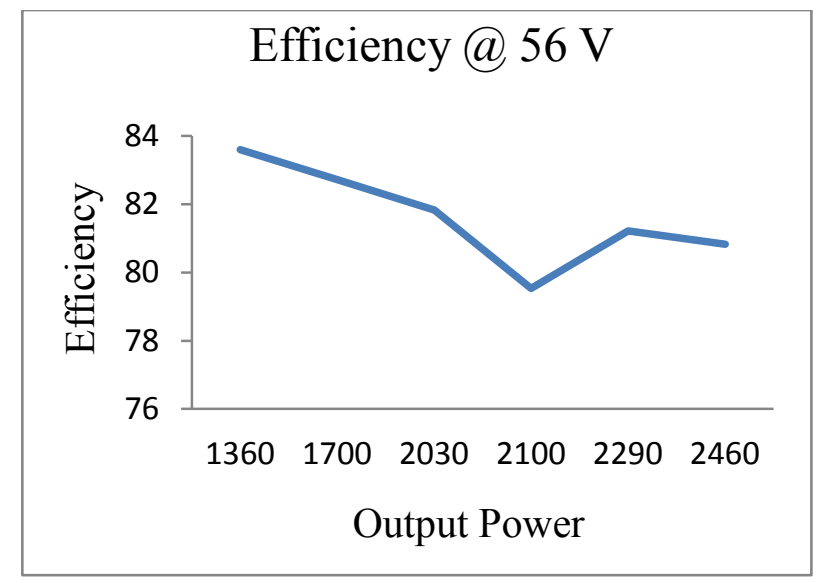

Figure 48. Efficiency of inverter with inductive load connected to grid while selling power to grid at $56 \mathrm{~V}$ DC.

Table 23 shows performance of the inverter when selling power to the grid and supplying power to the load at $60 \mathrm{~V}$ DC. When the grid voltage was $123.6 \mathrm{~V}$, the inverter was selling around $340 \mathrm{~W}$ of power to the grid and consuming $160 \mathrm{VAr}$ of reactive power. When the grid voltage was $120 \mathrm{~V}$, the inverter was selling $1320 \mathrm{~W}$ of active power. A constant load was maintained the entire time, but as the voltage decreased, the power supply to the load also 
decreased, hence the reason for seeing different load levels. Figure 49 shows the relationship between the grid voltage and the output power of the inverter, and Figure 50 shows the efficiency of the inverter.

TABLE 23

PERFORMANCE OF INVERTER WITH INDUCTIVE LOAD CONNECTED TO GRID WHILE SELLING POWER TO GRID AT 60 V DC

\begin{tabular}{|c|c|c|c|c|c|c|c|c|c|c|}
\hline $\begin{array}{c}\mathbf{V}_{\text {RMS }} \\
\text { No } \\
\text { Load }\end{array}$ & $\begin{array}{c}\mathbf{V}_{\text {RMS }} \\
\text { No Inverter } \\
\text { with Load }\end{array}$ & $\begin{array}{c}\mathbf{V}_{\text {RMS }} \\
\text { with Inverter } \\
\text { and Load }\end{array}$ & $\mathbf{D C}_{\text {Power }}$ & $\mathbf{P}_{\text {Inverter }}$ & $\mathbf{Q}_{\text {Inverter }}$ & $\mathbf{P}_{\text {Source }}$ & $\mathbf{Q}_{\text {Source }}$ & $\mathbf{P}_{\text {Load }}$ & $\mathbf{Q}_{\text {Load }}$ & $\begin{array}{c}\text { Load } \\
\mathbf{P F}\end{array}$ \\
\hline 122.9 & 121.2 & 123.6 & 1833 & 1520 & -160 & -340 & 1420 & 1180 & 1260 & 0.68 \\
\hline 122.2 & 120.4 & 123.1 & 2091 & 1740 & -160 & -560 & 1400 & 1180 & 1240 & 0.68 \\
\hline 121.4 & 119.7 & 122.4 & 2202 & 1820 & -180 & -660 & 1380 & 1160 & 1200 & 0.68 \\
\hline 120.5 & 118.7 & 121.9 & 2460 & 2040 & -200 & -880 & 1360 & 1160 & 1160 & 0.69 \\
\hline 119.4 & 117.8 & 121.2 & 2559 & 2110 & -170 & -970 & 1310 & 1140 & 1140 & 0.7 \\
\hline 118.6 & 117 & 120.6 & 2814 & 2300 & -190 & -1180 & 1310 & 1120 & 1120 & 0.7 \\
\hline 117.9 & 116.4 & 120 & 2985 & 2420 & -170 & -1320 & 1270 & 1100 & 1100 & 0.7 \\
\hline
\end{tabular}

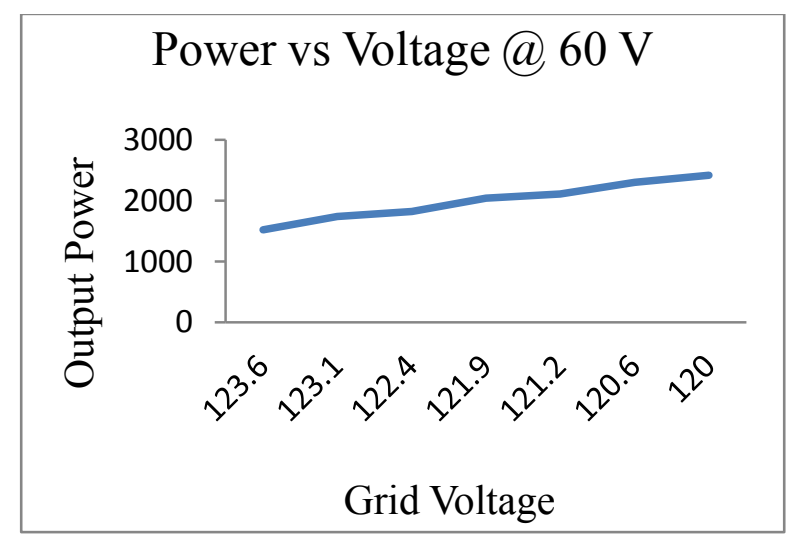

Figure 49. Performance of inverter with inductive load connected to grid while selling power to grid at $60 \mathrm{~V} \mathrm{DC}$.

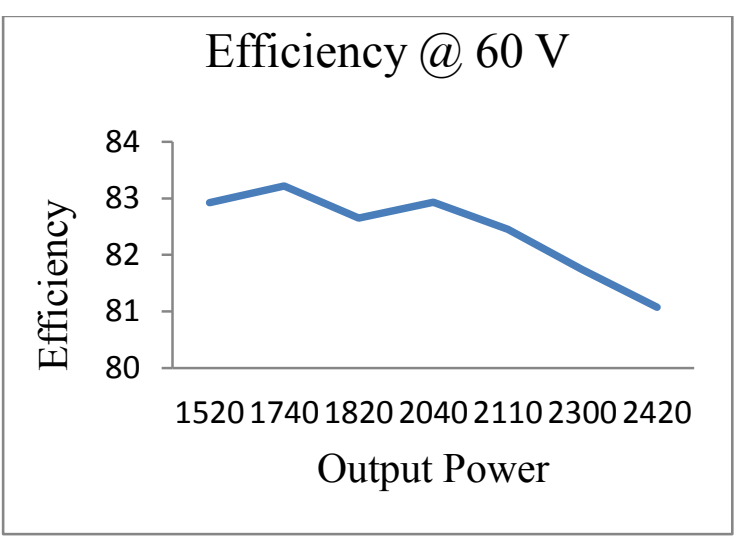

Figure 50. Efficiency of inverter with inductive load connected to grid while selling power to grid at $60 \mathrm{~V} \mathrm{DC}$.

Table 24 shows performance of the inverter when selling power to the grid and supplying power to the load at $64 \mathrm{~V} \mathrm{DC}$. At $123.9 \mathrm{~V}$ of grid voltage, the inverter sold $490 \mathrm{~W}$ of active power and received $180 \mathrm{VAr}$ of reactive power. The grid voltage as $123.9 \mathrm{~V}$ after the distribution 
resource was connected to the grid; otherwise, the grid voltage was $121.2 \mathrm{~V}$. When the grid voltage was $120.2 \mathrm{~V}$, the inverter was selling $1420 \mathrm{~W}$ of active power and it was receiving 120 VAr of reactive power. Results s how that the inverter always took reactive power from the grid when it was connected to the grid, but it also had the ability to generate reactive power. Figure 51 shows the relationship between the grid voltage and the output power of the inverter, and Figure 52 shows the efficiency of the inverter.

TABLE 24

PERFORMANCE OF INVERTER WITH INDUCTIVE LOAD CONNECTED TO GRID WHILE SELLING POWER TO GRID AT 64 V DC

\begin{tabular}{|c|c|c|c|c|c|c|c|c|c|c|}
\hline $\begin{array}{c}\mathbf{V}_{\text {RMS }} \\
\text { No } \\
\text { Load }\end{array}$ & $\begin{array}{c}\mathbf{V}_{\text {RMS }} \\
\text { No Inverter } \\
\text { with Load }\end{array}$ & $\begin{array}{c}\mathbf{V}_{\text {RMS }} \\
\text { with Inverter } \\
\text { and Load }\end{array}$ & DCP $_{\text {ower }}$ & $\mathbf{P}_{\text {Inverter }}$ & $\mathbf{Q}_{\text {Inverter }}$ & $\mathbf{P}_{\text {Source }}$ & $\mathbf{Q}_{\text {Source }}$ & $\mathbf{P}_{\text {Load }}$ & $\mathbf{Q}_{\text {Load }}$ & $\begin{array}{c}\text { Load } \\
\mathbf{P F}\end{array}$ \\
\hline 122.9 & 121.2 & 123.9 & 2038.4 & 1670 & -180 & -490 & 1440 & 1180 & 1260 & 0.68 \\
\hline 122.2 & 120.4 & 123.3 & 2150.4 & 1780 & -160 & -600 & 1400 & 1180 & 1240 & 0.68 \\
\hline 121.4 & 119.7 & 122.7 & 2412.8 & 1980 & -190 & -820 & 1390 & 1160 & 1200 & 0.68 \\
\hline 120.5 & 118.7 & 120.9 & 3046.4 & 2500 & -120 & -1340 & 1280 & 1160 & 1160 & 0.69 \\
\hline 119.4 & 117.8 & 120.2 & 3145.6 & 2560 & -120 & -1420 & 1260 & 1140 & 1140 & 0.7 \\
\hline
\end{tabular}

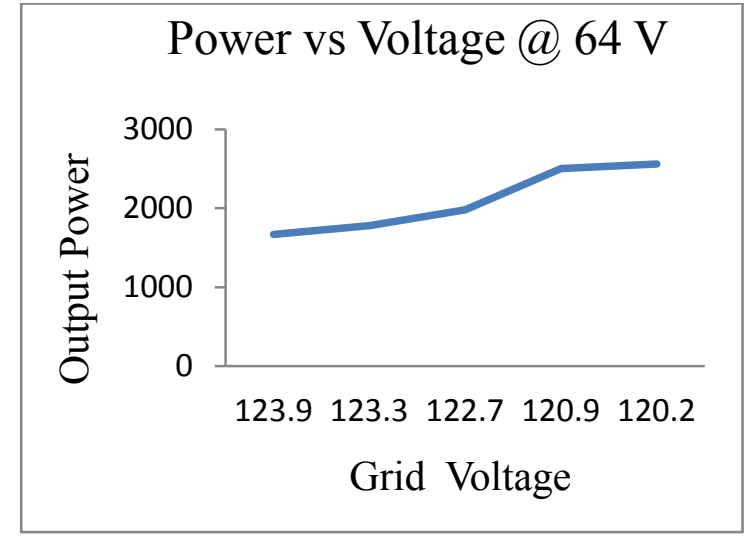

Figure 51. Performance of inverter with inductive load connected to grid while selling power to grid at $64 \mathrm{~V}$ DC.

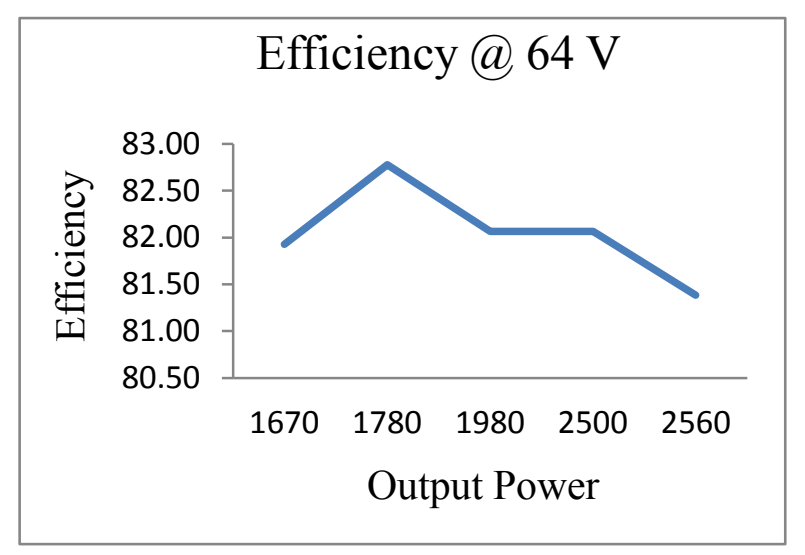

Figure 52.Efficiency of inverter with inductive load connected to grid while selling power to grid at $64 \mathrm{~V} \mathrm{DC}$.

Table 25 shows performance of the inverter when selling power to the grid and also supplying power to the load, which is directly connected to the grid. Since the DC voltage is 68 
$\mathrm{V}$, the inverter calculated more energy available at the DC terminals, so even if the grid voltage was high it was selling a large amount of power to the grid. The starting selling power was at $1780 \mathrm{~W}$ at normal grid voltage and reached to $2480 \mathrm{~W}$ when the grid voltage reached $121 \mathrm{~V}$. The input power of the inverter was limited to close to $3000 \mathrm{~W}$ for the safety of the programmable DC supply. Figure 53 shows the relationship between the output power and grid voltage, and Figure 54 shows the efficiency of inverter.

TABLE 25

PERFORMANCE OF INVERTER WITH INDUCTIVE LOAD CONNECTED TO GRID WHILE SELLING POWER TO GRID AT 68 V DC

\begin{tabular}{|c|c|c|c|c|c|c|c|c|c|c|}
\hline $\begin{array}{c}\mathbf{V}_{\text {RMS }} \\
\text { No } \\
\text { Load }\end{array}$ & $\begin{array}{c}\mathbf{V}_{\text {RMS }} \\
\text { No Inverter } \\
\text { with Load }\end{array}$ & $\begin{array}{c}\mathbf{V}_{\text {RMS }} \\
\text { with Inverter } \\
\text { and Load }\end{array}$ & DC $_{\text {Power }}$ & $\mathbf{P}_{\text {Inverter }}$ & $\mathbf{Q}_{\text {Inverter }}$ & $\mathbf{P}_{\text {Source }}$ & $\mathbf{Q}_{\text {Source }}$ & $\mathbf{P}_{\text {Load }}$ & $\mathbf{Q}_{\text {Load }}$ & $\begin{array}{c}\text { Load } \\
\text { PF }\end{array}$ \\
\hline 122.9 & 121.2 & 124 & 2210 & 1780 & -180 & -600 & 1440 & 1180 & 1260 & 0.68 \\
\hline 122.2 & 120.4 & 123.4 & 2318.8 & 1890 & -200 & -710 & 1440 & 1180 & 1240 & 0.68 \\
\hline 121.4 & 119.7 & 122.8 & 2611.2 & 2100 & -200 & -940 & 1400 & 1160 & 1200 & 0.68 \\
\hline 120.5 & 118.7 & 122.2 & 2723.4 & 2200 & -190 & -1040 & 1350 & 1160 & 1160 & 0.69 \\
\hline 119.4 & 117.8 & 121.6 & 2995.4 & 2400 & -260 & -1260 & 1400 & 1140 & 1140 & 0.7 \\
\hline 118.6 & 117 & 121 & 3090.6 & 2480 & -230 & -1360 & 1350 & 1120 & 1120 & 0.7 \\
\hline
\end{tabular}

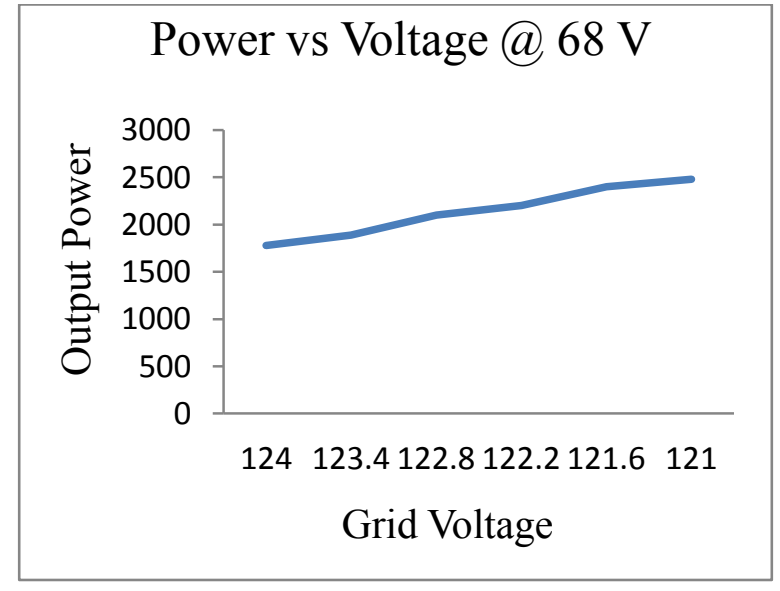

Figure 53. Performance of inverter with inductive load connected to grid while selling power to grid at $68 \mathrm{~V} \mathrm{DC}$.

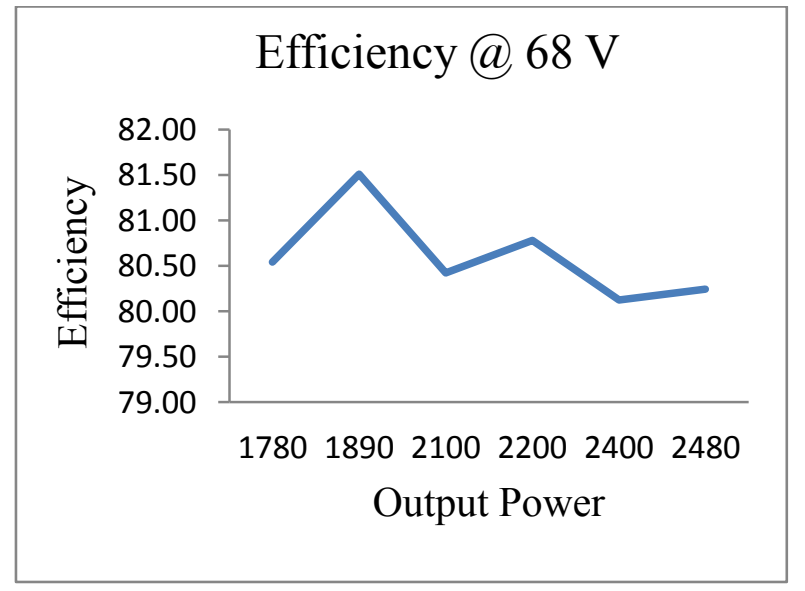

Figure 54. Efficiency of inverter with inductive load connected to grid while selling power to grid at $68 \mathrm{~V} \mathrm{DC}$. 


\subsection{Transient-State Analysis with Load Connected to Inverter}

The performance of the inverter while selling energy to the grid and supplying energy to the load that is directly connected to the inverter was evaluated. A programmable DC supply was connected to the inverter, a programmable AC supply was connected to the $\mathrm{AC}$ terminals of the inverter, and an inductive load was connected to the load terminals of the inverter.

Tables 26 to 28 show the test results of the transient-state analysis with inductive load connected to the output terminals of the inverter. $\mathrm{V}_{\mathrm{RMS}}$ is the grid voltage (which is simply the output of programmable AC supply measured by the power quality analyzer), $\mathrm{I}_{\mathrm{DC}}$ is the DC current supplied to the inverter and measured by an ammeter, $\mathrm{P}_{\mathrm{DC}}$ is the power supplied to the inverter and measured from the programmable DC supply, $\mathrm{P}_{\mathrm{LOAD}}$ is the active power supplied to the load and measured by the power quality analyzer, QLOAD is the reactive power supplied to the load and measured by the power quality analyzer, $\mathrm{PF}_{\mathrm{LOAD}}$ is the power factor of the load and measured by the power quality analyzer, $\mathrm{P}_{\text {INVERTER }}$ and $\mathrm{Q}_{\text {INVERTER }}$ are active and reactive power of the inverter, respectively, $\mathrm{P}_{\text {SOURCE }}$ is the active power supplied to the grid (negative number indicate power flow in opposite direction), QSOURCE is the reactive power supplied to the grid, P.F SOURCE $_{\text {is }}$ the power factor of the grid, Losses are the power losses in the grid, and EFF is the efficiency of the inverter.

Table 26 shows performance of the inverter when supplying power to the load, which is directly connected to the inverter, and when selling power to the grid when the DC supply voltage is $48 \mathrm{~V}$. Efficiency of the inverter varies from $85.87 \%$ to $87.46 \%$. The inverter did not supply any reactive power to the load but rather received reactive power from the grid to supply to the load. Inverter selling power was increasing when the grid voltage was decreasing. Figure 
55 shows the relationship between the grid voltage and output power, and Figure 56 shows the efficiency of the inverter.

TABLE 26

PERFORMANCE OF INVERTER WITH INDUCTIVE LOAD CONNECTED TO OUTPUT TERMINALS WHILE SELLING POWER TO GRID AT 48 V DC

\begin{tabular}{|l|c|c|c|c|c|c|c|c|c|c|c|c|}
\hline $\mathbf{V}_{\text {RMS }}$ & $\mathbf{I}_{\text {DC }}$ & $\mathbf{P}_{\text {DC }}$ & $\mathbf{P}_{\text {Load }}$ & $\mathbf{Q}_{\text {load }}$ & $\mathbf{P . F}_{\text {Load }}$ & $\mathbf{P}_{\text {Inverter }}$ & $\mathbf{Q}_{\text {Inverter }}$ & $\mathbf{P}_{\text {Source }}$ & $\mathbf{Q}_{\text {Source }}$ & $\mathbf{P . F}_{\text {Source }}$ & LOSSES & EFF \\
\hline 124.1 & 47.1 & 2260.8 & 1237.5 & 1512.5 & 0.64 & 1977.5 & 72.5 & -740 & 1440 & 0.45 & 283.3 & 87.46 \\
\hline 123.5 & 49.35 & 2368.8 & 1237.5 & 1487.5 & 0.64 & 2067.5 & 57.5 & -830 & 1430 & 0.54 & 301.3 & 87.28 \\
\hline 122.9 & 53.7 & 2577.6 & 1237.5 & 1487.5 & 0.64 & 2247.5 & 57.5 & -1010 & 1430 & 0.58 & 330.1 & 87.19 \\
\hline 122.2 & 58.4 & 2803.2 & 1237.5 & 1487.5 & 0.64 & 2427.5 & 57.5 & -1190 & 1430 & 0.645 & 375.7 & 86.59 \\
\hline 121.4 & 62.65 & 3007.2 & 1237.5 & 1487.5 & 0.64 & 2597.5 & 77.5 & -1360 & 1410 & 0.695 & 409.7 & 86.37 \\
\hline 120.6 & 67.35 & 3232.8 & 1237.5 & 1487.5 & 0.64 & 2797.5 & 77.5 & -1560 & 1410 & 0.74 & 435.3 & 86.53 \\
\hline 120 & 71.75 & 3444 & 1237.5 & 1487.5 & 0.64 & 2957.5 & 87.5 & -1720 & 1400 & 0.785 & 486.5 & 85.87 \\
\hline
\end{tabular}

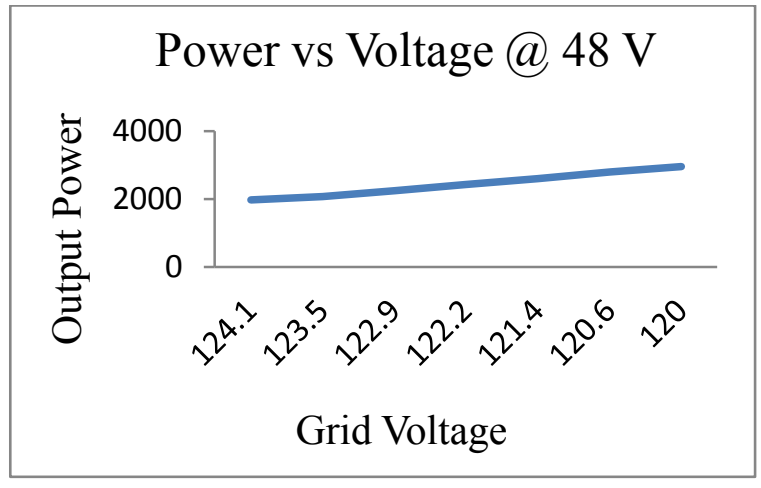

Figure 55. Performance of inverter with inductive load connected to output terminals while selling power to grid at $48 \mathrm{~V} \mathrm{DC}$.

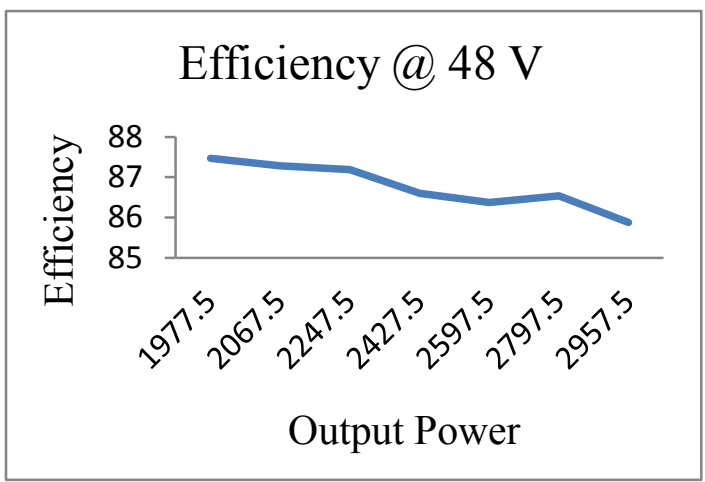

Figure 56. Efficiency of inverter with inductive load connected to output terminals while selling power to grid at $48 \mathrm{~V} \mathrm{DC}$.

Table 27 shows performance of the inverter when selling power to the grid and an inductive load is directly connected to the inverter when the DC supply voltage is $52 \mathrm{~V}$. The maximum efficiency of the inverter was $89.75 \%$, which is when the inverter was inverting around $2172 \mathrm{~W}$ of active power. Minimum efficiency of the inverter was $83.39 \%$, which is when the inverter was inverting $2990 \mathrm{~W}$ of power. Figure 57 shows the relationship between the output power and grid voltage, and Figure 58 shows the efficiency of the inverter. 
TABLE 27

PERFORMANCE OF INVERTER WITH INDUCTIVE LOAD CONNECTED TO OUTPUT TERMINALS WHILE SELLING POWER TO GRID AT 52 V DC

\begin{tabular}{|l|c|c|c|c|c|c|c|c|c|c|c|c|}
\hline $\mathbf{V}_{\mathbf{R M S}}$ & $\mathbf{I}_{\mathbf{D C}}$ & $\mathbf{P}_{\mathbf{D C}}$ & $\mathbf{P}_{\text {Load }}$ & $\mathbf{Q}_{\text {load }}$ & $\mathbf{P . F}_{\text {Load }}$ & $\mathbf{P}_{\text {Inverter }}$ & $\mathbf{Q}_{\text {Inverter }}$ & $\mathbf{P}_{\text {Source }}$ & $\mathbf{Q}_{\text {Source }}$ & $\mathbf{P . F}_{\text {Source }}$ & LOSSES & $\mathbf{E F F}$ \\
\hline 124.3 & 46.55 & 2420.6 & 1262 & 1512.5 & 0.64 & 2172.5 & 32.5 & -910 & 1480 & 0.48 & 248.1 & 89.75 \\
\hline 123.6 & 49.95 & 2597.4 & 1262 & 1512.5 & 0.64 & 2272.5 & 52.5 & -1010 & 1460 & 0.57 & 324.9 & 87.49 \\
\hline 122.9 & 54.35 & 2826.2 & 1262 & 1512.5 & 0.64 & 2462.5 & 32.5 & -1200 & 1480 & 0.63 & 363.7 & 87.13 \\
\hline 122.2 & 58.85 & 3060.2 & 1262 & 1512.5 & 0.64 & 2672.5 & 32.5 & -1410 & 1480 & 0.69 & 387.7 & 87.33 \\
\hline 121.4 & 62.5 & 3250 & 1250 & 1500 & 0.64 & 2730 & 50 & -1480 & 1450 & 0.72 & 520 & 84 \\
\hline 121 & 67.05 & 3486.6 & 1250 & 1500 & 0.64 & 2920 & 70 & -1670 & 1430 & 0.78 & 476.6 & 83.74 \\
\hline 120.4 & 68.95 & 3585.4 & 1250 & 1500 & 0.64 & 2990 & 110 & -1740 & 1390 & 0.79 & 595.4 & 83.39 \\
\hline
\end{tabular}

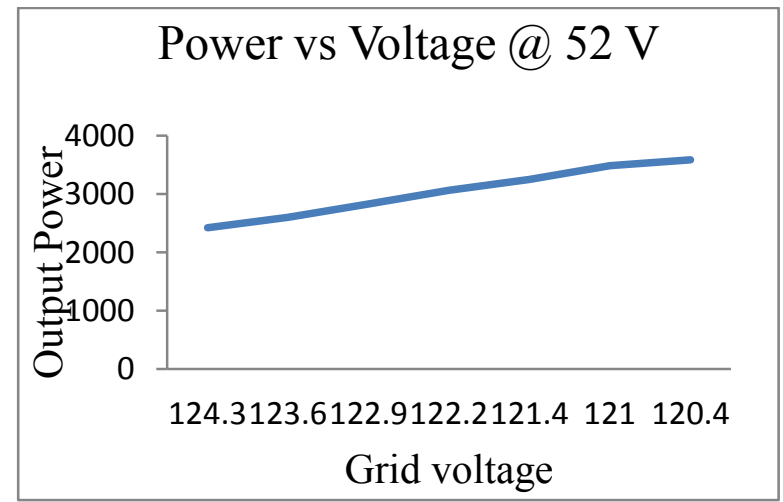

Figure 57. Performance of inverter with inductive load connected to output terminals while selling power to grid at $52 \mathrm{~V} \mathrm{DC}$.

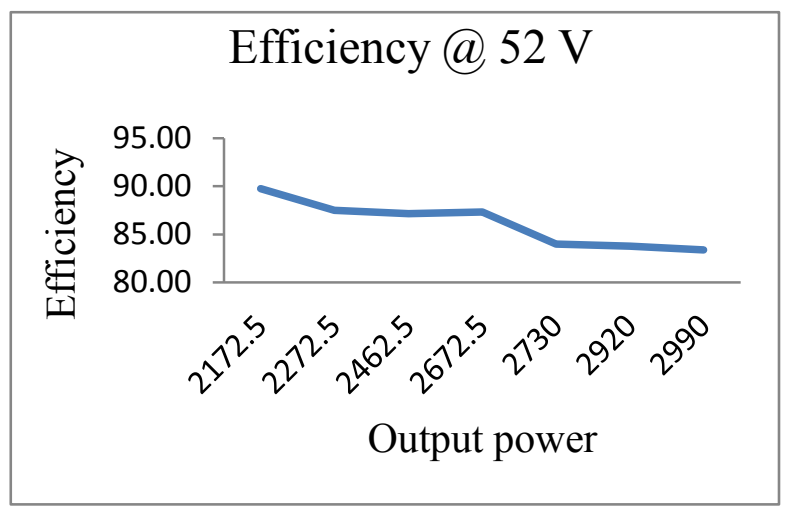

Figure 58. Efficiency of inverter with inductive load connected to output terminals while selling power to grid at $52 \mathrm{~V} \mathrm{DC}$.

Table 28 shows performance of the inverter when supplying power to the load selling power to the grid when DC voltage is $56 \mathrm{~V}$. Maximum power of the inverter was $85.64 \%$ when output power of the inverter was $2232 \mathrm{~W}$, and minimum efficiency of the inverter was $82.60 \%$ when output power of the inverter was $3212.5 \mathrm{~W}$. In all cases, the inverter never provided reactive power to the load when connected to the grid. Efficiency of the inverter was independent of the DC voltage. Figure 59 shows the relationship between the output power and grid voltage and Figure 60 shows the efficiency of the inverter. 
TABLE 28

PERFORMANCE OF INVERTER WITH INDUCTIVE LOAD CONNECTED TO OUTPUT TERMINALS WHILE SELLING POWER TO GRID AT 56 V DC

\begin{tabular}{|c|l|l|c|c|c|c|c|c|c|c|c|c|}
\hline $\mathbf{V}_{\text {RMS }}$ & $\mathbf{I}_{\text {DC }}$ & $\mathbf{P}_{\text {DC }}$ & $\mathbf{P}_{\text {Load }}$ & $\mathbf{Q}_{\text {load }}$ & $\mathbf{P . F}_{\text {Load }}$ & $\mathbf{P}_{\text {Inverter }}$ & $\mathbf{Q}_{\text {Inverter }}$ & $\mathbf{P}_{\text {Source }}$ & $\mathbf{Q}_{\text {Source }}$ & $\mathbf{P . F}_{\text {Source }}$ & LOSSES & EFF \\
\hline 124.6 & 46.55 & 2606.8 & 1262.5 & 1512.5 & 0.64 & 2232.5 & 2.5 & -970 & 1510 & 0.54 & 374.3 & 85.64 \\
\hline 123.8 & 49.5 & 2772 & 1262.5 & 1512.5 & 0.64 & 2332.5 & 22.5 & -1070 & 1490 & 0.61 & 439.5 & 84.14 \\
\hline 123.1 & 52.6 & 2945.6 & 1262.5 & 1512.5 & 0.64 & 2512.5 & 32.5 & -1250 & 1480 & 0.65 & 433.1 & 85.29 \\
\hline 122.3 & 57.1 & 3197.6 & 1262.5 & 1512.5 & 0.64 & 2712.5 & 22.5 & -1450 & 1490 & 0.68 & 485.1 & 84.82 \\
\hline 121.6 & 61.8 & 3460.8 & 1262.5 & 1512.5 & 0.64 & 2892.5 & 62.5 & -1630 & 1450 & 0.745 & 568.3 & 83.57 \\
\hline 120.9 & 65.9 & 3690.4 & 1262.5 & 1512.5 & 0.64 & 3082.5 & 102.5 & -1820 & 1410 & 0.79 & 607.9 & 83.52 \\
\hline 120.3 & 69.45 & 3889.2 & 1262.5 & 1512.5 & 0.64 & 3212.5 & 142.5 & -1950 & 1370 & 0.82 & 676.7 & 82.60 \\
\hline
\end{tabular}

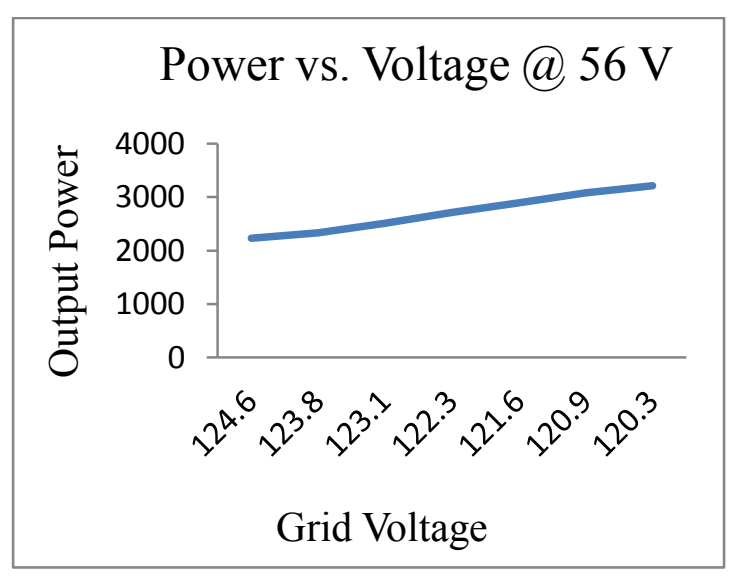

Figure 59. Performance of inverter with inductive load connected to output terminals while selling power to grid at $56 \mathrm{~V} \mathrm{DC}$.

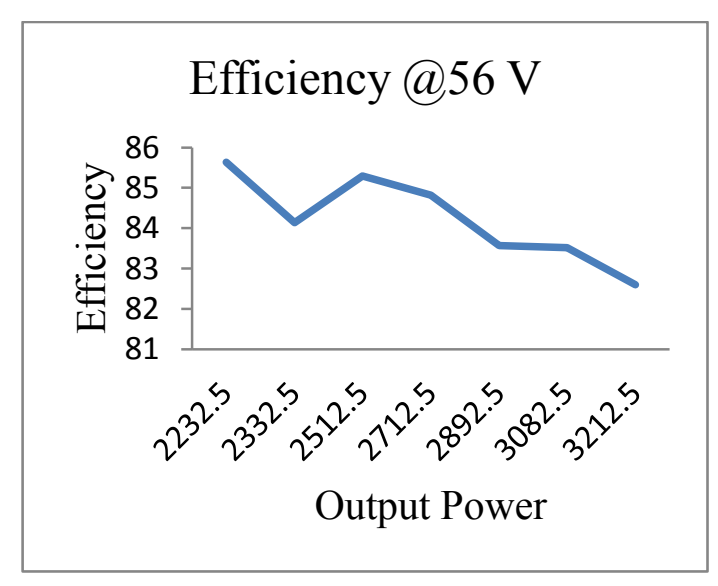

Figure 60. Efficiency of inverter with inductive load connected to output terminals while selling power to grid at $56 \mathrm{~V} \mathrm{DC}$.

\subsection{Transient-State Analysis When Load Connected to Inverter and Grid}

In this condition, load is connected to the load terminals of the inverter and at the node of the grid and inverter. The parameters for this condition are shown in Table 29. Here, $\mathrm{V}_{\mathrm{DC}}$ is the voltage of the inverter on the DC side, $\mathrm{P}_{\mathrm{DC}}$ is the input power of the inverter on the DC side, $\mathrm{V}_{\mathrm{LOAD}}$ is the voltage on the load terminals of the inverter, $\mathrm{P}_{\mathrm{LOAD}}$ is the power supply to the load that is connected to the load terminals of the inverter, $\mathrm{Q}_{\mathrm{LOAD}}$ is the reactive power consumed by the load that is connected to the load terminals of the inverter, $\mathrm{V}_{\mathrm{GRID}}$ is the grid voltage, $\mathrm{P}_{\mathrm{GRID}}$ is the power supplied by the grid, negative (-) indicates the power consumption of the grid, $\mathrm{Q}_{\mathrm{GRID}}$ is 


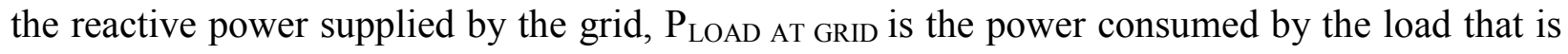
connected at the node of grid and inverter, $\mathrm{Q}_{\text {LOAD AT GRID }}$ is the reactive power consumed by the load that is connected at the node of grid and inverter, and $\mathrm{P}_{\text {INVERTER OUTPUT }}$ is the output power of the inverter.

In this analysis, if a constant DC voltage is maintained and the grid voltage is reduced, then the inverter is pulling more than the rated power from the DC supply, and it is not possible to take more readings at one voltage. When the voltage is $48 \mathrm{~V}$ on the DC side of the inverter, power is being supplied to both the loads and being sold to the grid. At $48 \mathrm{~V}$, output of the inverter is $2025 \mathrm{~W}$ when $\mathrm{AC}$ grid voltage is $122.1 \mathrm{~V}$. Once the grid voltage is reduced, the output of the inverter is increased to $2815 \mathrm{~W}$. From Table 29, it can be seen that when the DC voltage is increasing, then the output power of the inverter is increasing; and when the grid voltage is decreasing, then the output power of the inverter is increasing. The inverter is receiving reactive power from the grid to supply both loads.

TABLE 29

PERFORMANCE OF INVERTER WITH INDUCTIVE LOAD CONNECTED TO OUTPUT TERMINALS AND GRID WHILE SELLING POWER TO GRID AT 48 V DC

\begin{tabular}{|l|l|l|c|l|l|l|l|l|l|c|c|}
\hline $\mathbf{V}_{\text {DC }}$ & \multicolumn{1}{|c|}{$\mathbf{P}_{\text {DC }}$} & $\mathbf{V}_{\text {LOAD }}$ & $\mathbf{P}_{\text {LOAD }}$ & $\mathbf{Q}_{\text {LOAD }}$ & $\mathbf{V}_{\text {GRID }}$ & $\mathbf{P}_{\text {GRID }}$ & $\mathbf{Q}_{\text {GRID }}$ & $\begin{array}{c}\mathbf{P}_{\text {LOAD }} \\
\text { AT GRID }\end{array}$ & $\begin{array}{c}\mathbf{Q}_{\text {LOAD }} \\
\text { AT GRID }\end{array}$ & $\begin{array}{c}\mathbf{P}_{\text {INVERTER }} \\
\text { OUTPUT }\end{array}$ & Efficiency \\
\hline 48 & 2366.4 & 126.8 & 800 & 1175 & 122.1 & -850 & 1520 & 375 & 400 & 2025 & 85.57 \\
\hline 48 & 3223.2 & 126.6 & 1375 & 1175 & 121.8 & -540 & 1460 & 900 & 400 & 2815 & 87.34 \\
\hline 52 & 2652 & 127.7 & 825 & 1200 & 122.3 & -1060 & 1520 & 375 & 400 & 2260 & 85.22 \\
\hline 52 & 3403.4 & 127.1 & 1375 & 1200 & 122 & -720 & 1480 & 900 & 400 & 2995 & 88.00 \\
\hline 56 & 2822.4 & 128.2 & 825 & 1200 & 122.4 & -1170 & 1600 & 375 & 400 & 2370 & 83.97 \\
\hline 56 & 3724 & 128.2 & 1400 & 1200 & 122 & -840 & 1460 & 900 & 400 & 3140 & 84.32 \\
\hline 60 & 3042 & 129.1 & 850 & 1225 & 122.5 & -1320 & 1600 & 400 & 425 & 2570 & 84.48 \\
\hline 60 & 3972 & 129 & 1425 & 1250 & 122.3 & -1000 & 1480 & 925 & 425 & 3350 & 84.34 \\
\hline 64 & 3289.6 & 129.9 & 875 & 1250 & 122.6 & -1500 & 1650 & 400 & 425 & 2775 & 84.36 \\
\hline 68 & 3549.6 & 130.3 & 875 & 1275 & 122.7 & -1700 & 1700 & 400 & 425 & 2975 & 83.81 \\
\hline
\end{tabular}




\subsection{Transient-State Analysis with Voltage Spike}

The purpose of this test was to see how a sudden voltage drop of a few seconds would affect the inverter. The inverter was connected to the programmable DC supply on the DC side terminals and a programmable AC supply to the grid terminals of the inverter. The load terminals of the inverter were kept open, but by using virtual programming software, voltage sags were created on the output voltage of the programmable AC supply. The DC voltage was kept at $50 \mathrm{~V}$ on the programmable DC supply and the inverter was programmed to sell energy.

The inverter started selling energy at a constant rate of $1200 \mathrm{~W}$ per second. The AC voltage on the grid side (output of the programmable AC supply) was $122.2 \mathrm{~V}$. Then a sag in the voltage of $5 \%$ for $100 \mathrm{~ms}$ was created, and no changes occurred in the power flow. The sag voltage was kept at $5 \%$ and the sag period was increased to 5 seconds. Selling power increased to $2500 \mathrm{~W}$ during the sag period, and stopped once the sag period was over, but nothing was disconnected in the loop. After a minute, the inverter began selling power to the grid. Table 30 shows the power sales during the sag period. From the results of this test, it can be concluded that whether the inverter sold power depended on the level and duration of the sag. If the sag voltage was high, it was selling more energy, and if the sag duration was longer, then it was selling more energy. At a high sag voltage and high sag period, the inverter tried to pull more power from the programmable DC supply, and its supply power was limited to $5000 \mathrm{~W}$, so it was disconnected from the system. If the inverter was not selling power under normal conditions, it would not sell any power to the grid during the sag period; however, the inverter would continue to sell more power if it was already selling energy to the grid. If the inverter saw a sudden load change or voltage change, then it stopped selling energy to the grid. It never disconnected from the grid as long as it was not at fault, and it started selling power to the gird after a minute of 
conditions resuming to normal. Table 30 shows the performance of the inverter when there is a voltage sag on the grid.

TABLE 30

PERFORMANCE OF INVERTER DURING VOLTAGE SAG

\begin{tabular}{|c|c|c|c|l|}
\hline $\begin{array}{c}\text { AC } \\
\text { Voltage } \\
(\mathbf{V})\end{array}$ & $\begin{array}{c}\text { Sag/Swell } \\
(\mathbf{\%})\end{array}$ & $\begin{array}{c}\text { Time } \\
(\mathbf{m s})\end{array}$ & $\begin{array}{c}\text { Selling } \\
\text { Power } \\
\mathbf{( W )}\end{array}$ & \multicolumn{1}{|c|}{ Comments } \\
\hline 122.2 & 95 & 100 & 1200 & No change \\
\hline 122.2 & 95 & 5,000 & 1200 & $\begin{array}{l}\text { Power increased to 2500 W during sag } \\
\text { period and stopped selling energy (started } \\
\text { selling after a minute) }\end{array}$ \\
\hline 122.2 & 95 & 50,000 & 1200 & $\begin{array}{l}\text { Power increased to 2500 W during sag } \\
\text { period and stopped selling energy (started } \\
\text { selling after a minute) }\end{array}$ \\
\hline 122.2 & 90 & 5 & 1200 & $\begin{array}{l}\text { Power increased to 1400 W and returned } \\
\text { to 1200 W after sag period and selling } \\
\text { 1200 W }\end{array}$ \\
\hline 122.2 & 80 & 50,000 & 1200 & $\begin{array}{l}\text { Power increased to 3100 W during sag } \\
\text { period and stopped selling energy (started } \\
\text { selling after a few minutes) }\end{array}$ \\
\hline 122.2 & 85 & 5,000 & 1200 & $\begin{array}{l}\text { Power increased to 1400 W and returned } \\
\text { to 1200 W after sag period and selling } \\
\text { 1200 W }\end{array}$ \\
\hline 122 & 50,000 & $\begin{array}{l}\text { Selling power reached 3200 W and } \\
\text { supplied almost 5 seconds and then } \\
\text { became zero }\end{array}$ \\
\hline
\end{tabular}

Table 31 shows the performance of the inverter when connected to the load terminals and selling energy to the grid. As can be seen, when the voltage reached $95 \%$ of grid voltage, the duration of the sag was only $5 \mathrm{~ms}$; in that condition, the inverter did not notice the sag and continued selling $900 \mathrm{~W}$ of power to the grid and supplying $575 \mathrm{~W}$ of power to the load. When the sag period increased to $50 \mathrm{~ms}$ with the same sag voltage, then the selling power increased to 
$1000 \mathrm{~W}$ during the sag period. If the sag period increased to $500 \mathrm{~ms}$ with the same sag voltage (95\%), then the selling power increased to $1100 \mathrm{~W}$ during the sag period and returned to $900 \mathrm{~W}$. When the sag period was $5000 \mathrm{~ms}$ and sag voltage was $95 \%$ of normal grid voltage, then selling power increased to $2000 \mathrm{~W}$ during the sag period, and selling power stopped after the sag period was over but power was still being supplied to the load. When the sag period was $2000 \mathrm{~ms}$ and sag voltage was $90 \%$ of normal grid voltage, the inverter increased selling power from $900 \mathrm{~W}$ to $2000 \mathrm{~W}$ and stopped selling power once the voltage returned to normal, and the inverter started buying power from the grid to supply power to the load. A few minutes later, the inverter started selling power to the grid. When the sag period was $2000 \mathrm{~ms}$ and the sag voltage was $85 \%$ of normal grid voltage, the inverter increased selling power to $3000 \mathrm{~W}$ for a moment, but the DC supply was unable to provide that much power, so the inverter stopped supplying power to the inverter and started buying power from the grid. When the sag period was $1 \mathrm{~ms}$ and the sag voltage was $80 \%$ of normal grid voltage, the programmable DC supply give an error signal, because the inverter might try to pull more power than what the DC power supply could supply, so the inverter started buying energy from the grid to supply the load. Once the error on the DC supply was cleared, the inverter immediately started supplying power to the load and selling power to the grid. From Table 31, it can be seen that as sag voltage increased on the grid, selling power increased, and as the sag period increased, selling power also increased. During this test, the inverter always supplied power to the load, either from the DC source or from the grid. 
TABLE 31

PERFORMANCE OF INVERTER DURING VOLTAGE SAG WITH LOAD CONNECTED TO OUPUT TERMINALS WHILE SELLING POWER TO GRID

\begin{tabular}{|c|c|c|c|c|c|}
\hline $\begin{array}{c}\text { AC } \\
\text { Voltage } \\
\text { (V) }\end{array}$ & $\begin{array}{l}\text { Sag/Swell } \\
(\%)\end{array}$ & $\begin{array}{c}\text { Time } \\
(\mathrm{ms})\end{array}$ & $\begin{array}{c}\text { Load } \\
\text { Power }(W)\end{array}$ & $\begin{array}{c}\text { Selling } \\
\text { Power } \\
\text { (W) }\end{array}$ & Comments \\
\hline 124.9 & 95 & 5 & 575 & 900 & No change \\
\hline 124.9 & 95 & 50 & 575 & 900 & $\begin{array}{l}\text { Selling power increased to } 1000 \mathrm{~W} \\
\text { during sag period }\end{array}$ \\
\hline 124.9 & 95 & 500 & 575 & 900 & $\begin{array}{l}\text { Selling power increased to } 1100 \mathrm{~W} \\
\text { during sag period }\end{array}$ \\
\hline 124.9 & 95 & 1000 & 575 & 900 & $\begin{array}{l}\text { Selling power increased to } 1300 \mathrm{~W} \\
\text { during sag period }\end{array}$ \\
\hline 124.9 & 95 & 2000 & 575 & 900 & $\begin{array}{l}\text { Selling power increased to } 1900 \mathrm{~W} \\
\text { during sag period }\end{array}$ \\
\hline 124.9 & 95 & 5000 & 575 & 900 & $\begin{array}{l}\text { Selling power increased to } 2000 \mathrm{~W} \\
\text { during sag period and disconnected } \\
\text { once it returned to normal voltage; } \\
\text { after a minute, it started selling } \\
\text { energy; during this period, inverter } \\
\text { still supplying energy to load }\end{array}$ \\
\hline 124.7 & 90 & 5 & 575 & 900 & $\begin{array}{l}\text { Selling power increased to } 100 \mathrm{~W} \\
\text { during sag period }\end{array}$ \\
\hline 124.7 & 90 & 50 & 575 & 900 & $\begin{array}{l}\text { Selling power increased to } 1000 \mathrm{~W} \\
\text { during sag period }\end{array}$ \\
\hline 124.7 & 90 & 500 & 575 & 900 & $\begin{array}{l}\text { Selling power increased to } 1700 \mathrm{~W} \\
\text { during sag period }\end{array}$ \\
\hline 124.7 & 90 & 1000 & 575 & 900 & $\begin{array}{l}\text { Selling power increased to } 2100 \mathrm{~W} \\
\text { during sag period }\end{array}$ \\
\hline 124.7 & 90 & 2000 & 575 & 900 & $\begin{array}{l}\text { Selling power increased to } 2600 \mathrm{~W} \\
\text { during sag period and stopped after } \\
\text { voltage returned to normal; then } \\
\text { started buying power from grid; it } \\
\text { took awhile to sell back power }\end{array}$ \\
\hline 124.7 & 85 & 5 & 575 & 900 & $\begin{array}{l}\text { Selling power increased to } 1100 \mathrm{~W} \\
\text { during sag period }\end{array}$ \\
\hline 124.7 & 85 & 50 & 575 & 900 & $\begin{array}{l}\text { Selling power increased to } 1200 \mathrm{~W} \\
\text { during sag period }\end{array}$ \\
\hline 124.7 & 85 & 500 & 575 & 900 & $\begin{array}{l}\text { Selling power increased to } 1800 \mathrm{~W} \\
\text { during sag period }\end{array}$ \\
\hline 124.7 & 85 & 1000 & 575 & 900 & $\begin{array}{l}\text { Selling power increased to } 2300 \mathrm{~W} \\
\text { during sag period }\end{array}$ \\
\hline
\end{tabular}


Table 31 continued

\begin{tabular}{|c|c|c|c|c|l|}
\hline 124.7 & $85 \%$ & 2000 & 575 & 900 & $\begin{array}{l}\text { Selling power increased to 3000 W } \\
\text { during sag period but DC supply } \\
\text { unable to provide that power so was } \\
\text { disconnected, and inverter started } \\
\text { buying energy from grid }\end{array}$ \\
\hline 124.7 & 80 & 1 & 575 & 900 & $\begin{array}{l}\text { Programmable DC supply give an } \\
\text { error signal during period inverter } \\
\text { started buying power from grid; } \\
\text { once error in DC supply cleared, } \\
\text { inverter started selling energy } \\
\text { immediately }\end{array}$ \\
\hline
\end{tabular}

From the transient-state analysis results, it can be concluded that the power injection to the grid from the inverter not only depended on the DC voltage (energy available on DC side of inverter) but also depended on the grid voltage. If grid voltage was decreasing, the energy supplied by the inverter was also increasing. The inverter always maintained a power supply to the load, even if there were faults on the grid. If there was a voltage sag on the grid, then the inverter supplied more power to the grid to maintain a continuous power supply. Once the grid voltage was lower than $80 \%$, the inverter did not supply power to the grid and automatically disconnected from the grid since the grid voltage was out of range. 


\section{CHAPTER 6}

\section{MATHEMATICAL ANALYSIS}

\subsection{Active Power Relation}

From the transient-state test results, it can be concluded that when grid voltage decreased, the power supplied by the inverter increased, and a higher DC voltage meant that energy was available on the DC side was higher and the selling power from the inverter to grid was also higher. If the grid was connected to the inverter, the inverter was not supplying any reactive power, but it was receiving a small amount of reactive power from the grid for its needs.

Tables 19 to 25 show the transient-state test results of the inverter when an inductive load was connected to the node where the grid and inverter were connected together and the grid terminals were connected to the grid. When grid voltage was decreasing, the power supply from the inverter was increasing. From these results, the power supplied by the inverter not only depended on energy available on the DC side but also depended on grid voltage. The power flow during these tests can be written as equations (1) and (2).

$$
\begin{aligned}
& \text { Active power supplied to the inverter + power supply to grid } \\
& =\text { Active power consumed by the load + losses in the inverter }
\end{aligned}
$$

\section{Active Power supplied to the inverter (input) \\ $=$ Output of the inverter + losses in the inverter}

From the transient-state test results, the reactive power consumed by the inverter varied between $70 \mathrm{VAR}$ and $260 \mathrm{VAR}$, which is not much variation when compared to the active power; therefore, this was taken as a constant reactive power. Relative to active power with the grid voltage drops, the power supplied by the inverter to the grid was increasing. 
Reactive power supplied by the source $=$ Reactive power consumed in the load

Power supplied by the source $=$ power consumed by the load - Power supply from grid + losses

$$
\begin{gathered}
P_{D C}=P_{L O A D}-P_{G R I D}+P_{\text {LOSSES }} \\
P_{D C}=P_{\text {INVERTER }}+P_{\text {LOSSES }}
\end{gathered}
$$

Here, negative (-) indicates that the grid is consuming power instead of supplying power.

where

$\mathrm{P}_{\mathrm{DC}}=$ power supplied by the DC source

$\mathrm{P}_{\mathrm{LOAD}}=$ power consumed by the load

$\mathrm{P}_{\mathrm{GRID}}=$ power supplied from the gird

$\mathrm{P}_{\text {LOSSES }}=$ power losses in the inverter

$\mathrm{P}_{\mathrm{INVERTER}}=$ output of the inverter

Equation (4) can be rewritten in terms of voltage and current power factor:

$$
V_{D C} I_{D C}=V_{L} I_{L} \cos \theta_{L}-V_{P H} I_{P H} \cos \theta_{P H}+\left(I_{L}+I_{P H}\right)^{2} R_{L}
$$

where

$$
\begin{aligned}
& V_{D C}=D C \text { voltage supplied to the inverter } \\
& I_{D C}=\text { DC current supplied to the inverter } \\
& V_{L}=A C \text { load voltage } \\
& V_{P H}=\text { AC grid voltage } \\
& I_{L}=\text { load current } \\
& I_{P H}=A C \text { grid current } \\
& \operatorname{Cos} \theta_{L}=\text { load power factor } \\
& \operatorname{Cos} \theta_{P H}=\text { grid power factor } \\
& R_{L}=\text { equivalent resistance of the inverter }
\end{aligned}
$$




\subsection{Regression Analysis}

When the AC grid voltage dropped $\left(\mathrm{V}_{\mathrm{PH}}\right)$, the power supplied by the inverter to the grid was increasing, which means that the AC grid current $\left(\mathrm{I}_{\mathrm{PH}}\right)$ supplied to the grid was increasing. Since active power supplied to the grid was increasing by a large amount, reactive power was not changing much, and the power factor of the grid was increasing. Since $\mathrm{I}_{\mathrm{PH}}$ was increasing, the power losses in the inverter were also increasing. While taking the readings, the load was kept constant, but there was a small drop in the load power. When the grid voltage dropped, this factor was not considered and the load power was taken as a constant power. $\mathrm{V}_{\mathrm{DC}}$ was constant since constant voltage was maintained on the DC side, and $\mathrm{I}_{\mathrm{DC}}$ was increasing with the decrease in $\mathrm{V}_{\mathrm{PH}}$. Therefore, if $\mathrm{V}_{\mathrm{PH}}$ decreased and $\mathrm{I}_{\mathrm{PH}}$ increased, then $\cos \theta_{\mathrm{PH}}$ increased and inverter losses also increased.

The grid power and losses in terms of grid voltage can be written as equations (7) and (8):

$$
\begin{gathered}
\mathrm{P}_{\mathrm{DC}}=\mathrm{P}_{\mathrm{LOAD}}-\left(\mathrm{A}+\mathrm{BV}_{\mathrm{PH}}\right)+\left(\mathrm{C}+\mathrm{DV}_{\mathrm{PH}}\right) \\
\mathrm{P}_{\mathrm{DC}}=\left(\mathrm{E}+\mathrm{FV}_{\mathrm{PH}}\right)+\left(\mathrm{G}+\mathrm{HV}_{\mathrm{PH}}\right)
\end{gathered}
$$

where A, C, E, and $\mathrm{G}$ are constants (intercepts) from the regression analysis, and B, D, F, and $\mathrm{H}$ are coefficients (variables of $\mathrm{V}_{\mathrm{PH}}$ ) for the grid voltage from the regression analysis.

The results show a nonlinear relation between the output power of the inverter to the grid voltage drops, so to linearize the relation between them, regression analysis was used. To minimize the error between the real values and regression analysis values, results of the $44 \mathrm{~V}$ and $68 \mathrm{~V}$ transient-state analyses were not considered, and average value of the remaining results of the transient-state analysis (from Tables 20 to 24) were used instead. 
To obtain the intercepts and variables, first, the output powers of the inverter (from Tables 20 to 24$)$ were added and then averaged. The average value of the grid voltage $\left(\mathrm{V}_{\mathrm{RMS}}\right.$ with load and inverter) from Tables 20 to 24 was also calculated. Regression analysis was used to find $\mathrm{A}$ and $\mathrm{E}$ (intercepts) and $\mathrm{B}$ and $\mathrm{F}$ (coefficients). To find $\mathrm{C}$ and $\mathrm{G}$ (intercept) and $\mathrm{D}$ and $\mathrm{H}$ (coefficients), losses in the inverter, from Tables 20 to 24, were added at each interval and then averaged. Then regression analysis was performed on the losses and the grid voltage. The error between the real values and the regression analysis values was less than $20 \%$.

Table 32 shows the average values of the grid voltage, output power of the inverter, and power losses of the inverter when the inverter was selling power to the grid and supplying power to the load that was directly connected to the grid. These average values are taken from Tables 20 to 24 .

TABLE 32

AVERAGE VALUES OF GRID VOLTAGE, OUTPUT POWER OF INVERTER

\begin{tabular}{|c|c|c|}
\hline $\begin{array}{c}\text { Average } \\
\text { Grid Voltage }\end{array}$ & $\begin{array}{c}\text { Average } \\
\text { Output Power }\end{array}$ & $\begin{array}{c}\text { Average } \\
\text { Power Losses }\end{array}$ \\
\hline 123.42 & 1400 & 273.6 \\
\hline 122.54 & 1654 & 321.36 \\
\hline 121.58 & 1904 & 389.4 \\
\hline 120.74 & 2102 & 466.12 \\
\hline 120.1 & 2238 & 492.52 \\
\hline 119.5 & 2325 & 522.25 \\
\hline 118.97 & 2358.33 & 561.33 \\
\hline 117.85 & 2550 & 598.5 \\
\hline
\end{tabular}

Regression analysis from the transient-state analysis yielded equations (9) and (10):

$$
\begin{gathered}
\mathrm{P}_{\mathrm{DC}}=\left(26843.84-205.47 \mathrm{~V}_{\mathrm{PH}}\right)+\left(7844.99-61.29 \mathrm{~V}_{\mathrm{PH}}\right) \\
\text { Output of Inverter }=26843.84-205.47 \mathrm{~V}_{\mathrm{PH}}
\end{gathered}
$$


Chapter 7 shows the results of voltage drops across each node when $5 \%$ or $10 \%$ of distributed energy resources were connected to the IEEE 13-bus system. Active power injection at each voltage drop was determined by equation (10), and equation (10) was derived from the regression analysis of real data obtained in the laboratory. 


\section{CHAPTER 7}

\section{RESULTS OF DISTRIBUTION SYSTEM SIMULATOR}

\subsection{Simulation Results}

It was assumed that a $5 \%$ distribution system and a $10 \%$ distribution system of power sources were available through the inverter at bus 680 . This bus was randomly chosen.

Table 33 shows the voltage drop at each node phase of the 13-bus system without distributed energy resources. At $123.4 \mathrm{~V}$ of grid voltage, bus 675 had the lowest voltage on Phases A and B, and the highest voltage on Phase C, compared with all other buses. As the grid voltage decreased, the voltage on each phase of the bus also decreased until the grid voltage reached $120.7 \mathrm{~V}$; then the voltage increased at each phase of the bus. The grid voltage even decreased because the capacitors started to inject reactive power once the grid voltage reached a certain level. At $117.85 \mathrm{~V}$ of grid voltage, the voltage of each node phase decreased because the capacitors were no longer injecting reactive power into the 13-bus system.

TABLE 33

VOLTAGE DROP OF EACH PHASE OF 13-BUS SYSTEM DURING VOLTAGE SAG WITH NO DISTRIBUTED ENERGY RESOURCES

\begin{tabular}{|c|c|c|c|c|}
\hline Phase & Node 650 & Node 680 & $\begin{array}{c}\text { Power Supply } \\
\text { from Grid }\end{array}$ & Losses \\
\hline A & 123.4 & 119.2 & & \\
B & 123.4 & 123.5 & 3551 & 116 \\
C & 123.4 & 115.5 & & \\
\hline A & 122.5 & 119.1 & & 116 \\
B & 122.5 & 123.4 & 3550 & \\
C & 122.5 & 115.4 & & 116 \\
\hline A & 121.6 & 118.94 & & \\
B & 121.6 & 123.2 & 3549 & 116 \\
C & 121.6 & 115.24 & & \\
\hline A & 120.7 & 118.89 & & \\
B & 120.7 & 123.15 & 3549 & \\
C & 120.7 & 115.2 & & \\
\hline
\end{tabular}




\begin{tabular}{|c|c|c|c|c|}
\hline Phase & Node 650 & Node 680 & $\begin{array}{c}\text { Power Supply } \\
\text { from Grid }\end{array}$ & Losses \\
\hline A & 120.1 & 119.07 & & \\
B & 120.1 & 123.3 & 3550 & 116 \\
C & 120.1 & 115.4 & & \\
\hline A & 119.5 & 119.3 & & 116 \\
B & 119.5 & 123.5 & 3552 & \\
C & 119.5 & 115.6 & & 115 \\
A & 118.97 & 119.61 & & \\
B & 118.97 & 123.81 & 3554 & 116 \\
C & 118.97 & 115.96 & & \\
\hline A & 117.85 & 119.25 & & \\
B & 117.85 & 123.44 & 3552 & \\
C & 117.85 & 115.59 & & \\
\hline \multicolumn{5}{|l}{}
\end{tabular}

Table 34 shows voltage drops at the source (SRC 1) and the node where the DR was connected to the 13-bus system when 5\% of the DR was connected to the 13-bus system and grid voltage was $123.42 \mathrm{~V}$. Even when the DR was $5 \%(180 \mathrm{KW})$ of the rating of the 13-bus system, it was unable to supply all $180 \mathrm{KW}$ of power. The power supply from the DR depended on the voltage of the phase of the bus where it was connected. Phase A voltage without DR was 119.2 V. According to this voltage, when a DR was connected to it, then it would inject $109.68 \mathrm{KW}$ of power. This value was found after three iterations. Following power injection from the DR to the 13-bus system, the voltage at Phases A and C increased and the voltage at Phase B decreased. When the DR was connected to Phase C at the same node, the DR was injecting $144.92 \mathrm{KW}$ of power into the 13-bus system because of the very low voltage on Phase C at bus 680 . Highlighted values in Tables 34 to 39 are the final values after a number of iterations after the DR system supplied energy to the 13-bus system. 
TABLE 34

VOLTAGE DROP OF GRID WHEN 5\% OF DR SUPPLYING POWER AT BUS 680

\begin{tabular}{|c|c|c|c|c|c|}
\hline Phase & $\begin{array}{c}\text { SRC 1 } \\
\text { Node 650 }\end{array}$ & Node 680 & $\begin{array}{c}\text { Power } \\
\text { Supply } \\
\text { from Grid }\end{array}$ & Losses & $\begin{array}{c}\text { DR } \\
\text { (KW) }\end{array}$ \\
\hline A & 123.42 & 119.2 & & & 0 \\
B & 123.42 & 123.5 & 3551 & 116 & 0 \\
C & 123.42 & 115.5 & & & 0 \\
\hline A & 123.42 & 120.02 & & & 117.59 \\
B & 123.42 & 122.5 & 3428.00 & 109.00 & 0 \\
C & 123.42 & 116.14 & & & 0 \\
\hline A & 123.42 & 119.96 & & & 109.17 \\
B & 123.42 & 122.60 & 3437.00 & 109.00 & 0 \\
C & 123.42 & 116.09 & & & 0 \\
\hline A & 123.42 & 119.97 & & & 109.78 \\
B & 123.42 & 122.56 & 3436.00 & 109.00 & 0 \\
C & 123.42 & 116.09 & & & 0 \\
\hline A & 123.42 & 119.97 & & & 109.68 \\
B & 123.42 & 122.56 & 3436.00 & 109.00 & 0 \\
C & 123.42 & 116.09 & & & 0 \\
\hline A & 123.42 & 117.84 & & & 0 \\
B & 123.42 & 124.37 & 3388.00 & 109.00 & 0 \\
C & 123.42 & 116.61 & & & 155.60 \\
\hline A & 123.42 & 117.94 & & & 0 \\
B & 123.42 & 124.30 & 3400.00 & 109.00 & 0 \\
C & 123.42 & 116.54 & & & 144.20 \\
\hline A & 123.42 & 117.93 & & & 0 \\
B & 123.42 & 124.31 & 3399.00 & 109.00 & 0 \\
C & 123.42 & 116.54 & & & 144.92 \\
\hline & & & & & \\
\hline
\end{tabular}

Table 35 shows the voltage drops of each phase of a 13-bus system when $10 \%$ (360 KW) of the DR was connected to it at bus 680 and the supply voltage was $123.42 \mathrm{~V}$. When connected to Phase A at node 680, $206.42 \mathrm{KW}$ of power was supplied to the 13-bus system, and Phase A voltage at node 680 was raised from $119.2 \mathrm{~V}$ to $120.6 \mathrm{~V}$, Phase $\mathrm{C}$ voltage was raised from 115.5 $\mathrm{V}$ to $116.63 \mathrm{~V}$; on the other hand, Phase B voltage dropped from $123.50 \mathrm{~V}$ to $121.77 \mathrm{~V}$. Phase A and Phase $\mathrm{C}$ voltages were raised at each node, not just at node 680, and Phase $\mathrm{B}$ voltage dropped at each node. 
TABLE 35

VOLTAGE DROP OF GRID WHEN 10\% OF DR SUPPLYING POWER AT BUS 680 AND GIRD VOLTAGE IS $123.42 \mathrm{~V}$

\begin{tabular}{|c|c|c|c|c|c|}
\hline Phase & $\begin{array}{c}\text { SRC 1 } \\
\text { Node } 650\end{array}$ & Node 680 & $\begin{array}{c}\text { Power } \\
\text { Supply } \\
\text { from Grid }\end{array}$ & Losses & $\begin{array}{c}\mathrm{DR} \text { in } \\
\mathrm{KW}\end{array}$ \\
\hline $\mathrm{A}$ & 123.42 & 119.2 & \multirow{3}{*}{3551} & \multirow{3}{*}{116} & 0 \\
\hline B & 123.42 & 123.5 & & & 0 \\
\hline $\mathrm{C}$ & 123.42 & 115.5 & & & 0 \\
\hline A & 123.42 & 120.78 & \multirow{3}{*}{3307} & \multirow{3}{*}{103} & 235.18 \\
\hline B & 123.42 & 121.53 & & & 0 \\
\hline $\mathrm{C}$ & 123.42 & 116.80 & & & 0 \\
\hline A & 123.42 & 120.58 & \multirow{3}{*}{3340} & \multirow{3}{*}{104} & 202.72 \\
\hline B & 123.42 & 121.80 & & & 0 \\
\hline $\mathrm{C}$ & 123.42 & 116.61 & & & 0 \\
\hline $\mathrm{A}$ & 123.42 & 120.60 & \multirow{3}{*}{3336} & \multirow{3}{*}{104} & 206.83 \\
\hline B & 123.42 & 121.76 & & & 0 \\
\hline $\mathrm{C}$ & 123.42 & 116.64 & & & 0 \\
\hline A & 123.42 & 120.60 & \multirow{3}{*}{3337} & \multirow{3}{*}{104} & 206.42 \\
\hline B & 123.42 & 121.77 & & & 0 \\
\hline $\mathrm{C}$ & 123.42 & 116.63 & & & 0 \\
\hline $\mathrm{A}$ & 123.42 & 116.52 & \multirow{3}{*}{3228} & \multirow{3}{*}{104} & 0 \\
\hline B & 123.42 & 125.31 & & & 0 \\
\hline $\mathrm{C}$ & 123.42 & 117.62 & & & 311.21 \\
\hline $\mathrm{A}$ & 123.42 & 116.88 & \multirow{3}{*}{3272} & \multirow{3}{*}{105} & 0 \\
\hline B & 123.42 & 125.04 & & & 0 \\
\hline $\mathrm{C}$ & 123.42 & 117.35 & & & 267.65 \\
\hline $\mathrm{A}$ & 123.42 & 116.84 & \multirow{3}{*}{3267} & \multirow{3}{*}{105} & 0 \\
\hline B & 123.42 & 125.08 & & & 0 \\
\hline $\mathrm{C}$ & 123.42 & 117.39 & & & 273.19 \\
\hline $\mathrm{A}$ & 123.42 & 116.84 & \multirow{3}{*}{3268} & \multirow{3}{*}{105} & 0 \\
\hline B & 123.42 & 125.07 & & & 0 \\
\hline $\mathrm{C}$ & 123.42 & 117.38 & & & 272.37 \\
\hline A & 123.42 & 116.84 & \multirow{3}{*}{3267} & \multirow{3}{*}{105} & 0 \\
\hline B & 123.42 & 125.07 & & & 0 \\
\hline $\mathrm{C}$ & 123.42 & 117.38 & & & 272.58 \\
\hline
\end{tabular}

Table 36 shows the voltage drops on each phase at each node of a 13-bus system when $5 \%$ $(180 \mathrm{KW})$ of the DR was connected to it at bus 680 and the supply voltage was $120.10 \mathrm{~V}$. When there was no DR connected to any one of the nodes in the 13-bus system, Phase A voltage at node 680 was $119.07 \mathrm{~V}$, Phase B voltage was $123.3 \mathrm{~V}$, and Phase C voltage was $115.4 \mathrm{~V}$. If the 
DR was connected to Phase A at node 680, according to calculations, it would require 118.93 KW of active power. After this DR power input, the voltages at each phase and each node would change, and the active power supply from the DR would also change. Following a few iterations, the output from the DR system settled down at $110.91 \mathrm{KW}$. The same steps were repeated by connecting the DR at Phase $\mathrm{C}$ on the same bus. According to calculations, the output power from the DR settled at $145.95 \mathrm{KW}$.

TABLE 36

VOLTAGE DROP OF GRID WHEN 5\% OF DR SUPPLYING POWER AT BUS 680 AND GRID VOLTAGE IS $120.10 \mathrm{~V}$

\begin{tabular}{|c|c|c|c|c|c|}
\hline Phase & $\begin{array}{c}\text { SRC } 1 \\
\text { Node } 650\end{array}$ & $\begin{array}{l}\text { Node } \\
680\end{array}$ & $\begin{array}{c}\text { Power } \\
\text { Supply } \\
\text { from Grid }\end{array}$ & Losses & $\begin{array}{c}\text { DR } \\
(\mathbf{K W})\end{array}$ \\
\hline $\begin{array}{l}\text { A } \\
\text { B } \\
\text { C }\end{array}$ & $\begin{array}{l}120.1 \\
120.1 \\
120.1\end{array}$ & $\begin{array}{l}119.07 \\
123.3 \\
115.4\end{array}$ & 3550 & 116 & $\begin{array}{l}0 \\
0 \\
0\end{array}$ \\
\hline $\begin{array}{l}\text { A } \\
\text { B } \\
\text { C }\end{array}$ & $\begin{array}{l}120.10 \\
120.10 \\
120.10\end{array}$ & $\begin{array}{l}119.90 \\
122.31 \\
116.03\end{array}$ & 3426 & 109 & $\begin{array}{c}118.93 \\
0 \\
0\end{array}$ \\
\hline $\begin{array}{l}\text { A } \\
\text { B } \\
\text { C }\end{array}$ & $\begin{array}{l}120.10 \\
120.10 \\
120.10\end{array}$ & $\begin{array}{l}119.85 \\
122.39 \\
115.99\end{array}$ & 3435 & 109 & $\begin{array}{c}110.40 \\
0 \\
0\end{array}$ \\
\hline $\begin{array}{l}\text { A } \\
\text { B } \\
\text { C }\end{array}$ & $\begin{array}{l}120.10 \\
120.10 \\
120.10\end{array}$ & $\begin{array}{l}119.85 \\
122.39 \\
115.99\end{array}$ & 3434 & 109 & $\begin{array}{c}110.91 \\
0 \\
0\end{array}$ \\
\hline $\begin{array}{l}\text { A } \\
\text { B } \\
\text { C }\end{array}$ & $\begin{array}{l}120.10 \\
120.10 \\
120.10\end{array}$ & $\begin{array}{l}117.70 \\
124.21 \\
116.51\end{array}$ & 3386 & 109 & $\begin{array}{c}0 \\
0 \\
153.63\end{array}$ \\
\hline $\begin{array}{l}\text { A } \\
\text { B } \\
\text { C }\end{array}$ & $\begin{array}{l}120.10 \\
120.10 \\
120.10\end{array}$ & $\begin{array}{l}117.80 \\
124.14 \\
116.44\end{array}$ & 3398 & 109 & $\begin{array}{c}0 \\
0 \\
145.23\end{array}$ \\
\hline $\begin{array}{l}A \\
B \\
C\end{array}$ & $\begin{array}{l}120.10 \\
120.10 \\
120.10\end{array}$ & $\begin{array}{l}117.80 \\
124.15 \\
116.44\end{array}$ & 3397 & 109 & $\begin{array}{c}0 \\
0 \\
145.95\end{array}$ \\
\hline
\end{tabular}

Table 37 shows the voltage drops on each phase at each node of a 13-bus system when $10 \%(360 \mathrm{KW})$ of the DR was connected to it at bus 680 and the supply voltage was $120.10 \mathrm{~V}$. 
When the DR was not connected to any one of the nodes in the 13-bus system, Phase A voltage at node 680 was $120.67 \mathrm{~V}$, Phase B voltage was $121.34 \mathrm{~V}$, and Phase C voltage was $115.4 \mathrm{~V}$. If the DR was connected to Phase A at node 680, according to calculations, it would take 237.85 KW of active power. After this DR power input, the voltages at each phase and each node would change so the active power supply from the DR would also change. After a few iterations, the output from the DR settled down at $208.68 \mathrm{KW}$. The same steps were repeated by connecting the DR system at Phase $\mathrm{C}$ on the same bus, but according to calculations, the output power from the DR settled at $274.43 \mathrm{KW}$.

TABLE 37

VOLTAGE DROP OF GRID WHEN 10\% OF DR SUPPLYING POWER AT BUS 680 AND GRID VOLTAGE IS $120.10 \mathrm{~V}$

\begin{tabular}{|c|c|c|c|c|c|}
\hline Phase & $\begin{array}{c}\text { SRC 1 } \\
\text { Node 650 }\end{array}$ & $\begin{array}{c}\text { Node } \\
\mathbf{6 8 0}\end{array}$ & $\begin{array}{c}\text { Power } \\
\text { Supply } \\
\text { from Grid }\end{array}$ & Losses & $\begin{array}{c}\text { DR } \\
\text { (KW) }\end{array}$ \\
\hline A & 120.10 & 120.67 & & & 237.85 \\
B & 120.10 & 121.34 & 3303 & 103 & 0 \\
C & 120.10 & 116.71 & & & 0 \\
\hline A & 120.10 & 120.47 & & 104 & 204.98 \\
B & 120.10 & 121.61 & 3307 & & 0 \\
C & 120.10 & 116.52 & & & 0 \\
\hline A & 120.10 & 120.49 & 3333 & & 209.09 \\
B & 120.10 & 121.57 & & & 0 \\
C & 120.10 & 116.54 & & & 0 \\
\hline A & 120.10 & 120.49 & & 104 & 0 \\
B & 120.10 & 121.57 & 3333 & & 0 \\
C & 120.10 & 116.54 & & & 0 \\
\hline A & 120.10 & 116.37 & & & 0 \\
B & 120.10 & 125.15 & 3225 & 104 & 313.26 \\
C & 120.10 & 117.53 & & & 0 \\
\hline A & 120.10 & 116.69 & & & 0 \\
B & 120.10 & 124.92 & 3264 & 105 & 275.04 \\
C & 120.10 & 117.29 & & & 0 \\
\hline A & 120.10 & 116.69 & & & 0 \\
B & 120.10 & 124.92 & 3265 & 105 & 274.43 \\
C & 120.10 & 117.29 & & & \\
\hline
\end{tabular}


Table 38 shows the voltage drops on each phase at each node of a 13-bus system when $5 \%(180 \mathrm{KW})$ of a DR was connected to it at bus 680 and the supply voltage was $117.85 \mathrm{~V}$. With no DR connected to any one of the nodes in the 13-bus system, Phase A voltage at node 680 was 119.25 V, Phase B voltage was 123.49 V, and Phase C voltage was 115.59 V. If the DR was connected to Phase A at node 680, according to calculations, it would require $117.08 \mathrm{KW}$ of active power. After DR power input, the voltages at each phase and each node would change so an active power supply from the DR would also change. After a few iterations, the output from the DR settled down at 109.27 KW. The same steps were repeated by connecting the DR system at Phase $\mathrm{C}$ on the same bus. According to calculations, the output power from the DR settled at $144.20 \mathrm{KW}$.

TABLE 38

VOLTAGE DROP OF GRID WHEN 5\% OF DR SUPPLYING POWER AT BUS 680 AND GRID VOLTAGE IS $117.85 \mathrm{~V}$

\begin{tabular}{|c|c|c|c|c|c|}
\hline Phase & $\begin{array}{c}\text { SRC 1 } \\
\text { Node 650 }\end{array}$ & $\begin{array}{c}\text { Node } \\
\mathbf{6 8 0}\end{array}$ & $\begin{array}{c}\text { Power } \\
\text { Supply } \\
\text { from Grid }\end{array}$ & Losses & $\begin{array}{c}\text { DR } \\
\text { (KW) }\end{array}$ \\
\hline A & 117.85 & 119.25 & & 116 & 0 \\
B & 117.85 & 123.44 & 3552 & 0 \\
C & 117.85 & 115.59 & & & 0 \\
\hline A & 117.85 & 120.06 & & & 117.08 \\
B & 117.85 & 122.47 & 3430 & 109 & 0 \\
C & 117.85 & 116.22 & & & 0 \\
\hline A & 117.85 & 120.01 & & & 108.76 \\
B & 117.85 & 122.53 & 3438 & 109 & 0 \\
C & 117.85 & 116.18 & & & 0 \\
\hline A & 117.85 & 120.01 & & & 109.27 \\
B & 117.85 & 122.53 & 3438 & 109 & 0 \\
C & 117.85 & 116.18 & & & 0 \\
\hline A & 117.85 & 117.89 & & & 0 \\
B & 117.85 & 124.33 & 3389 & 109 & 0 \\
C & 117.85 & 116.70 & & & 154.68 \\
\hline A & 117.85 & 117.99 & & & 0 \\
B & 117.85 & 124.26 & 3401 & 109 & 0 \\
C & 117.85 & 116.62 & & & 144.20 \\
\hline
\end{tabular}


Table 39 shows the voltage drops on each phase at each node of a 13 bus system when $10 \%$ (360 KW) of the DR is connected to it at bus-680 and the supply voltage is $117.85 \mathrm{~V}$. When the DR was not connected to any nodes in the 13-bus system, the Phase A voltage at node 680 was 119.25 V, Phase B voltage was $123.44 \mathrm{~V}$, and Phase C voltage was 115.59 volts. If the DR was connected to Phase A at node 680 , according to calculations, it would take $234.15 \mathrm{KW}$ of active power. After the DR power input, voltages at each phase and each node would change, so the active power supply from the DR would also change. After a few iterations, the output from the DR system settled down at $206.00 \mathrm{KW}$. The same steps were repeated by connecting the DR system at Phase $\mathrm{C}$ on the same bus. According to calculations, the output power from the DR settled at $270.73 \mathrm{KW}$.

TABLE 39

VOLTAGE DROP OF GRID WHEN 10\% OF DR SUPPLYING POWER AT BUS 680 AND GRID VOLTAGE IS $117.85 \mathrm{~V}$

\begin{tabular}{|c|c|c|c|c|c|}
\hline Phase & $\begin{array}{c}\text { SRC 1 } \\
\text { Node 650 }\end{array}$ & $\begin{array}{c}\text { Node } \\
\mathbf{6 8 0}\end{array}$ & $\begin{array}{c}\text { Power } \\
\text { Supply } \\
\text { from Grid }\end{array}$ & Losses & $\begin{array}{c}\text { DR } \\
\text { (KW) }\end{array}$ \\
\hline A & 117.85 & 119.25 & & & 0 \\
B & 117.85 & 123.44 & 3552 & 116 & 0 \\
C & 117.85 & 115.59 & & & 0 \\
\hline A & 117.85 & 120.82 & & & 234.15 \\
B & 117.85 & 121.51 & 3309 & 103 & 0 \\
C & 117.85 & 116.88 & & & 0 \\
\hline A & 117.85 & 120.62 & & & 201.90 \\
B & 117.85 & 121.77 & 3341 & 104 & 0 \\
C & 117.85 & 116.70 & & & 0 \\
\hline A & 117.85 & 120.64 & & & 206.00 \\
B & 117.85 & 121.74 & 3337 & 104 & 0 \\
C & 117.85 & 116.72 & & & 0 \\
\hline A & 117.85 & 116.58 & & & 0 \\
B & 117.85 & 125.26 & 3230 & 104 & 0 \\
C & 117.85 & 117.70 & & & 309.36 \\
\hline
\end{tabular}


Table 39 continued

\begin{tabular}{|c|c|c|c|c|c|}
\hline A & 117.85 & 116.94 & & & 0 \\
B & 117.85 & 125.00 & 3274 & 105 & 0 \\
C & 117.85 & 117.43 & & & 266 \\
\hline A & 117.85 & 116.90 & & & 0 \\
B & 117.85 & 125.03 & 3268 & 105 & 0 \\
C & 117.85 & 117.47 & & & 271.55 \\
\hline A & 117.85 & 116.90 & & & 0 \\
B & 117.85 & 125.03 & 3269 & 105 & 0 \\
C & 117.85 & 117.47 & & & 270.73 \\
\hline
\end{tabular}

From the simulation results, the following can be concluded:

- A $10 \%$ penetration of the distribution resource reduced losses from $116 \mathrm{KW}$ to $104 \mathrm{KW}$ or $10.34 \%$.

- Because of a $10 \%$ penetration of the distribution resource, voltage improved by $3.58 \mathrm{~V}$ at one bus.

- Voltage increased at most of the buses because of PV penetration, but at some buses, voltage dropped because of the distribution resource. 


\section{CHAPTER 8}

\section{CONCLUSIONS AND FUTURE WORK}

\subsection{Conclusions}

- From the steady-state analysis test results, efficiency of the inverter was higher with a resistive load than with an inductive load, since the inverter was generating reactive power for the inductive loads.

- With a no-load condition and zero power flow, the power contributing to inverter losses came from both sources.

- If the inverter was acting as a pass-through, then power losses of the inverter were from the grid, but DC voltage was still needed to keep the inverter turned on.

- The voltage at the load terminals of the inverter varied, depending on the source of the power. For example, if power was coming from the grid and no power was coming from the DC source, then the voltage at the load terminals of the inverter was around $118 \mathrm{~V}$ for a $1000 \mathrm{~W}$ load. If power was coming from the DC source only, then the output terminal voltage of the inverter was around $122 \mathrm{~V}$ with the same load. If power was coming from the DC source, and the DC source was selling power to the grid, then the voltage at the load terminals was around $127 \mathrm{~V}$ for a $1000 \mathrm{~W}$ load.

- Efficiency of the inverter was independent of the input voltage on the DC side.

- The inverter was able to supply reactive power to the load, if the grid was not connected to the inverter.

- Voltage across the load terminals increased with the increase in load, until the midpoint of the rating of the inverter; then the voltage dropped with respect to load. 
- Power supply to the grid from the inverter depended on voltage from both the DC side and the $\mathrm{AC}$ side.

- Selling power from the inverter depended on the voltage on both the DC side and AC side. If the DC voltage was more, then sold more power to the grid, and if the grid voltage was low, then sold more power.

- Selling power depended on the duration and depth of sag. If the duration of the sag period was longer, then it sold more power, and if the sag was too deep (low value), then it sold more energy.

- A percentage of $5 \%$ to $10 \%$ of the DR in a neighborhood helped improve voltage in that area, and if there was a voltage sag for a shorter period, then the DR system helped the power grid maintain continuous power in that neighborhood.

\subsection{Future Work}

- Determine how the inverter will react if there is voltage sag or spike on the DC side of the inverter.

- Optimize the efficiency of the grid by finding where to keep the distribution resource in the system.

- Develop a software model to determine the accurate output of the inverter in order to perform iterations.

- Because the inverter will not turn on without a DC source, develop a new model of inverter that can act like a pass-through if connected to the grid.

- Because vehicle-to-grid technology, where energy will flow between a vehicle and a grid when needed, is in the future, and because electric vehicles store energy in batteries 
where they discharge their energy in the form of DC and thus need an inverter, determine how this inverter will be used in the new technology. 
REFERENCES 


\section{REFERENCES}

[1] U.S. Energy Information Administration, Independent Statics and Analysis, Solar Photovoltaic Cell/Module Manufacturing Activities, URL: http://www.eia.doe.gov/cneaf/solar.renewables/page/solarphotv/solarpv.html [cited February 20, 2011].

[2] U.S. Energy Information Administration, Electric Power Annual 2009, November 2010, URL: http://www.eia.gov/FTPROOT/electricity/034809.pdf [cited February 20, 2011].

[3] Ed Gurdjian and Carol Maxwell, "Inverter history," March 2000, URL: http:/www.rvtechstop.com/articles/Invhist.pdf, [cited August 25, 2010].

[4] Nagaraju Pogaku, Milan Prodanovic, and Timothy C. Green, "Modeling, analysis and testing of autonomous operation of an inverter-based micro grid," IEEE Trans. Power Electronics, Vol. 22, No. 2, March 2007.

[5] Thomas S. Key, "Evaluation of grid-connected inverter power systems: The utility interface," IEEE Trans. on Industry Applications, Vol. IA-20, No. 4, July/August 1984.

[6] Alejandro R. Oliva and Juan Carlos Balda, "A PV dispersed generator: A power quality analysis within the IEEE 519," IEEE Trans. on Power Delivery, Vol. 18, No. 2, April 2003.

[7] Achim Woyte, Ronnie Belmans, and Johan Nijs, "Testing the islanding protection function of photovoltaic inverter," IEEE Trans. on Energy Conversion, Vol. 18, No. 1, March 2003.

[8] Androw Kotsopoulous, Peter J. M. Heskes, and Mark J. Jansen, “Zero-crossing distortion in grid-connected PV inverters," IEEE Trans. on Industrial Electronics, Vol. 52, No. 2, April 2005.

[9] W. Enders, Ch. Halter, and P. Wurm, "Investigation of typical problems of PV inverters," in Proc. Eur. Photovoltaic and Solar Energy Conference, 2001, pp. 763-767.

[10] Rolls Battery Engineering, URL: http://www.rollsbattery.com/pdf/S-460.pdf [cited March 10, 2010].

[11] OutBack Power, Grid interactive inverter/charger product specifications,

URL: http://www.outbackpower.com/products/sinewave inverter/grid tie/ [cited March $10,2010]$. 


\section{REFERENCES (continued)}

[12] OutBack Power Systems, Grid-Interactive GTFX AND GVFX Inverter/Charger Programmable Manual,

URL: http://www.outbackpower.com/docman/1401103035849gtfx_gvfx.pdf [cited March 10, 2010].

[13] OutBack Power Systems, FX Circuit Board Replacement Instructions, Installations and Programmable Manual

URL: http://www.pvpower.com/uploads/products/fx_circuit_board_replacement.pdf

[cited March 10, 2010].

[14] Outback Power Systems, HUB Communications Manager User's Manual

URL: http://www.outbackpower.com/pdf/manuals/hub.pdf [cited March 10, 2010].

[15] Outback Power Systems, MATE System Controller and Display Installation and User Manual, URL: http://www.outbackpower.com/pdf/manuals/mate.pdf [cited March 10, 2010].

[16] Pacific Power Source, G Series AC Power Systems, URL: http://www.pacificpower.com/Resources/Documents/GSeries(1).pdf [cited:February 2011].

[17] Chroma Ate Inc., Programmable DC Power Supply, Model 62000P Series, URL: http://www.chromausa.com/pdf/62000P-Edm.pdf [cited May 25, 2011].

[18] OutBack Power Systems, Wattplot and Wattplot Pro, Version 4.2, Monitoring and Diagnostics Program for Renewable Energy Device, User's Guide, URL: http://www.wmrs.edu/projects/BARenergy/resource\%20docs/WattPlot\%20Users_Guide. pdf [cited March 20, 2010].

[19] Electropaedia, Battery and Energy Technologies, URL: http://www.mpoweruk.com/leadacid.htm\#vrla [cited March 25, 2010].

[20] OutBack Power Systems, Product Guide, FLEXware Surge Protector, FW-SP-ACA, FWSP-250, FW-SP-R,

URL: http://www.outbackpower.com/pdfs spec/OutBackCatalog.pdf [cited March 30, 2010].

[21] W. H. Kersting, Radial Distribution Test Feeders, Distribution System Analysis Subcommittee Report, URL: http://ewh.ieee.org/soc/pes/dsacom/testfeeders/testfeeders.pdf [cited July 20, 2011]. 


\section{REFERENCES (continued)}

[22] Milsoft Utility Solutions, Engineering Analysis, URL:

http://milsoft.com/uploads/images/product_additional_details/Milsoft_EA_Brochure.pdf [cited August 20, 011].

[23] IEEE-SA Standards Board, IEEE Standards Coordinating Committee 21 on Fuel Cells, Photovoltaics, Dispersed Generation, and Energy Storage, "IEEE Application Guide for IEEE Std. $1547^{\mathrm{TM}}$, IEEE Standard for Interconnecting Distributed Resources with Electric Power Systems," approved December 10, 2008.

[24] American National Standard ANSI C84.1-2011 (revision of ANSI C84.1-2006) for Electric Power Systems and Equipment—Voltage Ratings (60 Hertz), URL:

http://www.nema.org/stds/complimentarydocs/upload/Contents\%20and\%20Scope\%20ANSI\%20C84.1-2011.pdf [cited September 10, 2011]. 
APPENDIX 


\section{APPENDIX}

TABLES SHOWING VOLTAGE DROPS AND POWER SUPPLY FROM DISTRIBUTED ENERGY RESOURCES (DR)

(highlighted columns indicate final output power from distributed power resources after a few iterations)

APPENDIX TABLE 1

VOLTAGE DROP OF EACH PHASE IN 13-BUS SYSTEM DURING VOLTAGE SAG NO DISTRIBUTED POWER RESOURCES

\begin{tabular}{|c|c|c|c|c|c|c|c|c|c|c|c|c|c|c|}
\hline $\begin{array}{c}\text { Node } \\
650\end{array}$ & $\begin{array}{c}\text { Node } \\
634\end{array}$ & $\begin{array}{c}\text { Node } \\
633\end{array}$ & $\begin{array}{c}\text { Node } \\
632\end{array}$ & $\begin{array}{c}\text { Node } \\
645\end{array}$ & $\begin{array}{c}\text { Node } \\
646\end{array}$ & $\begin{array}{c}\text { Node } \\
611\end{array}$ & $\begin{array}{c}\text { Node } \\
684\end{array}$ & $\begin{array}{c}\text { Node } \\
652\end{array}$ & $\begin{array}{c}\text { Node } \\
671\end{array}$ & $\begin{array}{c}\text { Node } \\
680\end{array}$ & $\begin{array}{c}\text { Node } \\
692\end{array}$ & $\begin{array}{c}\text { Node } \\
675\end{array}$ & \begin{tabular}{|c|} 
Power \\
Supply from \\
Grid \\
\end{tabular} & Losses \\
\hline 123.4 & 120 & 122.82 & 123.1 & 123.1 & 123.1 & 119.3 & 119.16 & 118.5 & 119.2 & 119.2 & 119.2 & 118.3 & 3551 & 116 \\
\hline 123.4 & 121.5 & 123.7 & 123.9 & 123.5 & 123.5 & 123.5 & 123.53 & 123.7 & 123.5 & 123.5 & 123.5 & 124 & & \\
\hline 123.4 & 119.2 & 121.45 & 121.7 & 121.7 & 121.6 & 115.2 & 115.32 & 115.5 & 115.5 & 115.5 & 115.5 & 114.8 & & \\
\hline 122.5 & 119.8 & 122.7 & 122.7 & 123. & 123.0 & 119.1 & 119.2 & 118.4 & 119.1 & 119.1 & 119.1 & 118.2 & 3550 & 116 \\
\hline 122.5 & 121.3 & 123.6 & 123.6 & 123.4 & 123.3 & 123.4 & 123.4 & 123.6 & 123.3 & 123.4 & 123.4 & 123.9 & & \\
\hline 122.5 & 119.1 & 121.4 & 121.3 & 121.6 & 121.5 & 115.0 & 115.1 & 115.4 & 115.4 & 115.4 & 115.4 & 114.7 & & \\
\hline 121.6 & 119.7 & 122.56 & 122.9 & 122.87 & 122.9 & 119 & 118.9 & 118.27 & 118.95 & 118.94 & 118.94 & 118 & 3549 & 116 \\
\hline 121.6 & 121.2 & 123.42 & 123.2 & 123.23 & 123.2 & 123.2 & 123.25 & 123.42 & 123.20 & 123.2 & 123.2 & 123.72 & & \\
\hline 121.6 & 118.9 & 121.2 & 121.4 & 121.44 & 121.3 & 114.9 & 115.06 & 115.22 & 115.24 & 115.24 & 115.24 & 114.5 & & \\
\hline 120.7 & 119.6 & 122.5 & 122.8 & 122.8 & 123.8 & 118.95 & 118.85 & 118.22 & 118.9 & 118.89 & 118.9 & 117.95 & 3549 & 116 \\
\hline 120.7 & 121.4 & 123.37 & 123.1 & 123.2 & 123.1 & 123.17 & 123.2 & 123.36 & 123.15 & 123.15 & 123.15 & 123.67 & & \\
\hline 120.7 & 118.9 & 121.17 & 121.4 & 121.4 & 121.3 & 114.87 & 115.0 & 115.18 & 115.2 & 115.2 & 115.2 & 114.48 & & \\
\hline 120.1 & 119.8 & 122.7 & 123 & 123 & 123 & 119.12 & 119.03 & 118.4 & 119.07 & 119.07 & 119.07 & 118.13 & 3550 & 116 \\
\hline 120.1 & 121.3 & 123.5 & 123.3 & 123.3 & 123.3 & 123.33 & 123.36 & 123.5 & 123.3 & 123.3 & 123.31 & 123.8 & & \\
\hline 120.1 & 119.1 & 121.3 & 121.6 & 121.6 & 121.5 & 115.06 & 115.21 & 115.4 & 115.4 & 115.4 & 115.4 & 114.7 & & \\
\hline 119.5 & 120.1 & 122.92 & 123.2 & 123.22 & 123.23 & 119.35 & 119.2 & 118.6 & 119.3 & 119.3 & 119.3 & 118.3 & 3552 & 116 \\
\hline 119.5 & 121.5 & 123.74 & 123.5 & 123.54 & 123.5 & 123.54 & 123.57 & 123.7 & 123.5 & 123.5 & 123.5 & 124 & & \\
\hline 119.5 & 119.3 & 121.6 & 121.8 & 121.81 & 121.7 & 115.3 & 115.46 & 115.62 & 115.6 & 115.6 & 115.6 & 114.92 & & \\
\hline 118.97 & 120.37 & 123.22 & 123.5 & 123.53 & 123.53 & 119.66 & 119.56 & 118.93 & 119.61 & \begin{tabular}{|l|}
119.61 \\
\end{tabular} & 119.61 & 118.67 & 3554 & 115 \\
\hline 118.97 & 121.8 & 124 & 123.8 & 123.83 & 123.8 & 123.83 & 123.86 & 124.02 & 123.81 & 123.81 & 123.81 & 124.33 & & \\
\hline 118.97 & 119.64 & 121.9 & 122.1 & 122.13 & 122.02 & 115.63 & 115.79 & 115.94 & 115.96 & 115.96 & 115.96 & 115.25 & & \\
\hline 117.85 & 120 & 122.86 & 123.2 & 123.2 & 123.17 & 119.3 & 119.2 & 118.57 & 119.2 & 119.25 & 119.25 & 118.3 & 3552 & 116 \\
\hline 117.85 & 120.44 & 123.66 & 123.5 & 123.47 & 123.43 & 123.47 & 123.5 & 123.66 & 123.49 & 123.44 & 123.44 & 123.96 & & \\
\hline 117.85 & 119.28 & 121.54 & 121.8 & 121.77 & 121.66 & 115.26 & 115.42 & 115.58 & 115.42 & 115.59 & 115.59 & 114.88 & & \\
\hline
\end{tabular}


APPENDIX TABLE 2

PERFORMANCE OF GRID WHEN 5\% OF DR SYSTEM IS SUPPLYING POWER AT BUS 680 AND SOURCE VOLTAGE IS $123.42 \mathrm{~V}$

\begin{tabular}{|c|c|c|c|c|c|c|c|c|c|c|c|c|c|c|c|}
\hline $\begin{array}{c}\text { SRC } 1 \\
\text { Node } \\
650\end{array}$ & $\begin{array}{c}\text { Node } \\
634\end{array}$ & $\begin{array}{c}\text { Node } \\
633\end{array}$ & $\begin{array}{c}\text { Node } \\
632\end{array}$ & $\begin{array}{c}\text { Node } \\
645\end{array}$ & $\begin{array}{c}\text { Node } \\
646\end{array}$ & $\begin{array}{c}\text { Node } \\
611\end{array}$ & $\begin{array}{c}\text { Node } \\
684\end{array}$ & $\begin{array}{c}\text { Node } \\
652\end{array}$ & $\begin{array}{c}\text { Node } \\
671\end{array}$ & $\begin{array}{c}\text { Node } \\
680\end{array}$ & $\begin{array}{c}\text { Node } \\
692\end{array}$ & $\begin{array}{c}\text { Node } \\
675\end{array}$ & $\begin{array}{c}\text { Power } \\
\text { Supply } \\
\text { from } \\
\text { Grid }\end{array}$ & Losses & $\begin{array}{c}\text { DR } \\
(\mathbf{K W})\end{array}$ \\
\hline 123.42 & 120 & 122.82 & 23.1 & 123.1 & 123.1 & 119.3 & 119.16 & 118.5 & 119.2 & 119.2 & 119.2 & 118.3 & 3551.00 & 116.00 & 0 \\
\hline 123.42 & 121.5 & 123.7 & 123.9 & 123.5 & 123.5 & 123.5 & 123.53 & 123.7 & 123.5 & 123.5 & 123.5 & 124 & & & 0 \\
\hline 123.42 & 119.2 & 121.45 & 121.7 & 121.7 & 121.6 & 115.2 & 115.32 & 115.5 & 115.5 & 115.5 & 115.5 & 114.8 & & & 0 \\
\hline 123.42 & 120.36 & 123.21 & 123.54 & 123.52 & 123.52 & 119.93 & 119.84 & 119.21 & 119.88 & 120.02 & 119.88 & 118.94 & 3428.00 & 109.00 & 117.59 \\
\hline 123.42 & 121.07 & 123.30 & 123.50 & 123.11 & 123.07 & 122.72 & 122.75 & 122.92 & 122.7 & 122.5 & 122.70 & 123.23 & & & 0 \\
\hline 123.42 & 119.43 & 121.70 & 121.95 & 121.93 & 121.82 & 115.70 & 115.82 & 115.98 & 116 & 116.14 & 116.00 & 115.28 & & & 0 \\
\hline 123.42 & 120.33 & 123.18 & 123.52 & 123.49 & 123.49 & 119.89 & 119.79 & 119.16 & 119.84 & 119.96 & 119.84 & 118.89 & 3437.00 & 109.00 & 109.17 \\
\hline 123.42 & 121.10 & 123.33 & 123.53 & 123.14 & 123.10 & 122.78 & 122.80 & 122.98 & 122.75 & 122.60 & 122.75 & 123.28 & & & 0 \\
\hline 123.42 & 119.42 & 121.68 & 121.93 & 121.91 & 121.80 & 115.63 & 115.79 & 115.94 & 115.96 & 116.09 & 115.96 & 115.24 & & & 0 \\
\hline 123.42 & 120.33 & 123.18 & 123.52 & 123.49 & 123.49 & 119.89 & 119.80 & 119.16 & 119.84 & 119.97 & 119.84 & 118.901 & 3436.00 & 109.00 & 109.78 \\
\hline 123.42 & 121.10 & 123.33 & 123.53 & 123.13 & 123.10 & 122.78 & 122.80 & 122.97 & 122.75 & 122.56 & 122.75 & 23.28 & & & 0 \\
\hline 123.42 & 119.42 & 121.68 & 121.93 & 121.91 & 121.80 & 115.63 & 115.79 & 115.95 & 115.96 & 116.09 & 115.96 & 115.24 & & & 0 \\
\hline 123.42 & 120.33 & 123.18 & 123.52 & 123.49 & 123.49 & 119.89 & 119.80 & 119.16 & 119.84 & 119.97 & 119.84 & 118.901 & 3436.00 & 109.00 & 109.68 \\
\hline 123.42 & 121.10 & 123.33 & 123.53 & 123.13 & 123.10 & 122.78 & 122.80 & 122.97 & 122.75 & 122.56 & 122.75 & 23.28 & & & 0 \\
\hline 123.42 & 119.42 & 121.68 & 121.93 & 121.91 & 121.80 & 115.63 & 115.79 & 115.95 & 115.96 & 116.09 & 115.96 & 115.24 & & & 0 \\
\hline 123.42 & 119.39 & 122.26 & 122.60 & 122.58 & 122.58 & 118.16 & 118.06 & 117.44 & 118.11 & 117.84 & 118.11 & 117.16 & 3388.00 & 109.00 & 0 \\
\hline 123.42 & 121.83 & 124.05 & 124.24 & 123.85 & 123.82 & 124.20 & 124.23 & 124.4 & 124.18 & 124.37 & 124.18 & 124.70 & & & 0 \\
\hline 123.42 & 119.70 & 121.96 & 122.21 & 122.19 & 122.08 & 116.10 & 116.26 & 116.42 & 116.43 & 116.61 & 116.43 & 115.74 & & & 155.60 \\
\hline 123.42 & 119.43 & 122.30 & 122.64 & 122.62 & 122.92 & 118.24 & 118.14 & 117.52 & 118.18 & 117.94 & 118.18 & 117.24 & 3400.00 & 109.00 & 0 \\
\hline 123.42 & 121.80 & 124.02 & 124.22 & 123.83 & 123.80 & 124.15 & 124.18 & 124.34 & 124.13 & 124.30 & 124.13 & 124.65 & & & 0 \\
\hline 123.42 & 119.67 & 121.93 & 122.18 & 122.15 & 122.04 & 116.04 & 116.19 & 116.36 & 116.36 & 116.54 & 116.37 & 115.68 & & & 144.20 \\
\hline 123.42 & 119.43 & 122.30 & 122.64 & 122.61 & 122.61 & 118.23 & 118.14 & 117.51 & 118.18 & 117.93 & 118.181 & 117.23 & 3399.00 & 109.00 & 0 \\
\hline 123.42 & 121.80 & 124.02 & 124.22 & 123.83 & 123.80 & 124.15 & 124.18 & 124.35 & 124.13 & 124.31 & 24.13 & 124.65 & & & 0 \\
\hline 123.42 & 119.67 & 121.93 & 122.18 & 122.15 & 122.04 & 116.04 & 116.20 & 116.36 & 116.36 & 116.54 & 116.37 & 115.68 & & & 144.92 \\
\hline
\end{tabular}


APPENDIX TABLE 3

PERFORMANCE OF GRID WHEN 10\% OF DR SYSTEM IS SUPPLYING POWER AT BUS 680 AND GRID VOLTAGE IS 123.42 V

\begin{tabular}{|c|c|c|c|c|c|c|c|c|c|c|c|c|c|c|c|}
\hline $\begin{array}{c}\text { SRC 1 } \\
\text { Node } \\
650 \\
\end{array}$ & $\begin{array}{c}\text { Node } \\
634\end{array}$ & $\begin{array}{c}\text { Node } \\
633\end{array}$ & $\begin{array}{c}\text { Node } \\
632\end{array}$ & $\begin{array}{c}\text { Node } \\
645\end{array}$ & $\begin{array}{c}\text { Node } \\
646\end{array}$ & $\begin{array}{c}\text { Node } \\
611\end{array}$ & $\begin{array}{c}\text { Node } \\
684\end{array}$ & $\begin{array}{c}\text { Node } \\
652\end{array}$ & $\begin{array}{c}\text { Node } \\
671\end{array}$ & $\begin{array}{c}\text { Node } \\
680\end{array}$ & $\begin{array}{c}\text { Node } \\
692\end{array}$ & $\begin{array}{c}\text { Node } \\
675\end{array}$ & $\begin{array}{c}\text { Power } \\
\text { Supply } \\
\text { from Grid }\end{array}$ & Losses & $\begin{array}{c}\text { DR } \\
(\mathbf{K W})\end{array}$ \\
\hline 123.42 & 120 & 122.82 & 123.1 & 123.1 & 123.1 & 119.3 & 119.16 & 118.5 & 119.2 & 119.2 & 119.2 & 118.3 & 3551 & 116 & 0 \\
\hline 123.42 & 121.5 & 123.7 & 123.9 & 123.5 & 123.5 & 123.5 & 123.53 & 123.7 & 123.5 & 123.5 & 123.5 & 124 & & & 0 \\
\hline 123.42 & 119.2 & 121.45 & 121.7 & 121.7 & 121.6 & 115.2 & 115.32 & 115.5 & 115.5 & 115.5 & 115.5 & 114.8 & & & 0 \\
\hline 123.42 & 120.72 & 123.56 & 123.90 & 123.87 & 123.87 & 120.56 & 120.47 & 119.83 & 120.51 & 120.78 & 120.51 & 119.57 & 3307 & 103 & 235.18 \\
\hline 123.42 & 120.67 & 122.91 & 123.11 & 122.72 & 122.69 & 121.96 & 121.98 & 122.16 & 121.93 & 121.53 & 121.93 & 122.46 & & & 0 \\
\hline 123.42 & 119.69 & 121.95 & 122.20 & 122.18 & 122.07 & 116.18 & 116.34 & 116.50 & 116.52 & 116.80 & 116.52 & 115.78 & & & 0 \\
\hline 123.42 & 120.62 & 123.47 & 123.80 & 123.78 & 123.78 & 120.39 & 120.30 & 119.66 & 120.34 & 120.58 & 120.35 & 119.40 & 3340 & 104 & 202.72 \\
\hline 123.42 & 120.78 & 123.02 & 123.22 & 122.82 & 122.79 & 122.17 & 122.19 & 122.37 & 122.14 & 121.80 & 122.14 & 122.67 & & & 0 \\
\hline 123.42 & 119.62 & 121.88 & 122.13 & 122.11 & 122.00 & 116.04 & 116.20 & 116.35 & 116.37 & 116.61 & 116.37 & 115.64 & & & 0 \\
\hline 123.42 & 120.64 & 123.48 & 123.81 & 123.80 & 123.80 & 120.42 & 120.32 & 119.68 & 120.37 & 120.60 & 120.37 & 119.42 & 3336 & 104 & 206.83 \\
\hline 123.42 & 120.77 & 123.01 & 123.21 & 122.81 & 122.78 & 122.14 & 122.17 & 122.34 & 122.11 & 121.76 & 122.11 & 122.65 & & & 0 \\
\hline 123.42 & 119.63 & 121.88 & 122.14 & 122.12 & 122.01 & 116.06 & 116.21 & 116.37 & 116.40 & 116.64 & 116.40 & 115.66 & & & 0 \\
\hline 123.42 & 120.64 & 123.48 & 123.81 & 123.80 & 123.80 & 120.42 & 120.32 & 119.68 & 120.37 & 120.60 & 120.37 & 119.42 & 3337 & 104 & 206.42 \\
\hline 123.42 & 120.77 & 123.01 & 123.21 & 122.81 & 122.78 & 122.14 & 122.17 & 122.35 & 122.12 & 121.77 & 122.12 & 122.65 & & & 0 \\
\hline 123.42 & 119.63 & 121.88 & 122.14 & 122.12 & 122.01 & 116.06 & 116.21 & 116.36 & 116.40 & 116.63 & 116.40 & 115.66 & & & 0 \\
\hline 123.42 & 118.83 & 121.72 & 122.06 & 122.03 & 122.03 & 117.10 & 117.00 & 116.38 & 117.04 & 116.52 & 117.04 & 116.10 & 3228 & 104 & 0 \\
\hline 123.42 & 122.20 & 124.41 & 124.61 & 124.22 & 124.19 & 124.10 & 124.97 & 125.13 & 124.92 & 125.31 & 124.92 & 125.43 & & & 0 \\
\hline 123.42 & 120.15 & 122.40 & 122.65 & 122.62 & 122.51 & 116.94 & 117.09 & 117.26 & 117.26 & 117.62 & 117.26 & 116.60 & & & 311.21 \\
\hline 123.42 & 118.99 & 121.87 & 122.21 & 122.18 & 122.18 & 117.40 & 117.30 & 116.67 & 117.34 & 116.88 & 117.34 & 116.38 & 3272 & 105 & 0 \\
\hline 123.42 & 122.10 & 124.31 & 124.51 & 124.12 & 124.09 & 124.73 & 124.76 & 124.92 & 124.71 & 125.04 & 124.71 & 125.23 & & & 0 \\
\hline 123.42 & 120.03 & 122.28 & 122.53 & 122.51 & 122.40 & 116.71 & 116.87 & 117.04 & 117.04 & 117.35 & 117.04 & 116.37 & & & 267.65 \\
\hline 123.42 & 118.96 & 121.85 & 122.19 & 122.16 & 122.16 & 117.35 & 117.25 & 116.64 & 117.30 & 116.84 & 117.30 & 116.35 & 3267 & 105 & 0 \\
\hline 123.42 & 122.11 & 124.32 & 124.52 & 124.13 & 124.10 & 124.75 & 124.78 & 124.95 & 124.74 & 125.08 & 124.74 & 125.25 & & & 0 \\
\hline 123.42 & 120.05 & 122.30 & 122.55 & 122.52 & 122.41 & 116.74 & 116.90 & 117.07 & 117.07 & 117.39 & 117.07 & 116.40 & & & 273.19 \\
\hline 123.42 & 118.96 & 121.85 & 122.19 & 122.17 & 122.17 & 117.36 & 117.26 & 116.64 & 117.30 & 116.84 & 117.30 & 116.35 & 3268 & 105 & 0 \\
\hline 123.42 & 122.11 & 124.32 & 124.52 & 124.13 & 124.10 & 124.75 & 124.78 & 124.95 & 124.74 & 125.07 & 124.74 & 125.25 & & & 0 \\
\hline 123.42 & 120.05 & 122.30 & 122.55 & 122.52 & 122.41 & 116.74 & 116.90 & 117.07 & 117.06 & 117.38 & 117.07 & 116.40 & & & 272.37 \\
\hline 123.42 & 118.97 & 121.85 & 122.19 & 122.17 & 122.17 & 117.36 & 117.26 & 116.64 & 117.30 & 116.84 & 117.30 & 116.35 & 3267 & 105 & 0 \\
\hline 123.42 & 122.11 & 124.32 & 124.52 & 124.13 & 124.10 & 124.75 & 124.78 & 124.95 & 124.74 & 125.07 & 124.74 & 125.25 & & & 0 \\
\hline 123.42 & 120.05 & 122.30 & 122.55 & 122.52 & 122.41 & 116.74 & 116.90 & 117.07 & 117.06 & 117.38 & 117.07 & 116.40 & & & 272.58 \\
\hline
\end{tabular}


APPENDIX TABLE 4

PERFORMANCE OF GRID WHEN 5\% OF DR SYSTEM IS SUPPLYING POWER AT BUS 680 AND GRID VOLTAGE IS 120.10 V

\begin{tabular}{|c|c|c|c|c|c|c|c|c|c|c|c|c|c|c|c|}
\hline $\begin{array}{c}\text { SRC 1 } \\
\text { Node } \\
650\end{array}$ & $\begin{array}{c}\text { Node } \\
634\end{array}$ & $\begin{array}{c}\text { Node } \\
633\end{array}$ & $\begin{array}{c}\text { Node } \\
632\end{array}$ & $\begin{array}{c}\text { Node } \\
645\end{array}$ & $\begin{array}{c}\text { Node } \\
646\end{array}$ & $\begin{array}{c}\text { Node } \\
611\end{array}$ & $\begin{array}{c}\text { Node } \\
684\end{array}$ & $\begin{array}{c}\text { Node } \\
652\end{array}$ & $\begin{array}{c}\text { Node } \\
671\end{array}$ & $\begin{array}{c}\text { Node } \\
680\end{array}$ & $\begin{array}{c}\text { Node } \\
692\end{array}$ & $\begin{array}{c}\text { Node } \\
675\end{array}$ & \begin{tabular}{|c|} 
Power \\
Supply \\
from Grid
\end{tabular} & Losses & $\begin{array}{c}\text { DR } \\
(\mathbf{K W})\end{array}$ \\
\hline 120.1 & 119.83 & 122.70 & 123.03 & 123.01 & 123.00 & 119.13 & 119.03 & 118.40 & 119.07 & 119.07 & 119.07 & 118.13 & 3550 & 116 & 0 \\
\hline 120.1 & 121.30 & 123.53 & 123.73 & 123.33 & 123.30 & 123.33 & 123.36 & 123.53 & 123.31 & 123.3 & 123.31 & 123.8 & & & 0 \\
\hline 120.1 & 119.09 & 121.35 & 121.60 & 121.58 & 121.47 & 115.06 & 115.21 & 115.4 & 115.40 & 115.4 & 115.4 & 114.7 & & & 0 \\
\hline 120.10 & 120.23 & 120.09 & 123.42 & 123.40 & 123.4 & 119.81 & 119.72 & 119.09 & 119.76 & 119.90 & 119.76 & 118.82 & 3426 & 109 & 118.93 \\
\hline 120.10 & 120.89 & 123.13 & 123.33 & 122.93 & 122.90 & 122.54 & 122.57 & 122.74 & 122.52 & 122.31 & 122.52 & 123.05 & & & 0 \\
\hline 120.10 & 119.33 & 121.60 & 121.85 & 121.83 & 121.72 & 115.56 & 115.72 & 115.87 & 115.90 & 116.03 & 115.90 & 115.17 & & & 0 \\
\hline 120.10 & 120.21 & 123.06 & 123.39 & 123.37 & 123.37 & 119.70 & 119.67 & 119.04 & 119.72 & 119.85 & 119.72 & 118.77 & 3435 & 109 & 110.40 \\
\hline 120.10 & 120.92 & 123.16 & 123.36 & 122.96 & 122.93 & 122.60 & 122.63 & 122.80 & 122.57 & 122.39 & 122.57 & 123.10 & & & 0 \\
\hline 120.10 & 119.31 & 121.58 & 121.83 & 121.81 & 121.70 & 115.53 & 115.68 & 115.84 & 115.86 & 115.99 & 115.86 & 115.14 & & & 0 \\
\hline 120.10 & 120.21 & 123.06 & 123.39 & 123.37 & 123.37 & 119.77 & 119.67 & 119.04 & 119.72 & 119.85 & 119.72 & 118.77 & 3434 & 109 & 110.91 \\
\hline 120.10 & 120.92 & 123.16 & 123.36 & 122.96 & 122.93 & 122.60 & 122.63 & 122.80 & 122.57 & 122.39 & 122.57 & 123.10 & & & 0 \\
\hline 120.10 & 119.31 & 121.58 & 121.83 & 121.81 & 121.70 & 115.53 & 115.68 & 115.84 & 115.86 & 115.99 & 115.86 & 115.14 & & & 0 \\
\hline 120.10 & 119.25 & 122.13 & 122.47 & 122.44 & 122.44 & 118.02 & 117.93 & 117.30 & 117.97 & 117.70 & 117.97 & 117.02 & 3386 & 109 & 0 \\
\hline 120.10 & 121.66 & 123.88 & 124.08 & 123.69 & 123.66 & 124.04 & 124.07 & 124.23 & 124.02 & 124.21 & 124.02 & 124.54 & & & 0 \\
\hline 120.10 & 119.60 & 121.86 & 122.11 & 122.09 & 121.98 & 116.00 & 116.16 & 116.32 & 116.33 & 116.51 & 116.33 & 115.64 & & & 153.63 \\
\hline 120.10 & 119.29 & 122.17 & 122.51 & 122.50 & 122.48 & 118.10 & 118.01 & 117.38 & 118.05 & 117.80 & 118.05 & 117.10 & 3398 & 109 & 0 \\
\hline 120.10 & 121.63 & 123.85 & 124.05 & 123.66 & 123.63 & 123.99 & 124.01 & 124.18 & 123.96 & 124.14 & 123.96 & 124.48 & & & 0 \\
\hline 120.10 & 119.57 & 121.83 & 122.08 & 122.05 & 121.94 & 115.94 & 116.10 & 116.26 & 116.26 & 116.44 & 116.26 & 115.57 & & & 145.23 \\
\hline 120.10 & 119.29 & 122.17 & 122.51 & 122.50 & 122.48 & 122.48 & 118.00 & 117.38 & 118.05 & 117.80 & 118.04 & 117.10 & 3397 & 109 & 0 \\
\hline 120.10 & 121.64 & 123.86 & 124.05 & 123.66 & 123.63 & 123.63 & 124.02 & 124.18 & 123.97 & 124.15 & 123.97 & 124.49 & & & 0 \\
\hline 120.10 & 119.57 & 121.83 & 122.08 & 122.05 & 121.94 & 121.94 & 116.10 & 116.26 & 116.27 & 116.44 & 116.27 & 115.58 & & & 145.95 \\
\hline
\end{tabular}


APPENDIX TABLE 5

PERFORMANCE OF GRID WHEN 10\% OF DR SYSTEM IS SUPPLYING POWER AT BUS 680 AND GRID VOLTAGE IS 120.10 V

\begin{tabular}{|c|c|c|c|c|c|c|c|c|c|c|c|c|c|c|c|}
\hline $\begin{array}{c}\text { SRC } 1 \\
\text { Node } \\
650\end{array}$ & $\begin{array}{c}\text { Node } \\
634\end{array}$ & $\begin{array}{c}\text { Node } \\
633\end{array}$ & $\begin{array}{c}\text { Node } \\
632\end{array}$ & $\begin{array}{c}\text { Node } \\
645\end{array}$ & $\begin{array}{c}\text { Node } \\
646\end{array}$ & $\begin{array}{c}\text { Node } \\
611\end{array}$ & $\begin{array}{c}\text { Node } \\
684\end{array}$ & $\begin{array}{c}\text { Node } \\
652\end{array}$ & $\begin{array}{c}\text { Node } \\
671\end{array}$ & $\begin{array}{c}\text { Node } \\
680\end{array}$ & $\begin{array}{c}\text { Node } \\
692\end{array}$ & $\begin{array}{c}\text { Node } \\
675\end{array}$ & $\begin{array}{c}\text { Power } \\
\text { Supply } \\
\text { from } \\
\text { Grid }\end{array}$ & Losses & $\begin{array}{c}\text { DR } \\
(\mathbf{K W})\end{array}$ \\
\hline 120.10 & 120.60 & 123.45 & 123.78 & 122.76 & 123.76 & 120.45 & 120.35 & 119.72 & 120.40 & 120.67 & 120.40 & 119.45 & 3303 & 103 & 237.85 \\
\hline 120.10 & 120.49 & 122.74 & 122.94 & 122.54 & 122.51 & 121.77 & 121.80 & 121.97 & 121.74 & 121.34 & 121.74 & 122.28 & & & 0 \\
\hline 120.10 & 119.59 & 121.85 & 122.10 & 122.08 & 121.97 & 116.09 & 116.25 & 116.40 & 116.42 & 116.71 & 116.42 & 115.70 & & & 0 \\
\hline 120.10 & 120.50 & 123.35 & 123.68 & 123.66 & 123.66 & 120.28 & 120.18 & 119.55 & 120.23 & 120.47 & 120.23 & 119.28 & 3307 & 104 & 204.98 \\
\hline 120.10 & 120.60 & 122.84 & 123.04 & 122.65 & 122.62 & 121.98 & 122.01 & 122.18 & 121.95 & 121.61 & 121.96 & 122.49 & & & 0 \\
\hline 120.10 & 119.52 & 121.78 & 122.03 & 122.01 & 121.90 & 115.94 & 116.10 & 116.25 & 116.27 & 116.52 & 116.27 & 115.54 & & & 0 \\
\hline 120.10 & 120.51 & 123.36 & 123.70 & 123.67 & 123.67 & 120.30 & 120.20 & 119.57 & 120.25 & 120.49 & 120.25 & 119.30 & 3333 & 104 & 209.09 \\
\hline 120.10 & 120.59 & 122.83 & 123.03 & 122.64 & 122.60 & 121.96 & 121.98 & 122.16 & 121.93 & 121.57 & 121.93 & 122.46 & & & 0 \\
\hline 120.10 & 119.53 & 121.79 & 122.04 & 122.02 & 121.91 & 115.96 & 116.12 & 116.27 & 116.29 & 116.54 & 116.29 & 115.56 & & & 0 \\
\hline 120.10 & 120.51 & 123.36 & 123.70 & 123.67 & 123.67 & 120.30 & 120.20 & 119.57 & 120.25 & 120.49 & 120.25 & 119.30 & 3333 & 104 & 208.68 \\
\hline 120.10 & 120.59 & 122.83 & 123.03 & 122.64 & 122.60 & 121.96 & 121.98 & 122.16 & 121.93 & 121.57 & 121.93 & 122.46 & & & 0 \\
\hline 120.10 & 119.53 & 121.79 & 122.04 & 122.02 & 121.91 & 115.96 & 116.12 & 116.27 & 116.29 & 116.54 & 116.29 & 115.56 & & & 0 \\
\hline 120.10 & 118.69 & 121.58 & 121.92 & 121.90 & 121.90 & 116.95 & 116.85 & 116.24 & 116.89 & 116.37 & 116.90 & 115.94 & 3225 & 104 & 0 \\
\hline 120.10 & 122.04 & 124.25 & 124.45 & 124.06 & 124.03 & 124.78 & 124.81 & 124.97 & 124.76 & 125.15 & 124.77 & 125.28 & & & 0 \\
\hline 120.10 & 120.05 & 122.30 & 122.55 & 122.53 & 122.42 & 116.84 & 116.99 & 117.16 & 117.16 & 117.53 & 117.16 & 116.50 & & & 313.26 \\
\hline 120.10 & 118.85 & 121.73 & 122.07 & 122.05 & 122.05 & 117.25 & 117.15 & 116.53 & 117.19 & 116.74 & 117.20 & 116.24 & 3270 & 105 & 0 \\
\hline 120.10 & 121.93 & 124.15 & 124.34 & 123.95 & 123.92 & 124.57 & 124.60 & 124.76 & 124.55 & 124.90 & 124.55 & 125.07 & & & 0 \\
\hline 120.10 & 119.93 & 122.20 & 122.43 & 122.41 & 122.30 & 116.62 & 116.77 & 116.94 & 116.94 & 117.26 & 116.94 & 116.27 & & & 269.50 \\
\hline 120.10 & 118.83 & 121.71 & 122.05 & 122.03 & 122.03 & 117.21 & 117.11 & 116.49 & 117.15 & 116.69 & 117.15 & 116.20 & 3264 & 105 & 0 \\
\hline 120.10 & 121.94 & 124.16 & 124.36 & 123.97 & 123.94 & 124.59 & 124.62 & 124.79 & 124.58 & 124.92 & 124.58 & 125.09 & & & 0 \\
\hline 120.10 & 119.95 & 122.20 & 122.45 & 122.43 & 122.31 & 116.64 & 116.80 & 116.97 & 116.97 & 117.29 & 116.97 & 116.30 & & & 275.04 \\
\hline 120.10 & 118.83 & 121.72 & 122.06 & 122.03 & 122.03 & 117.21 & 117.12 & 116.50 & 117.16 & 116.69 & 117.16 & 116.20 & 3265 & 105 & 0 \\
\hline 120.10 & 121.94 & 124.16 & 124.36 & 123.97 & 123.94 & 124.59 & 124.62 & 124.79 & 124.58 & 124.92 & 124.58 & 125.09 & & & 0 \\
\hline 120.10 & 119.95 & 122.20 & 122.45 & 122.43 & 122.31 & 116.64 & 116.80 & 116.97 & 116.97 & 117.29 & 116.97 & 116.30 & & & 274.43 \\
\hline
\end{tabular}


APPENDIX TABLE 6

PERFORMANCE OF GRID WHEN 5\% OF DR SYSTEM IS SUPPLYING POWER AT BUS 680 AND GRID VOLTAGE IS 117.85 V

\begin{tabular}{|c|c|c|c|c|c|c|c|c|c|c|c|c|c|c|c|}
\hline $\begin{array}{c}\text { SRC 1 } \\
\text { Node } \\
650\end{array}$ & $\begin{array}{c}\text { Node } \\
634\end{array}$ & $\begin{array}{c}\text { Node } \\
633\end{array}$ & $\begin{array}{c}\text { Node } \\
632\end{array}$ & $\begin{array}{c}\text { Node } \\
645\end{array}$ & $\begin{array}{c}\text { Node } \\
646\end{array}$ & $\begin{array}{c}\text { Node } \\
611\end{array}$ & $\begin{array}{c}\text { Node } \\
684\end{array}$ & $\begin{array}{c}\text { Node } \\
652\end{array}$ & $\begin{array}{c}\text { Node } \\
671\end{array}$ & $\begin{array}{c}\text { Node } \\
680\end{array}$ & $\begin{array}{c}\text { Node } \\
692\end{array}$ & $\begin{array}{c}\text { Node } \\
675\end{array}$ & $\begin{array}{c}\text { Power } \\
\text { Supply } \\
\text { from } \\
\text { Grid }\end{array}$ & Losses & $\begin{array}{c}\text { DR } \\
(\mathbf{K W})\end{array}$ \\
\hline 117.85 & 120 & 122.86 & 123.20 & 123.17 & 123.17 & 119.30 & 119.20 & 118.57 & 119.25 & 119.25 & 119.25 & 118.30 & 3552 & 116 & 0 \\
\hline 117.85 & 121.44 & 123.66 & 123.86 & 123.47 & 123.44 & 123.47 & 123.50 & 123.66 & 123.49 & 123.44 & 123.44 & 123.96 & & & 0 \\
\hline 117.85 & 119.28 & 121.54 & 121.80 & 121.77 & 121.66 & 115.26 & 115.42 & 115.58 & 115.42 & 115.59 & 115.59 & 114.88 & & & 0 \\
\hline 117.85 & 120.40 & 123.25 & 123.59 & 123.56 & 123.56 & 119.98 & 119.88 & 119.25 & 119.93 & 120.06 & 119.93 & 118.98 & 3430 & 109 & 117.08 \\
\hline 117.85 & 121.04 & 123.27 & 123.47 & 123.07 & 123.04 & 122.69 & 122.72 & 122.89 & 122.67 & 122.47 & 122.67 & 123.19 & & & 0 \\
\hline 117.85 & 119.52 & 121.78 & 122.04 & 122.02 & 121.90 & 115.76 & 115.91 & 116.07 & 116.09 & 116.22 & 116.09 & 115.37 & & & 0 \\
\hline 117.85 & 120.37 & 123.23 & 123.56 & 123.54 & 123.54 & 119.93 & 119.83 & 119.20 & 119.88 & 120.01 & 119.88 & 118.94 & 3438 & 109 & 108.76 \\
\hline 117.85 & 121.07 & 123.30 & 123.50 & 123.10 & 123.07 & 122.75 & 122.77 & 122.94 & 122.72 & 122.53 & 122.72 & 123.25 & & & 0 \\
\hline 117.85 & 119.51 & 121.77 & 122.02 & 122.00 & 121.89 & 115.72 & 115.88 & 116.03 & 116.05 & 116.18 & 116.05 & 115.33 & & & 0 \\
\hline 117.85 & 120.37 & 123.23 & 123.56 & 123.54 & 123.54 & 119.93 & 119.84 & 119.20 & 119.88 & 120.01 & 119.88 & 118.94 & 3438 & 109 & 109.27 \\
\hline 117.85 & 121.07 & 123.30 & 123.50 & 123.10 & 123.07 & 122.75 & 122.77 & 122.94 & 122.72 & 122.53 & 122.72 & 123.25 & & & 0 \\
\hline 117.85 & 119.51 & 121.77 & 122.02 & 122.00 & 121.89 & 115.72 & 115.88 & 116.03 & 116.05 & 116.18 & 116.05 & 115.33 & & & 0 \\
\hline 117.85 & 119.44 & 122.31 & 122.65 & 122.62 & 122.62 & 118.21 & 118.11 & 117.49 & 118.16 & 117.89 & 118.16 & 117.21 & 3389 & 109 & 0 \\
\hline 117.85 & 121.79 & 124.01 & 124.21 & 123.82 & 123.78 & 124.16 & 124.19 & 124.36 & 124.14 & 124.33 & 124.14 & 124.66 & & & 0 \\
\hline 117.85 & 119.79 & 122.05 & 122.30 & 122.27 & 122.16 & 116.19 & 116.34 & 116.51 & 116.52 & 116.70 & 116.52 & 115.83 & & & 154.68 \\
\hline 117.85 & 119.48 & 122.35 & 122.69 & 122.66 & 122.66 & 118.29 & 118.19 & 117.57 & 118.24 & 117.99 & 118.24 & 117.29 & 3402 & 109 & 0 \\
\hline 117.85 & 121.77 & 123.98 & 124.18 & 123.79 & 123.76 & 14.11 & 124.14 & 124.30 & 124.09 & 124.26 & 124.09 & 124.61 & & & 0 \\
\hline 117.85 & 119.76 & 122.01 & 122.26 & 122.24 & 122.13 & 116.12 & 116.28 & 116.49 & 116.45 & 116.62 & 116.45 & 115.76 & & & 143.47 \\
\hline 117.85 & 119.48 & 122.35 & 122.69 & 122.66 & 122.66 & 118.29 & 118.19 & 117.57 & 118.23 & 117.99 & 118.24 & 117.29 & 3401 & 109 & 0 \\
\hline 117.85 & 121.77 & 123.98 & 124.18 & 123.79 & 123.76 & 14.11 & 124.14 & 124.31 & 124.09 & 124.26 & 124.09 & 124.61 & & & 0 \\
\hline 117.85 & 119.76 & 122.01 & 122.26 & 122.24 & 122.13 & 116.12 & 116.28 & 116.45 & 116.45 & 116.62 & 116.45 & 115.76 & & & 144.20 \\
\hline
\end{tabular}


APPENDIX TABLE 7

PERFORMANCE OF GRID WHEN 10\% OF DR SYSTEM IS SUPPLYING POWER AT BUS 680 AND GRID VOLTAGE IS 117.85 V

\begin{tabular}{|c|c|c|c|c|c|c|c|c|c|c|c|c|c|c|c|}
\hline $\begin{array}{c}\text { SRC } 1 \\
\text { Node } \\
650\end{array}$ & $\begin{array}{c}\text { Node } \\
634\end{array}$ & $\begin{array}{c}\text { Node } \\
633\end{array}$ & $\begin{array}{c}\text { Node } \\
632\end{array}$ & $\begin{array}{c}\text { Node } \\
645\end{array}$ & $\begin{array}{c}\text { Node } \\
646\end{array}$ & $\begin{array}{c}\text { Node } \\
611\end{array}$ & $\begin{array}{c}\text { Node } \\
684\end{array}$ & $\begin{array}{c}\text { Node } \\
652\end{array}$ & $\begin{array}{c}\text { Node } \\
671\end{array}$ & $\begin{array}{c}\text { Node } \\
680\end{array}$ & $\begin{array}{c}\text { Node } \\
692\end{array}$ & $\begin{array}{c}\text { Node } \\
675\end{array}$ & $\begin{array}{c}\text { Power } \\
\text { Supply } \\
\text { from } \\
\text { Grid }\end{array}$ & Losses & $\begin{array}{c}\text { DR } \\
(\mathbf{K W})\end{array}$ \\
\hline 117.85 & 120 & 122.86 & 123.20 & 123.17 & 23.17 & 119.30 & 119.20 & 118.57 & 119.25 & 119.25 & 119.25 & 118.30 & 3552 & 116 & 0 \\
\hline 117.85 & 121.44 & 123.66 & 123.86 & 123.47 & 123.44 & 123.47 & 123.50 & 123.66 & 123.49 & 123.44 & 123.44 & 123.96 & & & 0 \\
\hline 117.85 & 119.28 & 121.54 & 121.80 & 121.77 & 121.66 & 115.26 & 115.42 & 115.58 & 115.42 & 115.59 & 115.59 & 114.88 & & & 0 \\
\hline 117.85 & 120.76 & 123.60 & 123.94 & 123.92 & 123.92 & 120.60 & 120.50 & 119.87 & 120.55 & 120.82 & 120.55 & 119.61 & 3309 & 103 & 234.15 \\
\hline 117.85 & 120.64 & 122.88 & 123.08 & 122.69 & 122.66 & 121.93 & 121.96 & 122.13 & 121.90 & 121.51 & 121.90 & 122.44 & & & 0 \\
\hline 117.85 & 119.78 & 122.03 & 122.29 & 122.27 & 122.16 & 116.27 & 116.43 & 116.58 & 116.60 & 116.88 & 116.60 & 115.87 & & & 0 \\
\hline 117.85 & 120.67 & 123.51 & 123.84 & 123.82 & 123.82 & 120.43 & 120.34 & 119.70 & 120.38 & 120.62 & 120.38 & 119.44 & 3341 & 104 & 201.90 \\
\hline 117.85 & 120.75 & 122.99 & 123.19 & 122.79 & 122.76 & 122.14 & 122.16 & 122.34 & 122.11 & 121.77 & 122.11 & 122.64 & & & 0 \\
\hline 117.85 & 119.71 & 121.96 & 122.22 & 122.20 & 122.08 & 116.13 & 116.28 & 116.43 & 116.46 & 116.70 & 116.46 & 115.73 & & & 0 \\
\hline 117.85 & 120.68 & 123.52 & 123.86 & 123.83 & 123.83 & 120.45 & 120.36 & 119.72 & 120.41 & 120.64 & 120.41 & 119.46 & 3337 & 104 & 206.00 \\
\hline 117.85 & 120.74 & 122.97 & 123.18 & 122.78 & 122.75 & 122.11 & 122.14 & 122.31 & 122.09 & 121.74 & 122.09 & 122.62 & & & 0 \\
\hline 117.85 & 119.72 & 121.97 & 122.23 & 122.21 & 122.09 & 116.15 & 116.30 & 116.45 & 116.48 & 116.72 & 116.48 & 115.75 & & & 0 \\
\hline 117.85 & 118.88 & 121.77 & 122.11 & 122.08 & 122.08 & 117.15 & 117.06 & 116.44 & 117.10 & 116.58 & 117.10 & 116.15 & 3230 & 104 & 0 \\
\hline 117.85 & 122.16 & 124.37 & 124.57 & 124.18 & 124.15 & 124.89 & 124.92 & 125.09 & 124.88 & 125.26 & 124.88 & 125.39 & & & 0 \\
\hline 117.85 & 120.24 & 122.48 & 122.73 & 122.71 & 122.60 & 117.02 & 117.17 & 117.34 & 117.34 & 117.70 & 117.34 & 11.68 & & & 309.36 \\
\hline 117.85 & 119.04 & 121.92 & 122.26 & 122.23 & 122.23 & 117.45 & 117.35 & 116.73 & 117.39 & 116.94 & 117.39 & 116.44 & 3274 & 105 & 0 \\
\hline 117.85 & 122.06 & 124.27 & 124.47 & 124.08 & 124.05 & 124.68 & 124.71 & 124.88 & 124.67 & 125.00 & 124.67 & 125.18 & & & 0 \\
\hline 117.85 & 120.12 & 122.37 & 122.62 & 122.59 & 122.48 & 116.79 & 116.95 & 117.12 & 117.12 & 117.43 & 117.12 & 116.45 & & & 266 \\
\hline 117.85 & 119.02 & 121.90 & 122.24 & 122.21 & 122.21 & 117.41 & 117.31 & 116.69 & 117.35 & 116.90 & 117.35 & 116.40 & 3268 & 105 & 0 \\
\hline 117.85 & 122.07 & 124.28 & 124.48 & 124.09 & 124.06 & 124.71 & 124.74 & 124.91 & 124.69 & 125.03 & 124.69 & 125.21 & & & 0 \\
\hline 117.85 & 120.13 & 122.38 & 122.63 & 122.61 & 122.49 & 116.82 & 116.98 & 117.15 & 117.15 & 117.47 & 117.15 & 116.48 & & & 271.55 \\
\hline 117.85 & 119.02 & 121.90 & 122.24 & 122.22 & 122.22 & 117.41 & 117.32 & 116.70 & 117.36 & 116.90 & 117.36 & 116.41 & 3269 & 105 & 0 \\
\hline 117.85 & 122.07 & 124.28 & 124.48 & 124.09 & 124.06 & 124.71 & 124.74 & 124.90 & 124.69 & 125.03 & 124.69 & 125.20 & & & 0 \\
\hline 117.85 & 120.13 & 122.38 & 122.63 & 122.61 & 122.49 & 116.82 & 116.98 & 117.15 & 117.15 & 117.47 & 117.15 & 116.48 & & & 270.73 \\
\hline
\end{tabular}

